\title{
Targeting Metabolism in Cancer Cells and the Tumour Microenvironment for Cancer Therapy
}

\author{
Jiaqi Li ${ }^{1}$, Jie Qing Eu ${ }^{2}$, Li Ren Kong ${ }^{2,3}$, Lingzhi Wang ${ }^{2,4}$, Yaw Chyn Lim ${ }^{2,5}$, \\ Boon Cher Goh ${ }^{2,4,6}$ and Andrea L. A. Wong 2,6,* \\ 1 School of Clinical Medicine, University of Cambridge, Cambridge CB2 0SP, UK; j12006@cam.ac.uk \\ 2 Cancer Science Institute of Singapore, National University of Singapore, Singapore 117599, Singapore; \\ csiejq@nus.edu.sg (J.Q.E.); csiklr@nus.edu.sg (L.R.K.); csiwl@nus.edu.sg (L.W.); yc.lim@nus.edu.sg (Y.C.L.); \\ phcgbc@nus.edu.sg (B.C.G.) \\ 3 Medical Research Council Cancer Unit, University of Cambridge, Cambridge CB2 0XZ, UK \\ 4 Department of Pharmacology, Yong Loo Lin School of Medicine, National University of Singapore, \\ Singapore 117600, Singapore \\ 5 Department of Pathology, National University Health System, Singapore 119074, Singapore \\ 6 Department of Haematology-Oncology, National University Health System, Singapore 119228, Singapore \\ * Correspondence: Andrea_LA_WONG@nuhs.edu.sg; Tel.: +65-6779-5555
}

Academic Editors: Jacinta Serpa and Sofia C. Nunes

Received: 29 September 2020; Accepted: 16 October 2020; Published: 20 October 2020

\begin{abstract}
Targeting altered tumour metabolism is an emerging therapeutic strategy for cancer treatment. The metabolic reprogramming that accompanies the development of malignancy creates targetable differences between cancer cells and normal cells, which may be exploited for therapy. There is also emerging evidence regarding the role of stromal components, creating an intricate metabolic network consisting of cancer cells, cancer-associated fibroblasts, endothelial cells, immune cells, and cancer stem cells. This metabolic rewiring and crosstalk with the tumour microenvironment play a key role in cell proliferation, metastasis, and the development of treatment resistance. In this review, we will discuss therapeutic opportunities, which arise from dysregulated metabolism and metabolic crosstalk, highlighting strategies that may aid in the precision targeting of altered tumour metabolism with a focus on combinatorial therapeutic strategies.
\end{abstract}

Keywords: cancer cell metabolism; tumour microenvironment; metabolic reprogramming; targeted therapy; immunotherapy

\section{Introduction}

To sustain the rapid proliferation characterising cancer cells, corresponding alterations to tumour metabolism must occur to fuel the elevated bioenergetic demands. This understanding has led to the introduction of 'Deregulating Cellular Energetics' as a new hallmark of cancer [1]. Initial observations by Otto Warburg described an unusual reliance of cancer cells on glycolysis despite sufficient oxygen, which was later termed the 'Warburg effect' to describe this form of aerobic glycolysis [2]. This metabolic reprogramming, while less efficient in terms of ATP production, confers cancer cells with much-needed metabolic intermediates that can be channelled into biosynthetic pathways, such as the pentose-phosphate pathway (PPP) for nucleotide synthesis [3].

While this aerobic 'Warburg' glycolytic phenotype had been regarded as the norm in cancer cells, it is becoming increasingly clear that the metabolic needs of tumour cells do not rely on a single metabolic strategy. Recent studies suggest that certain subtypes of cancer cells may preferentially utilize oxidative phosphorylation (OXPHOS) for energy production in glucose-limiting conditions [4]. In addition, OXPHOS dependency may be induced by certain therapies, such as prolonged tyrosine 
kinase inhibitor (TKI) therapy in certain oncogene-addicted cancers [5,6]. This reflects a phenomenon termed 'metabolic flexibility' where cancer cells adjust their metabolic phenotypes in order to gain a selective advantage for cell growth and survival under hostile conditions throughout tumorigenesis up to the time of metastasis [7]. The significance of these metabolic alterations may diverge not only according to intrinsic signalling pathways within the cancer cell, but also rely on the interaction of cancer cells with their surrounding tumour microenvironment (TME), ranging from immune cells and stromal cells to extracellular matrix (ECM) components and soluble factors [8]. There is also emerging evidence to suggest that metabolic reprogramming within cancer stem cell (CSC)-like phenotypes contributes to treatment resistance, therapeutic failure, and cancer relapse.

This review aims to highlight the complex interplay of regulatory cell signalling pathways, interactions between cancer cells and their TME, and the contributions of CSCs to the intricate and coordinated induction of metabolic pathways. Understanding the regulation of cellular metabolism is key for unravelling cancer metabolism as an attractive target for therapeutic exploitation. In particular, we will focus on resistance mechanisms as a result of dysregulated metabolism and metabolic crosstalk, highlighting strategies that may lead to the improved precision targeting of cancer cell metabolism (CCM).

\section{Altered Cancer Cell Metabolism}

\subsection{Metabolic Dependencies in Cancer Cells}

Cancer cells display a distinct metabolic phenotype compared to non-neoplastic cells. As a whole, these changes in metabolic fluxes are achieved by extensive metabolic reprogramming to fuel anabolic growth in nutrient-replete conditions and to support catabolism under nutrient scarcity. Broadly, this involves extracellular uptake of simple nutrients (glucose, amino acids, etc.), which are channelled into biosynthesis via the core metabolic pathways of glycolysis, the tricarboxylic acid (TCA) cycle, the PPP, and non-essential amino acid synthesis, which is followed by subsequent ATP-dependent processes to produce complex biomolecules (Figure 1). Many cancers are known to upregulate glucose consumption, and the classical Warburg phenotype has been reported in a variety of tumour types [9-11]. However, a majority of tumours still retain oxidative capacity to produce ATP via OXPHOS [4,12-15]. Apart from glucose, fatty acids (FAs) and amino acid metabolites are diverted to the TCA cycle to sustain mitochondrial ATP production. Transporters are also upregulated to increase the extracellular uptake of raw materials, including serine and glutamine [16-23]. This not only serves as building blocks for protein synthesis, but also maintains activity of the mTORC signalling system [24]. Subsequently, in a process known as glutaminolysis, glutamine is converted to glutamate, then $\alpha$-ketoglutarate $(\alpha-K G)$, which serves as another means utilised by cancer cells to fuel the TCA cycle [25] (Figure 1). Glutamine dependency has been reported in non-small cell lung cancer (NSCLC), breast cancer, and brain tumours, and has been associated with greater metastatic potential, therapy resistance, and aggressive clinical phenotype [26-29]. The specific metabolic dependencies of tumours may be heterogeneous and depend on the driver oncogenes present, microenvironmental interactions, and effect of treatments. 


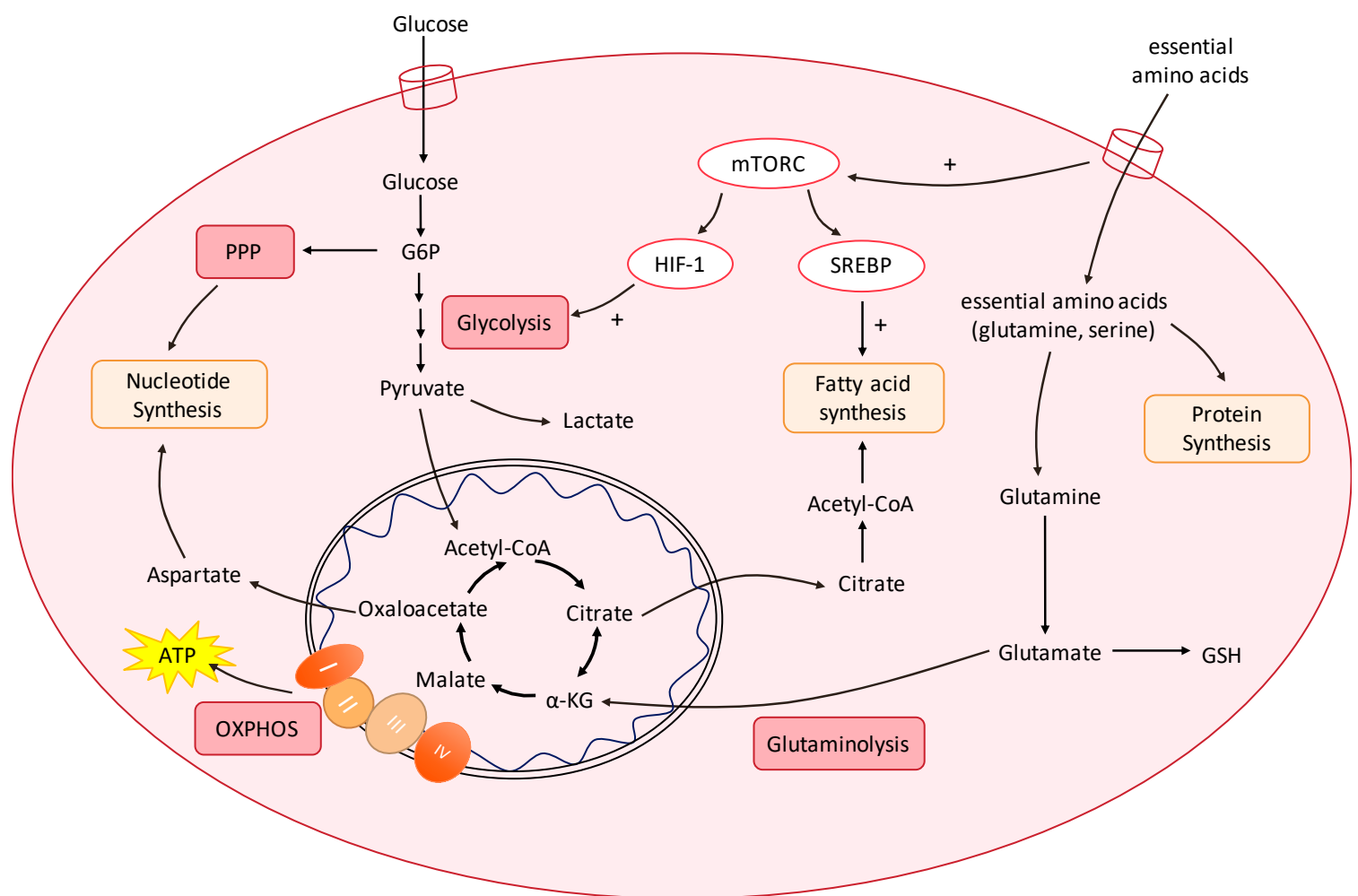

Figure 1. Overview of cancer cell metabolic reprogramming. Cancer cells require extensive metabolic reprogramming to fuel anabolic growth via increased nucleotide biosynthesis, protein synthesis, and FA synthesis. There is elevated glycolysis even under aerobic conditions (Warburg effect), which allows for the production of intermediates to be channelled into the PPP for nucleotide biosynthesis. However, a majority of tumours still retain oxidative capacity to produce ATP via OXPHOS. Glutaminolysis is also upregulated in many tumours for the production of $\alpha-\mathrm{KG}$ to fuel the TCA cycle. Increased glutaminolysis also produces glutathione (GSH) to defend against oxidative stress. Central to these metabolic changes is the PI3K/Akt/mTOR pathway. Downstream effectors that are activated by mTORC signalling include the transcription factors HIF-1 and SREBP.

G6P, glucose-6-phosphate; $\alpha$-KG, $\alpha$-ketoglutarate; ATP, adenosine 5' -triphosphate; GSH, glutathione; HIF-1, hypoxia-inducible factor-1; mTORC, mTOR complex 1; OXPHOS, oxidative phosphorylation; RTK, receptor tyrosine kinase; SREBP, sterol regulatory element-binding protein.

\subsection{Metabolic Reprogramming by Oncogenes and Tumour-Suppressor Genes}

Despite the great heterogeneity between tumours, metabolic reprogramming seems to involve a common, finite set of pathways to support anabolism, catabolism, and redox homeostasis [30]. Primarily, the PI3K/Akt/mTOR pathway acts as the central regulator of cellular energetics and metabolism, and acts to increase glycolysis and FA synthesis via hypoxia-inducible factor 1- $\alpha$ (HIF-1 $\alpha)$ and sterol regulatory element-binding protein (SREBP) activation, respectively [31] (Figure 1). This network is then co-opted by tumours in malignancy, where mutations in the receptor tyrosine kinases upstream of phosphoinositide 3-kinase (PI3K) (e.g., EGFR and HER2), the p110 $\alpha$ catalytic subunit of PI3K, the downstream kinase Akt, and the negative PI3K regulator phosphatase and tensin homologue (PTEN) are frequently observed in cancers [32]. Furthermore, many tumours reside in hypoxic environments, as the rapid proliferation exceeds the rate of angiogenesis [33]. To enable successful adaptation to hypoxia, tumours often upregulate HIF-1 $\alpha$ signalling, which is a downstream effector of the PI3K/Akt/mTOR pathway.

While HIF- $1 \alpha$ activation results in glycolysis, the glucose depletion due to rapid proliferation may lead to reduced energy stores and increased AMP/ATP intracellular levels. This subsequently 
activates the AMP-activated protein kinase (AMPK)-liver kinase B1 (LKB1) pathway. AMPK/LKB1 activation maintains energy stores by stimulating catabolic pathways that produce ATP, mostly by enhancing OXPHOS and mitochondrial biogenesis. Mechanistically, AMPK enhances sirtuin-1 (SIRT1) activity by increasing cellular $\mathrm{NAD}^{+}$levels, leading to the deacetylation and modulation of the activity of downstream SIRT1 targets especially peroxisome proliferator-activated receptor gamma coactivator $1-\alpha$ (PGC-1 $\alpha$ ) and the fork-head transcription factors FOXO1 and FOXO3a, triggering expression of genes that control mitochondrial biogenesis and activity [34].

FA synthesis is regulated by the transcription factor SREBP-1 [35], which regulates enzymes required in the synthesis of FA from acetyl-CoA, enzymes of the PPP for NADPH production, and enzymes that convert acetate and glutamine into acetyl-CoA [36]. Cancers with constitutively elevated rates of FA synthesis utilise mechanisms to keep SREBP-1 active, including sustained mTORC1 signalling, where the effector S6 kinase of mTORC1 activates SREBP-1 and SREBP-2 activity [36]. Elevated PI3K signalling also activates extracellular FA uptake to further sustain intracellular FA levels for FA synthesis [37].

Driver oncogenes are also involved in reprogramming of tumour energetics. Oncogenic MYC activity is known to promote aerobic glycolysis through the constitutive elevation of lactate dehydrogenase (LDH) A, upregulation of the glucose transporter GLUT1, and upregulation of several glycolytic enzymes including phosphofructokinase 1 (PFK-1) and enolase [38,39]. MYC has also been implicated in upregulating the uptake and catabolism of glutamine [20]. Specifically, MYC induces expression of genes needed for glutamine metabolism, including glutaminase (GLS), glutamine synthetase (GLUL), and the glutamine cell-entry transporter SLC1A5 (ASCT2) $[19,20,40]$.

Similarly, oncogenic KRAS is known to co-opt the metabolic effects of PI3K and MYC pathways to promote tumourigenesis. In KRAS-driven pancreatic ductal adenocarcinoma (PDAC), the constitutive MAPK signalling diverts glucose intermediates into hexosamine biosynthesis, and the PPP increases protein glycosylation and nucleotide synthesis [41]. Cells transformed by KRAS also show increased expression of genes related to glutamine metabolism and have greater glutamine dependency for anabolic synthesis [42,43]. In addition, the alteration of mitochondrial metabolism by oncogenic KRAS promotes carcinogenesis via the activation of growth factor signalling [44]. Finally, tumour-suppressor genes (TSGs) also contribute to the metabolic reprogramming of cancer cells. Loss of p53 triggers OXPHOS [45], and certain tumours are known to retain wild-type p53 to maintain glycolysis, such as in hepatocellular carcinoma (HCC) [46]. Mutant p53 has also been shown to drive Warburg glycolysis [47].

\subsection{Resistance to Conventional Therapies}

Despite advancements in cancer treatment and the availability of multi-modality therapy, development of resistance is still a major barrier contributing to treatment failure. In this section, we will discuss how metabolic reprogramming in cancer cells contributes to therapy resistance.

\subsubsection{Resistance to Cell Signalling Pathway Inhibitors}

Many cancers demonstrate treatment-induced metabolic adaptation as a mechanism of therapy resistance. In particular, treating oncogene-addicted tumours with TKIs led to resistance development in melanoma and NSCLC, which is accompanied by a metabolic switch to OXPHOS for survival [5,48-51]. This metabolic switch is thought to contribute to treatment resistance, therapeutic failure, and cancer progression [52]. Treatment of EGFR-mutant NSCLC with the 3rd-generation TKI, osimertinib, led to acquired resistance with glycolytic suppression and metabolic switch to OXPHOS [51]. Similar findings have been observed in gefitinib-treated EGFR-mutant NSCLC and vemurafenib-treated BRAF-mutant melanoma. OXPHOS inhibition restored sensitivity to TKI therapy, and was able to prolong survival and reduce tumour burden in-vivo [6].

Various mechanisms have been proposed to account for the relationship between OXPHOS and TKI resistance. For instance, treatment of BRAF-mutant melanomas with BRAF inhibitor, vemurafenib, or with MEK inhibitor, selumetinib, leads to microphthalmia-associated transcription factor (MITF) 
signalling and elevated expression of the mitochondrial master regulator, PGC- $1 \alpha$. This results in a PGC- $1 \alpha$-mediated induction of an OXPHOS gene programme and mitochondrial genesis $[5,49]$. Another proposed mechanism of treatment-induced upregulation of OXPHOS is via STAT3 signalling. Various oncogene-addicted cancer cells engage in a positive feedback loop leading to STAT3 activation in response to pathway-targeted therapy, limiting drug response [53]. It has been shown that the non-canonical STAT3 signalling via GRIM-19-dependent import of STAT3 into the mitochondria increases activity of complexes I and II of the electron transport chain (ETC), and, therefore, OXPHOS, leading to TKI therapy resistance [54].

\subsubsection{Resistance to Chemotherapy}

Metabolic reprogramming in response to conventional chemotherapy have also been described and may potentially be responsible for contributing to the resistant phenotype.

Glucose metabolism contributing to chemotherapy resistance. Enhanced glucose uptake and improved aerobic glycolysis have been shown to contribute to intrinsic and/or acquired resistance to chemotherapy $[55,56]$. Various glycolytic enzymes have been implicated, including pyruvate kinase muscle isozyme (PKM2). PKM2 catalyses the final step of glycolysis, and, hence, a key regulator of the switch between energy metabolism and anabolic synthesis: either routing glucose metabolism to pyruvate into the TCA cycle, or diverting glucose-derived carbons into other anabolic pathways. PKM2 overexpression has been implicated in carboplatin-resistant NSCLC and is associated with elevated glycolysis compared to parental non-resistant cells [57]. Increased PKM2 is also observed in sera and tissues from colorectal cancer (CRC) patients with poor response to 5-fluorouracil. Thus, PKM2 upregulation may also be linked to 5-fluorouracil resistance in CRC [58]. Other enzymes in glucose metabolism have also been associated with resistance to chemotherapies. Paclitaxel resistance in NSCLC is associated with increased expression of pyruvate dehydrogenase kinase-2 (PDK2) and upregulation of glycolysis. Cisplatin resistance in ovarian cancer was associated with increased expression and activity of glucose-6-phosphate dehydrogenase (G6PD), which enabled greater NADPH production via the PPP for redox homeostasis [55].

Glutamine metabolism contributing to chemotherapy resistance. Elevated glutaminolysis and GSH production is also thought to contribute to chemotherapy resistance. Altered CCM leading to raised GSH levels confers tumours with a greater ability to maintain redox homeostasis [59]. Cisplatin-resistant lung cancer cells have higher levels of glutamate cysteine ligase (GCL), which is the first enzyme of the GSH biosynthetic pathway, and, consequently, elevated GSH. The increased GSH production is thought to counteract the higher levels of reactive oxygen species (ROS) induced by common chemotherapeutic drugs such as cisplatin, and, thereby, protects the cancer cells from oxidative damage $[60,61]$. Consistent with this, blocking glutamate flux using riluzole was able to selectively kill cisplatin-resistant cells in-vitro and in-vivo [62], and inhibition of GSH biosynthesis with buthionine sulfoximine was found to synergise with cisplatin in breast cancer in-vitro and in-vivo [63].

FA metabolism contributing to chemotherapy resistance. Altered lipid metabolism is another key player in the development of chemoresistance. FA synthase (FASN) overexpression induces resistance to anti-tumoral drugs such as doxorubicin and mitoxantrone in breast cancer cells [64], docetaxel resistance in HER2-positive breast cancer [65], gemcitabine resistance in pancreatic cancer [66], and cisplatin resistance in ovarian cancer [67]. FASN overexpression is thought to confer tumour cells with an increased survival advantage and reduce apoptosis under the stress of chemotherapy. In breast cancer cells, FASN overexpression suppressed drug-induced production of ceramide and, thus, reduced caspase 8-mediated apoptosis under treatment with doxorubicin [64].

\section{Metabolic Crosstalk with the TME}

The homeostasis of the TME is controlled by an intimate crosstalk within and across cancer cells and their various cellular compartments, including endothelial, stromal, and immune cells (Figure 2) [68]. While metabolites that are consumed and released by tumour cells induce changes to 
TME components in order to support the malignant phenotype, TME cells also play a role in shaping and reprogramming tumour cells by directing paracrine effects, which activate signal transduction.

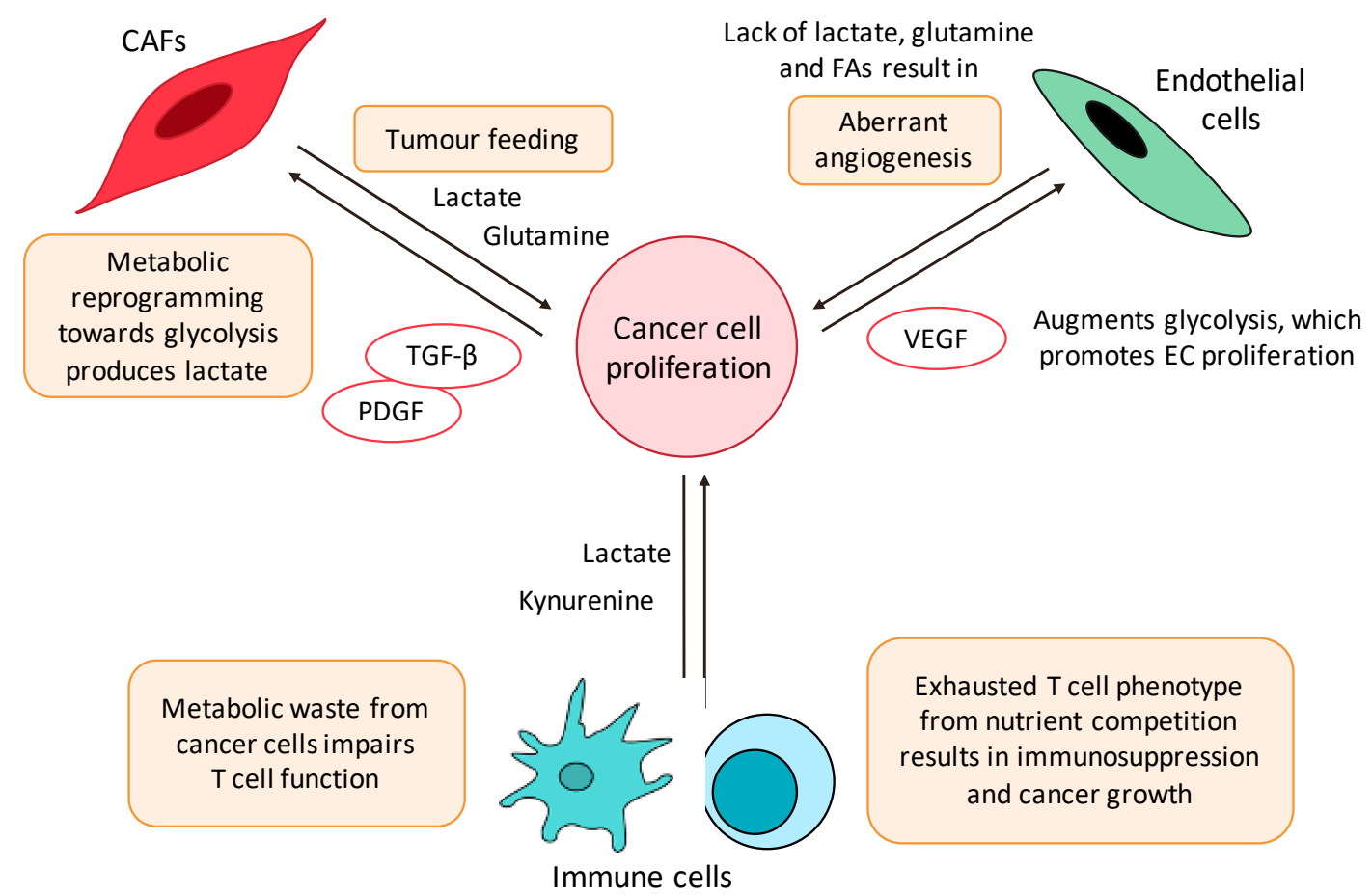

Figure 2. Key players of the metabolic crosstalk in the TME. Key players involved in the extensive, bidirectional crosstalk between tumour cells and the TME include CAFs, ECs, and immune cells. Tumours release factors such as PDGF and TGF- $\beta$, causing metabolic reprogramming in CAFs towards aerobic glycolysis, releasing energetic substrates such as lactate into the TME in a phenomenon known as 'tumour-feeding.' Meanwhile, tumour depletion of lactate, glutamine, and FAs in the TME lead to EC aberrant angiogenesis, which promotes proliferation and metastasis. VEGF is also released by tumours to promote EC proliferation. Tumour cells also induce metabolic changes to immune cells and cause immunosuppression. This is due to metabolic competition between immune cells and tumours for the same nutrients, producing an 'exhausted' T cell phenotype. Metabolic wastes, including lactate and kynurenine, are also released and impair $\mathrm{T}$ cell function, causing polarisation towards pro-tumorigenic T cell subtypes.

CAFs, cancer-associated fibroblasts; PDGF, platelet-derived growth factor; TGF- $\beta$, transforming growth factor beta; VEGF, vascular endothelial growth factor.

\subsection{Cancer-Associated Fibroblasts}

Often, the rapid growth of solid tumours produces a hypoxic and hypoglycaemic tumour core [69]. While this may be accompanied by aberrant angiogenesis, the vasculature produced are frequently leaky with poor integrity. The resultant hypoxic and nutrient-poor environment hinders tumour growth. Tumour cells overcome this nutrient limitation by reprogramming stromal cells in the TME. Cancer-associated fibroblasts (CAFs) are a key stromal component with a fundamental role in providing metabolic support to tumour cells, thereby facilitating tumour initiation, growth, invasion, and dissemination [70]. This is enabled by metabolic reprogramming of CAFs, releasing energetic substrates into the TME, a phenomenon termed 'tumour-feeding' [70,71].

Several modes of tumour-feeding have been postulated (Figure 2). Firstly, in a 'reverse Warburg effect,' CAFs undergo metabolic reprogramming switching toward a glycolytic phenotype, whereas the associated cancer cells are reprogrammed toward OXPHOS. Consequently, CAFs produce lactate, which is exported via the monocarboxylate transporter (MCT)- 4 into the TME, and taken up by tumour 
cells via the MCT-1 transporter. Such metabolic coupling have been reported in several tumour types [72-75]. This is supported in CAFs by an upregulation of glycolysis-related enzymes, such as hexokinase 2 (HK2) and 6-phosphofructokinase liver type (PFKL), and is thought to occur via signalling with platelet-derived growth factor (PDGF) and transforming growth factor beta (TGF- $\beta$ ) [76-78].

In addition to lactate, CAFs also supply tumours with glutamine. For example, in regions of glutamine scarcity in the ovarian tumour core, CAFs were reported to undergo metabolic reprogramming to upregulate glutamine anabolism to supply tumour cells [79]. The glutamine released into the TME is subsequently uptaken by cancer cells and converted to glutamate, which fuels the TCA cycle and supports energy production in cancer cells [79].

Apart from the direct release of metabolites into the TME, stromal cells have also been reported to fuel cancer metabolism by releasing metabolites carried in exosomes. These CAF-derived exosomes supply amino acids, lipids, and TCA cycle intermediates to fuel cancer metabolism [80]. CAFs have been reported to release paracrine signals to induce epigenetic changes and metabolic reprogramming of PDAC cells, resulting in changes similar to KRAS-driven oncogenic transformations by increasing anabolic metabolism and pro-tumourigenic changes in cancer cells [81].

\subsection{Endothelial Cells}

Tumour angiogenesis is the proliferation of a network of blood vessels that provide oxygen and nutrient support for tumours. In the past, the angiogenic switch was thought to be mediated by angiogenic molecules. However, it is now evident that distinct metabolic signatures of endothelial cells (ECs) are deregulated in cancer and vascular EC function can be modulated by metabolites [82] (Figure 2).

ECs are largely glycolytic and depend on glucose for proliferation. This phenotype is promoted by tumour paracrine signalling. For example, conditioned media from hypoxic glioma cells induced ECs to upregulate surface GLUT1 to enhance glucose uptake [83]. In addition, vascular endothelial growth factor (VEGF) signalling by tumours causes 6-phosphofructo-2-kinase/fructose-2,6-biphosphatase 3 (PFKFB3) upregulation in ECs, which activates PFK-1 to further augment the glycolytic phenotype [84]. Lactate is also enriched in the TME, which can trigger tube formation in ECs via HIF-1 $\alpha$-dependent NF- $\mathrm{KB}$ activation $[85,86]$.

Tumours also modulate amino acid availability in the TME, which have pleiotropic effects in vessel sprouting. ECs require glutamine for TCA cycle anaplerosis and non-essential amino acid synthesis. Depriving ECs of glutamine or inhibition of GLS1, thus, causes vessel sprouting defects due to impaired EC proliferation and migration $[87,88]$. VEGF signalling also requires glycine to promote angiogenesis and serine is also required for mitochondrial function in ECs [89,90]. Thus, tumour-dependent depletion of amino acids in the TME contributes to vascular defects and aberrant angiogenesis seen in some tumours.

Finally, FAs supply the carbon needed for dNTP synthesis during EC sprouting [91]. FA carbons are used by ECs to replenish the TCA cycle, and are incorporated into aspartate (nucleotide precursor) and uridine monophosphate (precursor in pyrimidine synthesis), supplying adequate dNTPs for proliferation [91]. Altered CCM may, therefore, alter FA availability to support EC proliferation.

\section{Tumour Immune Microenvironment}

The immune system interacts intimately with tumour development in a complex, bidirectional crosstalk that can both inhibit and enhance tumour growth and progression. This interaction has gained recognition as a hallmark of cancer and immunotherapy has become an established pillar of cancer therapy [1]. Immune cells execute their function most effectively when they are able to respond swiftly to environmental stimuli through phenotypic shifts, enhanced by the radical reprogramming of immune cell metabolism [92]. On the other hand, impaired metabolic flexibility results in an ineffective anti-tumour immune response, and may be explained by the mutual metabolic requirements of immune cells and tumour cells, which compete for similar essential nutrients such as glucose and 
glutamine. Besides nutrient availability, high production of metabolites such as lactate, kynurenine, and other metabolic by-products of cancer metabolism can be harmful for immune cells, resulting in tumour immunosuppression [93].

\subsection{T Cells}

The effects of altered tumour metabolism on $\mathrm{T}$ cell function is summarised in Figure 3.

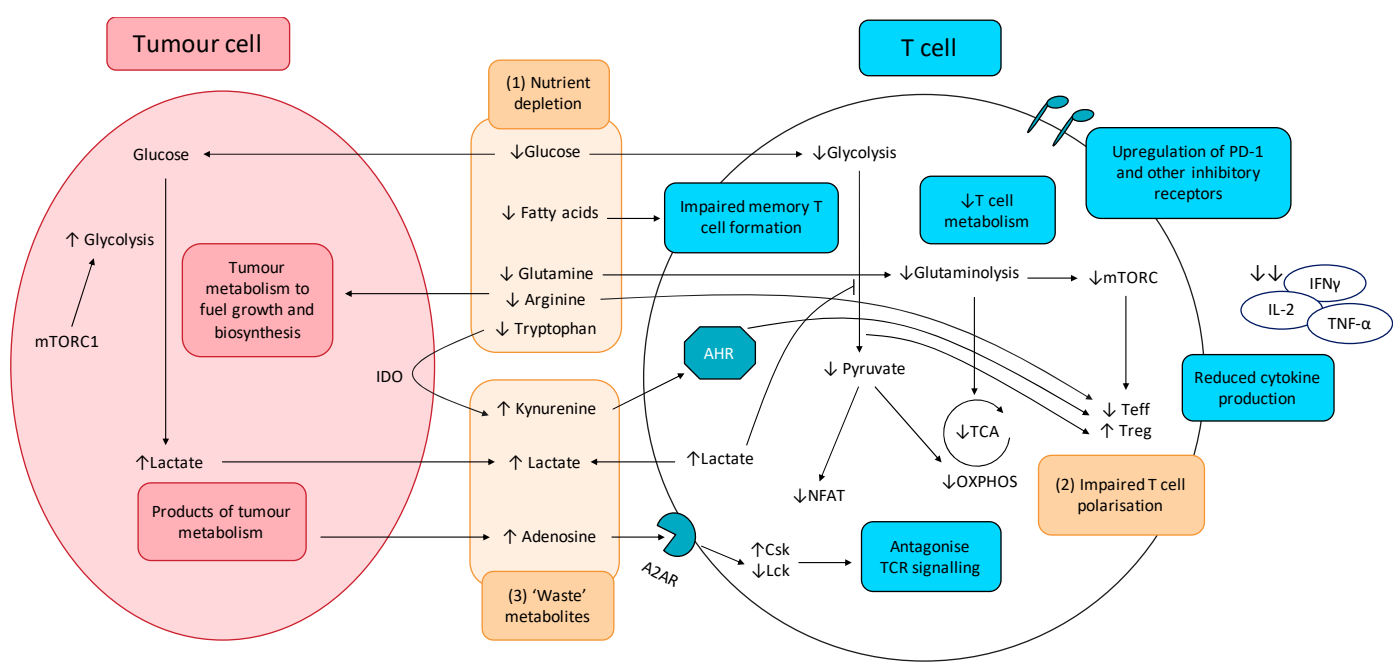

Figure 3. Effect of tumour metabolism on T cell function. (1) Altered cancer cell metabolism results in nutrient competition, depriving $\mathrm{T}$ cells of essential nutrients essential for robust anti-tumour activity, including glucose and key amino acids. Resultant exhausted $\mathrm{T}$ cell phenotype shows upregulation of inhibitory receptors including PD-1, CTLA-4, TIM-3, LAG-3, and TIGIT, impaired production and release of effector cytokines (IFN $\gamma, \mathrm{IL}-2$, and TNF- $\alpha$ ), as well as impaired degranulation. (2) Depletion of key nutrients and aberrant metabolite signalling promotes pro-tumourigenic $\mathrm{T}$ cell phenotypes.

(3) Cancer cell metabolism produces lactate and other 'waste' metabolites that inhibit T cell function and promote $\mathrm{T}$ cell exhaustion.

A2AR: Adenosine 2A receptor; AHR: aryl hydrocarbon receptor; Csk: C-terminal Src kinase; IDO: indoleamine-pyrrole 2,3-dioxygenase; Lck: lymphocyte-specific protein tyrosine kinase; mTORC1: mammalian target of rapamycin complex 1; NFAT: nuclear factor of activated T-cells; OXPHOS: oxidative phosphorylation; TCA: tricarboxylic acid cycle; Teff; effector T cells; Treg: regulatory T cells.

4.1.1. Altered CCM Deprives T cells of Nutrients Essential for Anti-Tumour Activity and Induces Polarisation of Immunosuppressive T Cell Subsets

When a T cell is activated, there is a dramatic metabolic reprogramming mediated through the $\mathrm{PI} 3 \mathrm{~K} / \mathrm{Akt} / \mathrm{mTOR}$ pathway, greatly reminiscent of the metabolic reprogramming observed in cancer cells. This 'Warburg phenotype' adopted by activated T cells involves upregulation of aerobic glycolysis, increased glucose metabolism through the PPP, increased glutaminolysis, and increased FA synthesis. This leads to a competition between effector $\mathrm{T}$ cells (Teff) and tumour cells for similar nutrients especially glucose, thereby impairing the Teff anti-tumour response. Furthermore, glucose limitation is reported to produce an 'exhausted' T cell phenotype, characterised by increased programmed cell death protein 1 (PD-1) expression on the surfaces of T cells, which accounts for the greater proportion of 'exhausted' T cells in tumours and leads to cancer immune evasion [94-96]. Tumour-mediated $\mathrm{T}$ cell exhaustion is also characterised by the upregulation of other inhibitory receptors including cytotoxic T lymphocyte-associated antigen 4 (CTLA-4), T-cell immunoglobulin, and mucin-domain containing-3 (TIM-3), lymphocyte activation gene-3 (LAG-3), and T cell immunoreceptor with Ig and immunoreceptor tyrosine-based inhibitory motif (ITIM) domains (TIGIT) [97-100]. Decreased glucose 
metabolism was also found to impair the epigenetic reprogramming required for $\mathrm{T}$ cell activation. Reduced flux through the glycolytic pathway leads to insufficient acetyl-CoA to maintain $\alpha$-KG levels required for cofactor function for histone acetylation, resulting in reduced interferon $\gamma$ (IFN $\gamma$ ) expression and impaired helper T cell (Th1) activity [101].

Similar to glucose, activated $\mathrm{T}$ cells have a higher requirement for amino acids, most notably glutamine. Glutamine is utilised by active $\mathrm{T}$ cells and is required for the inflammatory responses of Th1 and Th17 cells [102,103], and decreased glutamine availability in the TME is reported to blunt anti-tumour immunity by limiting essential biosynthetic pathways for $\mathrm{T}$ cell proliferation. A concern with targeting metabolic pathways is the extensive overlap between the metabolic phenotypes of tumour cells and activated immune cells. Theoretically, GLS inhibition can limit T cell metabolism along with crippling tumour metabolism since increased glutaminolysis is a hallmark of both tumour cells and activated T cells. However, Leone et al., 2019, showed that, while glutamine blockade in cancer cells led to suppression of oxidative and glycolytic metabolism, by contrast $\mathrm{CD}^{+} \mathrm{T}$ cells responded by upregulating acetate metabolism, generating high levels of acetyl-CoA for direct fuelling of the TCA cycle as well as indirect fuelling via increased glucose anaplerosis through pyruvate carboxylase activation. These resulted in upregulation of oxidative metabolism with $\mathrm{CD}^{+} \mathrm{T}$ cells adopting a long-lived, highly activated phenotype [104]. These divergent responses to GLS inhibition serves as a 'metabolic checkpoint' and an opportunity to simultaneously inhibit tumour metabolism while boosting anti-tumour immune activity. Other amino acids required for $\mathrm{T}$ cell activity includes arginine and tryptophan. Tumour-depletion of arginine in the TME can impair T cell anti-tumour immunity, particularly memory T cell immunity [105]. Tryptophan deficiency is also known to inhibit mTORC1 activity in T cells, impairing $\mathrm{T}$ cell activation and proliferation [106].

The effect of FAs is less well-characterised because different $T$ cell subsets utilise FAs differently. Of note, memory $\mathrm{T}$ cells are more dependent on FA oxidation (FAO) for energy and are unable to develop in the absence of FAs in culture. However, recent studies suggest that FAs used by memory $\mathrm{T}$ cells for FAO are derived from extracellular glucose, rather than direct utilisation of extracellular FAs [107]. Currently, the role of FAs in T cell metabolism is unclear, and further studies are required.

In addition, nutrient depletion in the TME alters T cell differentiation and induces the polarisation of immunosuppressive T cell subsets [108,109]. Glucose deficiency enriches for regulatory T cells (Tregs) because, in contrast to Teffs that rely on aerobic glycolysis, Tregs rely more on FAO. FOXP3 metabolic reprogramming leads to MYC and glycolysis suppression, which enhances OXPHOS and NADH oxidation. These adaptions confer Tregs a metabolic advantage in the low-glucose, high-lactate microenvironment in the TME, shifting the balance to favour Treg enrichment over Teffs and facilitating tumour immune evasion [110]. Glutamine deficiency in the TME may also shift T cell differentiation toward a pro-tumourigenic phenotype, as glutamine deficiency disproportionately impairs Th1 and Th17 subsets more than Tregs, thereby enriching for Tregs in the TME [108].

\subsubsection{CCM-Derived 'Waste' Metabolites Inhibit T Cell Function and Promotes T Cell Exhaustion}

Lactate is reported to inhibit T cell proliferation and cytokine production [111,112]. Tumour-derived lactate accumulates in the TME, leading to impaired T cell export of lactate and intracellular build-up. Elevated lactate suppresses glycolytic enzymes via end-product inhibition, impairing T cell metabolism and function. Lactate build-up in the TME also causes T cell acidification, preventing translocation of nuclear factor of activated T cells (NFAT) into the nucleus and NFAT-mediated transcription. This, thus, inhibits IFN $\gamma$ production and impairs T cell response [112]. Finally, lactate is reported to inhibit the PI3K/Akt/mTOR pathway in T cells, blunting T cell activation [113,114].

Other tumour-derived 'waste' metabolites are also suggested to play a key role in $\mathrm{T}$ cell immunosuppression (Figure 3). Adenosine is released by tumours into the TME and inhibits the $\mathrm{T}$ cell anti-tumour response. Upon binding to Adenosine A2A receptor (A2AR), signalling leads to an increase in cAMP levels, protein kinase A (PKA) phosphorylation of Csk, which subsequently inhibits Lck and antagonising TCR signalling. This leads to reduced T cell activation, cytokine production, 
and anti-tumour immunity [115]. Kynurenine, the first breakdown product in indoleamine 2,3-dioxygenase (IDO)-dependent tryptophan degradation, has also been reported to exert immunosuppressive effects and induce T cell apoptosis [106,116].

\subsection{Myeloid-Derived Suppressor Cells, Tumour-Associated Macrophages, and Dendritic Cells}

Myeloid-derived suppressor cells (MDSCs) are a heterogeneous population of cells of myeloid origin that contribute to TME immunosuppression and exert suppression on $\mathrm{T}$ cell and innate immune cell responses. The altered CCM environment influences MDSC functionality, which can further bolster their immunosuppressive effects.

For example, the hypoxic TME leads to HIF-1 $\alpha$ signalling, which aids in MDSC differentiation to tumour-promoting tumour-associated macrophages (TAMs) [117]. Lactate similarly induces polarisation toward the pro-tumourigenic M2 macrophage phenotype via HIF-1 $\alpha$ signalling [118], and induces upregulation of PD-L1 on myeloid cells, facilitating Teff suppression [119]. Furthermore, hypoxia and lactate in the TME induce a metabolic switch from glycolysis toward OXPHOS, which is consistent with the enrichment and continued functionality of MDSCs and TAMs in a primarily hypoglycaemic TME [120].

The anti-tumour functions of macrophages are also inhibited by altered cancer metabolism. Extracellular lactate reduces activation of monocytes, as measured by reduced glycolysis-dependent tumour necrosis factor (TNF) production [121]. Tumour prostaglandin $\mathrm{E}_{2}\left(\mathrm{PGE}_{2}\right)$ production is also found to subvert myeloid cell function. This was reported in various oncogene-addicted tumour models [122]. For example, in a BRAF-mutant model of melanoma, and NRAS-mutant models of melanoma, breast, and $C R C, \mathrm{PGE}_{2}$ production impairs myeloid cell activation especially the antigen-presenting ability required for $\mathrm{T}$ cell activation [122].

Dendritic cells (DCs) are also key players in anti-tumour immunity. Activation of DCs involves metabolic reprogramming not unlike that of T cells, switching from OXPHOS to aerobic glycolysis. Competition with tumour cells in the TME for essential nutrients, in particular glucose, can severely limit DC activity and antigen-presenting ability [123]. In addition, a low energy state leads to elevated AMPK signalling, which inhibits glycolysis and promotes greater OXPHOS and FAO. This is reminiscent of a tolerogenic DC phenotype [124]. In addition, FAO induction in tumour-associated DCs (TADCs) was found to drive the production of IDO, which results in Treg polarisation and further immunosuppression of T cells in a model of melanoma [125]. Expression of the inhibitory receptor CTLA-4 on Tregs can also induce IDO activity by DCs [126]. This immunosuppressive crosstalk between dysregulated immune cells serve to drive a positive-feedback loop whereby immunosuppression is self-maintained and further propagated in the TME [123].

\subsection{Natural Killer Cells and Neutrophils}

Other cells of the innate immune system are also intricately linked to metabolic changes in the TME. Due to the greater energetic demands of natural killer (NK) cells, in particular increased glycolysis, NK cells are also subject to competition with tumour cells for glucose. Thus, the perennial problem of glucose and nutrient deprivation in the TME also impairs NK function. Furthermore, the aberrant production of metabolites as a consequence of altered CCM also impacts NK activity. Metabolic reprogramming of NK cells upon activation requires the SREBP transcription factors. 25-hydroxycholesterol (25-HC) is a cholesterol-derived metabolite produced by various cancers, such as glioblastoma [127], and can inhibit translocation of SREBP from the ER to the Golgi, impairing NK activation [128]. Elevated lactate in the TME also reduces NFAT signalling in NK cells, reducing IFN $\gamma$ production, CD25 levels, and tumour-killing capabilities [112].

Neutrophils are frequently discounted from a metabolic perspective as purely glycolytic. The low glucose availability in the TME is predicted to limit neutrophil ROS production, which can disrupt CD4+ T cell viability and function. However, tumour-directed metabolic reprogramming can switch neutrophils to an oxidative phenotype. For instance, $4 \mathrm{~T} 1$ tumours was found to induce a metabolic 
shift to produce mitochondria-rich oxidative neutrophils through aberrant stem cell factor (SCF)/c-Kit signalling. Oxidative neutrophils can use mitochondrial FAO to support NADPH oxidase-dependent ROS production in the hypoglycaemic TME. Thus, tumour-mediated SCF/c-Kit signalling can induce an oxidative phenotype in neutrophils to overcome to metabolic limitations, resulting in maintained ROS production despite the hypoglycaemic TME, and, hence, sustained immunosuppression [129].

\subsection{PD-1 and CTLA-4 Signalling and the Effects of Immune Checkpoint Blockade on Metabolic Pathways}

PD-1 and CTLA-4 are immune checkpoints that serve as negative regulators of T cell function [130]. Signalling via PD-1 limits T cell activation, preventing excess inflammation and tissue damage [131]. This regulatory function is hijacked by cancer cells that upregulate the ligands PD-L1 and PD-L2 on their surface to dampen anti-tumour immunity [132]. PD-1 contains two intracellular tyrosine motifs that, when engaged by its ligands, result in phosphorylation of tyrosine residues, leading to recruitment of protein tyrosine phosphatases (PTPs) such as SHP2 [132]. PTPs antagonise positive signals from the TCR and CD28, hence antagonising downstream pathways including PI3K/Akt, Ras, ERK, Vav, and PLC $\gamma$, which are key pathways required for metabolic reprogramming of activated T cells [133-135].

Cancer therapy has entered the 'immunotherapy era' with anti-PD-1/PD-L1 and anti-CTLA-4 antibodies being incorporated into the treatment for melanoma, triple-negative breast cancer (TNBC), NSCLC, and metastatic renal cell carcinoma (RCC), among others. Such immune checkpoint blockade (ICB) therapy, aimed at reversing the immune suppression caused by tumour cells, also shapes the TME by affecting tumour metabolism [136]. Ligation of PD-1 on activated T cells impair glycolysis or amino acid metabolism [137], while PD-1 blockade upregulates GLUT1 to restore glucose uptake, promoting glycolysis in effector T cells [94]. Furthermore, PD-1 promotes FAO of endogenous lipids by increasing expression of CTP1A and upregulating lipolysis [137]. ROS generation by activators of mTOR, AMPK, and PGC-1 $\alpha$ were found to synergise with PD-1 blockade [138]. Taken together, this strengthens the role of combining PD-1 blocking therapies with metabolism-based therapies for more efficacious anti-tumour immunity.

Ligation of CTLA-4 also leads to similar inhibition of key metabolic reprogramming. However, CTLA-4 signalling on T cells inhibits glycolysis without augmenting FAO [137]. This suggests diverging roles of these two immune checkpoints: CTLA-4 sustains the metabolic profile of non-activated cells, while PD-1 functions to dampen metabolic reprogramming in activated cells [137]. Regardless, the function of PD-1 and CTLA-4 in antagonising key metabolic pathways in T cells are mechanisms tumours used to limit anti-tumour immunity, and provides an explanation for the capacity of $\mathrm{T}$ cells to be metabolically invigorated by ICB.

\subsection{Resistance to Immunotherapies}

However, in reality, only a small proportion of patients respond well to ICB [139]. Studies have uncovered several reasons for this gap, including poor tumour immunogenicity, tumour editing, and lack of sufficient tumour-infiltrating T cells in a 'cold' tumour [140,141].

The altered metabolism in cancer cells is often associated with dysregulated expression of key metabolic enzymes. The aberrantly expressed enzymes have pleiotropic effects that contribute to immunosuppression, limiting the effectiveness of immunotherapies. For example, many cancers display MYC-dependent upregulation of the alternatively spliced PKM2 enzyme as a mechanism to enhance aerobic glycolysis [142]. Furthermore, independent of its enzymatic action on glycolysis, PKM2 promotes the expression of PD-L1 on tumour surfaces and, hence, promotes immune suppression [143]. PKM2 activity also aids in recruitment of MDSCs, and is associated with increased metastasis and poor prognosis in HCC [144].

Tumour metabolism also limits the effectiveness of immunotherapies by affecting the tumour mutation rate and antigenicity [145]. Metabolism is tightly linked to DNA repair through chromatin remodelling, epigenetic modifications, and regulation of the redox status [146]. Altered tumour 
metabolism can promote chromatin remodelling and epigenetic modifications in multiple ways, such as by supplying acetyl and methyl groups and producing metabolites that act as key cofactors or inhibitors of epigenetic enzymes, such as $\alpha-K G$, succinate, fumarate, and 2-hydroxyglutarate [147]. Furthermore, the enhanced nucleotide biosynthesis in tumours promotes DNA repair [92]. Taken together, these processes lead to a reduced mutation rate and, hence, reduced tumour antigenicity, thereby limiting the effectiveness of immunotherapies.

Finally, CAFs in the TME may also contribute to immunotherapy resistance by several mechanisms. Firstly, the release of immunosuppressive cytokines TGF- $\beta$ and IL- 6 by CAFs lead to reduced proliferation and trafficking capacity of antigen-presenting DCs, thereby impairing $\mathrm{T}$ cell priming against tumour antigens $[145,148]$. CAFs also directly upregulate immune checkpoint ligands on their surface, including PD-L1 and PD-L2 [149,150]. Next, CAFs impair T cell migration to the tumour bed. Through tight regulation of the local chemokine gradient, CAFs limit $\mathrm{T}$ cell attraction to the TME [151,152]. CAFs also impair $\mathrm{T}$ cell access to the tumour, directly via inhibition of $\mathrm{T}$ cell migration through a TGF- $\beta$-dependent gene programme [153] as well as indirectly by altering the composition of the ECM, creating a denser ECM network, which functions as a physical barrier to T cell infiltration $[154,155]$.

\section{Cancer Stem Cells and Metabolic Reprogramming in CSCs as a Mechanism of Therapeutic Resistance}

The CSC model postulates that a small, metabolically distinct, and quiescent CSC population is responsible for resistance to therapies that target rapid proliferation [156]. This adds further to the complexity of the TME as CSCs reside in, actively remodel, and are reciprocally modulated by each element of the TME. This leads to an intricate crosstalk between CSCs and cancer cells, stromal components, and the immune milieu, generating a wide variety of resistance mechanisms [157].

A number of studies suggest stronger glycolytic metabolism in CSCs as compared to differentiated tumour cells [158-160]. Interestingly, elevated MYC was independently identified as the main driver of stemness in all of these cancer types [159]. This has been linked to a MYC-driven glycolytic programme, consistent with what is observed in induced pluripotent stem cells [160], leading to the notion that, rather than distinct metabolism being a 'by-product' of cancer stemness, metabolism may be the 'driver' controlling stemness characteristics. On the other hand, emerging evidence suggests that CSCs demonstrate extensive metabolic flexibility and acquiring increased oxidative metabolism confers greater ability to overcome therapy-induced stressful metabolic environments promoting CSC survival.

Therapy-induced enrichment of CSC populations was observed in various cancer models [6]. In a model of BCR-ABL driven chronic myeloid leukaemia (CML), persistent leukaemic stem cells (LSC) responsible for treatment resistance and relapse depended on OXPHOS upregulation for survival. Subsequently, combination therapy of OXPHOS inhibition plus BCR-ABL targeted therapy was able to selectively eradicate CML LSCs in-vitro and in-vivo [161]. Similarly, in a mouse model of PDAC, resistant cells surviving KRAS ablation showed more features of CSCs and reliance on OXPHOS for survival. Treatment with OXPHOS inhibitors also resulted in eradication of CSCs in-vitro and in-vivo [162]. Mechanistically, the metabolic switch to OXPHOS in pancreatic CSCs was found to be dependent on the MYC/PGC- $1 \alpha$ balance [163]. Suppression of MYC and subsequent increase in PGC-1 $\alpha$ stimulated PGC-1 $\alpha$-dependent mitochondrial biogenesis and OXPHOS dependency. Consequently, treatment of pancreatic CSCs with metformin led to an energy crisis and apoptosis [163].

\section{Therapeutic Opportunities Targeting Altered CCM}

With greater understanding of dysregulated cancer metabolism and the metabolic interplay of cancer cells, TME and CSCs, therapies can be developed to target these processes and overcome therapeutic resistance. In the following sections, we will highlight promising strategies that target altered pathways of metabolism, alone or in combination with other available anti-cancer therapies. 


\subsection{Glycolysis Inhibitors}

Hexokinase catalyses the first step in glycolysis of which the HK2 isoform is upregulated by many tumours and is needed to maintain the high glycolytic rate. HK2 is, thus, a potential target for inhibition [164]. Various HK2 inhibitors have been identified, including 2-deoxyglucose (2-DG), 3-bromopyruvate (3-BP), and lonidamine (LND). In particular, 2-DG is a glucose mimetic that competitively inhibits the production of glucose-6-phosphate (G6P) from glucose and causes ATP depletion and cell death [165]. As a single-agent therapy, 2-DG had shown promising results and reached phase I/II clinical trials for the treatment of solid tumours and hormone refractory prostate cancer, but, unfortunately, was halted due to limited efficacy on tumour growth and significant toxicities (NCT00633087). Detailed phase II and III clinical trials have also been performed for LND in several tumour types. Unfortunately, LND only showed modest clinical activity, and further research was halted due to concerns over liver enzyme abnormalities and its lack of specificity [166].

PFKFB3 is a potent regulator of glycolysis and is frequently upregulated in cancers [167]. Various inhibitors of PFKFB3 have been reported, including the weak PFKFB3 inhibitor, 3-(3-pyridinyl)-1-(4-pyridinyl)-2-propen-1-one (3PO). A derivative of 3PO, PFK15, showed improved pharmacokinetic and anti-neoplastic properties in-vitro and in-vivo. PFK15 was able to cause a rapid induction of apoptosis in transformed cells and showed anti-tumour effects in-vivo [168]. Another 3PO derivative, PFK158, is currently under evaluation in a phase I trials for advanced solid malignancies (NCT02044861) [169].

Finally, small molecular inhibitors of GLUT transporters are undergoing evaluation. Phloretin antagonises GLUT2 in TNBC and suppressed cell growth and metastasis of TNBC in-vitro and in-vivo [170]. STF-31 is a selective GLUT1 inhibitor, which showed effectiveness in Von Hippel-Lindau-dependent RCC models [171]. Another GLUT1 inhibitor, WZB117, was able to inhibit cancer growth and viability in-vivo, and was synergistic with cisplatin and paclitaxel [172]. GLUT3 inhibition has also been shown to be effective in delaying the resistance to temozolamide in the treatment of glioblastoma multiforme (GBM) [173]. The FDA-approved antiviral drug, ritonavir, was found to have GLUT4 inhibitory activity in multiple myeloma (MM) and is synergistic with metformin [174,175]. Of note, tumours expressing high levels of the cystine-glutamate antiporter xCT (SLC7A11) are heavily dependent on the PPP to supply reducing power in the form of NADPH [176], and GLUT inhibition selectively kills SLC7A11 high cancer cells in-vitro and in-vivo [177], presenting a metabolic vulnerability that can be targeted. Finally, an ongoing phase I trial is evaluating the role of ritonavir in combination with metformin in treating patients with relapsed or refractory MM or chronic lymphocytic leukaemia (CLL) (NCT02948283). Further work on small molecule GLUT inhibitors are required to establish safety and efficacy for translation to clinic.

\subsection{OXPHOS Inhibitors}

Strategies for inhibiting OXPHOS range from direct or indirect inhibition of mitochondrial respiratory chain complexes or inhibiting mitochondrial biosynthesis.

\subsubsection{Biguanides}

Of the complex I inhibitors, the biguanides, metformin, and phenformin, have been most extensively studied in cancer prevention and treatment $[178,179]$. Their anti-tumour activity relates to mTOR inhibition by the activation of AMPK and LKB1, thus reducing cellular proliferation. Proof-of-concept studies have confirmed biological evidence supporting the anti-proliferative effects of metformin in endometrial cancers, which are strongly associated with aberrations in the PI3K/AKT/mTOR pathway [180]. Observational studies have reported that the likelihood of developing cancer in type II diabetic patients treated with metformin is $30 \%$ lower than that of patients taking alternative oral hypoglycaemic agents (OHGAs). In a meta-analysis, metformin was found to be a useful adjuvant agent in preventing cancer relapse with the greatest benefits seen in prostate cancer 
and CRC [181]. Multiple trials investigating the effect of metformin as monotherapy and in combination with chemotherapy or TKI therapy are underway (e.g., NCT03137186, NCT01243385). However, there are doubts on whether metformin is able to reach sufficiently high concentrations to inhibit OXPHOS in-vivo. This is due to the requirement of uptake via organic cation transporters (OCTs), which may be reduced in various tumour types [182]. Phenformin, on the other hand, may have intrinsic pharmacokinetic properties to overcome this limitation. Being more hydrophobic, phenformin is able to cross biological membranes without requiring active transport. It is, therefore, nearly 50 times as potent as metformin due to its higher absorption and tissue bioavailability [183]. Phenformin had demonstrated more potent inhibition of cell proliferation compared to metformin in multiple tumour types (breast, lung, colon, melanoma, GBM, and prostate) [183]. Phenformin is also proposed to delay treatment resistance to conventional cancer therapies. For instance, in osimertinib-resistant EGFR-mutant NSCLC, which is reported to undergo a metabolic switch from glycolysis to OXPHOS, phenformin was able to delay the long-term development of osimertinib resistance [51]. There are also proposed biomarkers to indicate susceptibility and increase the efficacy of biguanide therapy. For example, LKB1 deficient cells show increased sensitivity to metabolic stress and were predictive of susceptibility to phenformin therapy, supporting its role as a potential biomarker for OXPHOS inhibition [179]. Unfortunately, due to its association with a higher incidence of lactic acidosis, phenformin had been withdrawn from clinical use as an OHGA and, hence, limited clinical studies are available looking into the effect of phenformin for cancer therapy [184].

\subsubsection{IACS and Other Complex I Inhibitors}

Another complex I inhibitor, IACS-010759, recently demonstrated preclinical efficacy in inhibiting growth of CLL and acute myeloid leukaemia (AML) [185]. IACS-010759 is potent and can be administered orally, and has progressed to phase I trials in advanced solid tumours, which was reported to be well-tolerated with preliminary evidence of anti-tumour activity. Maximum tolerated dose (MTD) expansions are planned for patients with TNBC, pancreatic cancer, and castration-resistant prostate cancer. Given the diverse metabolic dependencies of tumours, it is crucial to have means to stratify tumours to better predict their susceptibility to metabolism-based treatments. The loss of enolase 1 (ENO1) was found to be predictive of sensitivity to IACS-010759 in some brain tumour cell lines (D423, Gli56) [186]. Loss of SMARCA4, a component of the SWI/SNF chromatin remodelling complex, also results in greater reliance on OXPHOS, and cells are more sensitive to OXPHOS inhibition by IACS-010759 in NSCLC [187]. These findings have led to plans to investigate the efficacy of IACS-010759 in molecularly-selected tumours (ENO1 loss and SMARCA4 mutation) (NCT03291938, NCT02882321) [188].

Some of the other complex I inhibitors initially demonstrated promising results but were subsequently withdrawn due to toxicity. For instance, BAY87-2243 had advanced to phase I studies (NCT01297530). However, the trial was terminated due to significant toxicities (grade III nausea/vomiting). A phase Ib study was completed for ME-344. However, further research halted due to significant grade III/IV toxicities and lack of clinical efficacy in unselected patients with small cell lung cancer, ovarian cancer, and cervical cancers [189]. Other complex I inhibitors include carboxyamidotriazole (CAI). In particular, CAI had completed phase III clinical trial for advanced NSCLC (NCT00003869). Unfortunately, no additional clinical benefit was reported with the addition of CAI over placebo following chemotherapy [190].

\subsubsection{Complex II-V Inhibitors}

Apart from complex I inhibitors, various compounds that inhibit complexes II-V of the mitochondrial ETC have also been investigated. These include the low-affinity complex II inhibitor $\alpha$-tocopheryl succinate, complex III inhibitor atovaquone, and the complex IV inhibitor arsenic trioxide, which is used for treating acute promyelocytic leukaemia [4]. However, many of these compounds have pleiotropic effects apart from mitochondrial inhibition, and it may be difficult to distil and 
attribute their therapeutic effects to OXPHOS inhibition. Presently, limited data is available studying the anti-tumour efficacy of complex II-IV inhibitors, and further research is warranted.

A novel Complex V ( $\mathrm{F}_{0} \mathrm{~F}_{1}$ ATP synthase) inhibitor, gboxin, selectively accumulates in the mitochondria due to its positive charge. This leads to increased proton gradient and $\mathrm{pH}$ in the cancer cell mitochondria, thereby inhibiting ATP production via the ATP synthase [191]. In GBM cells, gboxin rapidly and irreversibly compromises oxygen consumption, leading to gboxin-mediated cell death [191].

\subsubsection{Indirect Inhibition of Mitochondrial Complexes and Mitochondrial Protein Synthesis}

Treatment-induced metabolic switch to OXPHOS has been hypothesized to involve mitochondrial STAT3 (mSTAT3), which indirectly promotes OXPHOS by interacting with retinoic-interferon-induced mortality 19 (GRIM-19) and the ETC complexes I and II [192]. Thus, indirect OXPHOS inhibition can also be achieved by mSTAT3 inhibition. OPB compounds able to indirectly inhibit OXPHOS via their action on mSTAT3, with several OPB compounds reaching clinical trials (OPB-51602, OPB-111077, OPB-31121) in treatment-refractory solid tumours as well as in haematological malignancies. OPB-51602 had been evaluated in a phase I first-in-human study (NCT01184807), demonstrating promising anti-tumour activity in EGFR-mutant NSCLC with prior EGFR-TKI exposure [193]. OPB-111077, a second-generation compound with an improved safety profile, had completed phase I evaluation in treatment-refractory solid tumours [194]. Further trials are underway in patients with diffuse large B-cell and oncogene-addicted solid tumours (NCT03158324) [194].

Mitochondrial dysfunction may also be induced by inhibiting mitochondrial protein translation. This can be achieved by using the antibiotic tigecycline, which was identified in a screen with OXPHOS-dependent leukaemia cells [195]. Subsequent studies using tigecycline to treat TKI-resistant CML cells were able to successfully eliminate the OXPHOS-dependent CSC population thought to be responsible for treatment resistance [161]. Another antibiotic, salinomycin, inhibits OXPHOS and was able to eliminate the CSC gene expression signature in in-vivo studies of breast cancer [196]. Mitochondrial metabolism can also be targeted by the mitochondrial chaperone TRAP1 inhibitor, gamitrinib, which leads to impairments to mitochondrial protein folding [197].

\subsection{Glutamine Blockade}

The pleiotropic effects of glutamine metabolism on cancer proliferation and signalling makes glutamine blockade another potential strategy for targeting cancer metabolism. Proposed strategies include depleting cancer cell glutamine supply, blocking glutamine uptake transporters, using glutamine mimetics as anti-metabolites, and the most promising, selective inhibition of GLS.

The mitochondrial enzyme GLS is a key component of glutaminolysis, which produces $\alpha-K G$ for the replenishment of TCA cycle intermediates. Small molecule GLS inhibitors such as bis-2-(5-phenylacetamido-1,2,4-thiadiazol-2-yl)ethyl sulfide (BPTES), CB-839, and compound 968, are able to inhibit GLS isoforms not commonly expressed in normal cells, allowing for greater selectivity in targeting cancer cells while reducing toxicity to normal cells [198,199]. The GLS1 inhibitor, CB-839, has reached the furthest in the developmental pipeline, and is selective, more potent, and demonstrates greater bioavailability compared to BPTES [200,201]. In early phase studies, CB-839 showed safety and tolerability in solid tumours with promising signs of clinical activity in multiple tumour types including TNBC, NSCLC, and mesothelioma (NCT02071862) [202,203]. In particular, for RCC, radiographic stable disease (SD) or partial response (PR) was observed in 9 of $15(60 \%)$ efficacy-evaluable RCC patients [202]. No specific biomarker of patient selection for GLS inhibition has been established, but studies have evaluated tumour GLS overexpression and the specific GLS1 variant that is overexpressed. GLS1 exists two main splice variants: KGA, the full length GLS1, and GAC, which has an alternative carboxy-terminus and a lower molecular weight [204]. Of these, only the GAC splice variant is sensitive to GLS inhibition by CB-839 [200]. 
Depletion of the cancer cell glutamine supply can be achieved via L-asparaginase, a recognised treatment for acute lymphoblastic leukaemia (ALL), which removes the amide nitrogen from glutamine to form glutamic acid [205]. Serum L-asparaginase activity strongly correlates with glutamine depletion in the blood and improved treatment outcomes in ALL patients [206].

Inhibitors have been developed for the glutamine uptake transporter SLC1A5 (ASCT2), which is upregulated across many tumour types to increase glutamine uptake $[207,208]$. A pharmacological agent used as a common preclinical tool to inhibit SLC1A5 is the L-glutamine analogue, L- $\gamma$-glutamyl-p-nitroanilide (GPNA). Pharmacological inhibition of SLC1A5 with GPNA was able to decrease lung cancer cell growth and viability by inhibiting glutamine-dependent mTORC1 signalling $[209,210]$. In an immunohistochemistry study on NSCLC patients, SLC1A5 protein expression was found to be a significant prognostic marker, and is a potential diagnostic marker for glutamine-dependent NSCLC [209]. However, toxicity in healthy cells slowed progress in bringing SLC1A5 inhibitors into clinical use [211].

Finally, targeting glutamine metabolism is also proposed to be effective in eradicating the CSC populations thought to be responsible for cancer relapse. Glutamine deprivation was found to diminish the proportion of CSC-like cells in various cancers including NSCLC, pancreatic cancer, and GBM [212]. Pharmacological inhibition of GLS was also shown to be effective in eradicating the GBM stem-like cell population, which is thought to be responsible for therapy resistance and tumour recurrence [213].

\section{Targeting Stromal Components}

\section{1. $C A F s$}

In the 'reverse Warburg' effect, CAFs undergo aerobic glycolysis and release lactate to fuel tumour OXPHOS [73]. Since this involves lactate export via MCT-4 into the TME, and subsequent lactate import via MCT-1 into the tumour, this metabolic crosstalk can potentially be blocked by MCT-1/MCT-4 inhibition. MCT-4 inhibition is able to block lactate export from tumours, resulting in lactate build-up, intracellular acidification, and end-product inhibition of glycolytic enzymes, which cripples tumour metabolism [214]. Syrosingopine is a dual MCT-1/MCT-4 inhibitor that leads to lactate accumulation and LDH inhibition in a mouse model of liver cancer, leading to reduced $\mathrm{NAD}^{+}$ levels [214]. Most other small-molecule MCT inhibitors developed to date are specific to MCT-1, with one drug (AZD3965) currently in clinical trials. However, AZD3965 is ineffective when MCT-4 is expressed [215], thus restricting its application to tumours that lack MCT-4.

The glutamine-based 'tumour-feeding' by CAFs may also be targeted. Inhibition of GLUL in CAFs, together with GLS inhibition in cancer cells, led to a synergistic effect in reducing tumour weight and metastasis in ovarian cancer mouse models when compared to monotherapy by disrupting the metabolic crosstalk between CAFs and ovarian tumour cells [79]. Similarly, GLS inhibition (by CB-839 and BTPES) in TNBC showed high efficacy initially, as TNBC is greatly reliant on exogenous glutamine for metabolism [200]. However, resistant cells soon emerged, which were able to respond to decreased glutamine inhibition by uptake of extracellular, CAF-derived pyruvate to replenish the TCA cycle, thus nullifying the effects of GLS inhibition [216].

\subsection{ECs}

As discussed in earlier sections, aberrant vessel sprouting is contributed by altered CCM leading to changes in the TME that impairs the normal vascularisation process in ECs. Thus, targeting CCM is a strategy to achieve tumour vessel normalisation as a potential anti-cancer treatment. Since tumour ECs (TECs) are highly glycolytic compared to normal proliferating ECs [217], one strategy is a blockade of glycolysis by inhibiting the glycolytic activator PFKFB3 with 3PO. Treatment with 3PO was found to promote tumour vessel normalisation, impairing cancer metastasis by tightening the $\mathrm{EC}$ barrier, and enhanced the efficiency of chemotherapy [84]. 
The hyperproliferative nature of TECs is also proposed to lead to greater dependency on mitochondrial metabolism, especially given the intense competition for nutrients in the TME, where glycolysis is likely already maximised by relying on mitochondrial ATP production to sustain angiogenesis [218]. As such, treating proliferating ECs with the weak mitochondrial uncoupler, Embelin, led to reduced OXPHOS, impairing tumour growth, and decreased microvessel density in mouse tumour models [219].

\section{Targeting Metabolic Flexibility as a Mechanism of Resistance to CCM Inhibitors}

Unfortunately, targeting inherent metabolic dependencies in isolation has met with halting failures due to metabolic plasticity in cancer cells. Upon inhibition of a particular pathway, tumours may simply reprogram their metabolism and upregulate a separate compensatory pathway, allowing escape from dependency on a single pathway. For instance, when various cancer cells were exposed to a continuous glycolytic block with 2-DG, a recurrent reprogramming mechanism was observed that led to escape from glycolytic addiction and, hence, escape from 2-DG susceptibility. This involved sustained mTORC1 signalling, directing glucose flux via the PPP back into glycolysis, nullifying the glycolytic block via anaplerosis [220]. This heightened metabolic flexibility is promoted by the pre-existing genetic and epigenetic instability in cancer cells, leading to rapid metabolic adaptation in response to inhibitors, and, in turn, therapy resistance [221,222]. Evidently, this flexibility and ease of switching to other pathways to fuel their metabolism poses a great challenge in developing successful CCM-targeting strategies.

Uncovering these mechanisms and metabolic tendencies has revealed evolutionary canalisations that can be exploited using a 'synthetic lethality' approach. In this section, combinatorial strategies involving dual metabolic inhibition and metabolic inhibitors in combination with targeted therapy, chemotherapy, and immunotherapy will be highlighted with multiple combinations showing promising advancements in clinical trials (Tables 1-4).

Table 1. Dual metabolic inhibitor combinations for cancer therapy.

\begin{tabular}{|c|c|c|c|c|}
\hline $\begin{array}{c}\text { Targeted } \\
\text { Metabolism }\end{array}$ & $\begin{array}{l}\text { Metabolic } \\
\text { Inhibitor } 1\end{array}$ & Metabolic Inhibitor 2 & Preclinical Data & Clinical Data \\
\hline \multirow{5}{*}{$\begin{array}{l}\text { OXPHOS + } \\
\text { Glycolysis }\end{array}$} & \multirow[t]{2}{*}{ Metformin } & 2-deoxyglucose (2-DG) & $\begin{array}{l}\text { Breast, prostate, GBM, } \\
\text { sarcoma, PDAC, } \\
\text { oesophageal, ovarian } \\
\text { cancers [223-229] }\end{array}$ & \\
\hline & & HK2 deletion & $\mathrm{HCC}[230]$ & \\
\hline & \multirow{2}{*}{$\begin{array}{l}\text { IACS-010759 } \\
\text { (complex I } \\
\text { inhibitor) }\end{array}$} & $\begin{array}{l}\text { Phosphogluconate } \\
\text { dehydrogenase } \\
\text { (PGD) inhibition }\end{array}$ & $\begin{array}{l}\text { Hereditary leiomyomastosis } \\
\text { RCC [231] }\end{array}$ & \\
\hline & & 2-DG & CLL [185] & \\
\hline & $\begin{array}{l}\text { BAY87-2243 } \\
\text { (B87) }\end{array}$ & Dimethyl $\alpha-K G$ (DMKG) & $\begin{array}{c}\text { Multiple: NSCLC, CRC, } \\
\text { glioma, breast, sarcoma [232] }\end{array}$ & \\
\hline $\begin{array}{l}\text { Glutaminolysis + } \\
\text { Glycolysis }\end{array}$ & CB-839 & 3-BP (HK2 inhibitor) & Renal [233] & \\
\hline \multirow{2}{*}{$\begin{array}{l}\text { OXPHOS + } \\
\text { Metabolite } \\
\text { Transporter }\end{array}$} & \multirow[t]{2}{*}{ Metformin } & $\begin{array}{c}\text { Syrosingopine (MCT-1 and } \\
\text { MCT-4 inhibitor) }\end{array}$ & Liver [214] & \\
\hline & & $\begin{array}{c}\text { Ritonavir } \\
\text { (GLUT4 inhibition) }\end{array}$ & & $\begin{array}{l}\text { Phase I-MM, CLL } \\
\text { (NCT02948283) }\end{array}$ \\
\hline
\end{tabular}


Table 2. Metabolic inhibitors in combination with targeted therapy for cancer therapy.

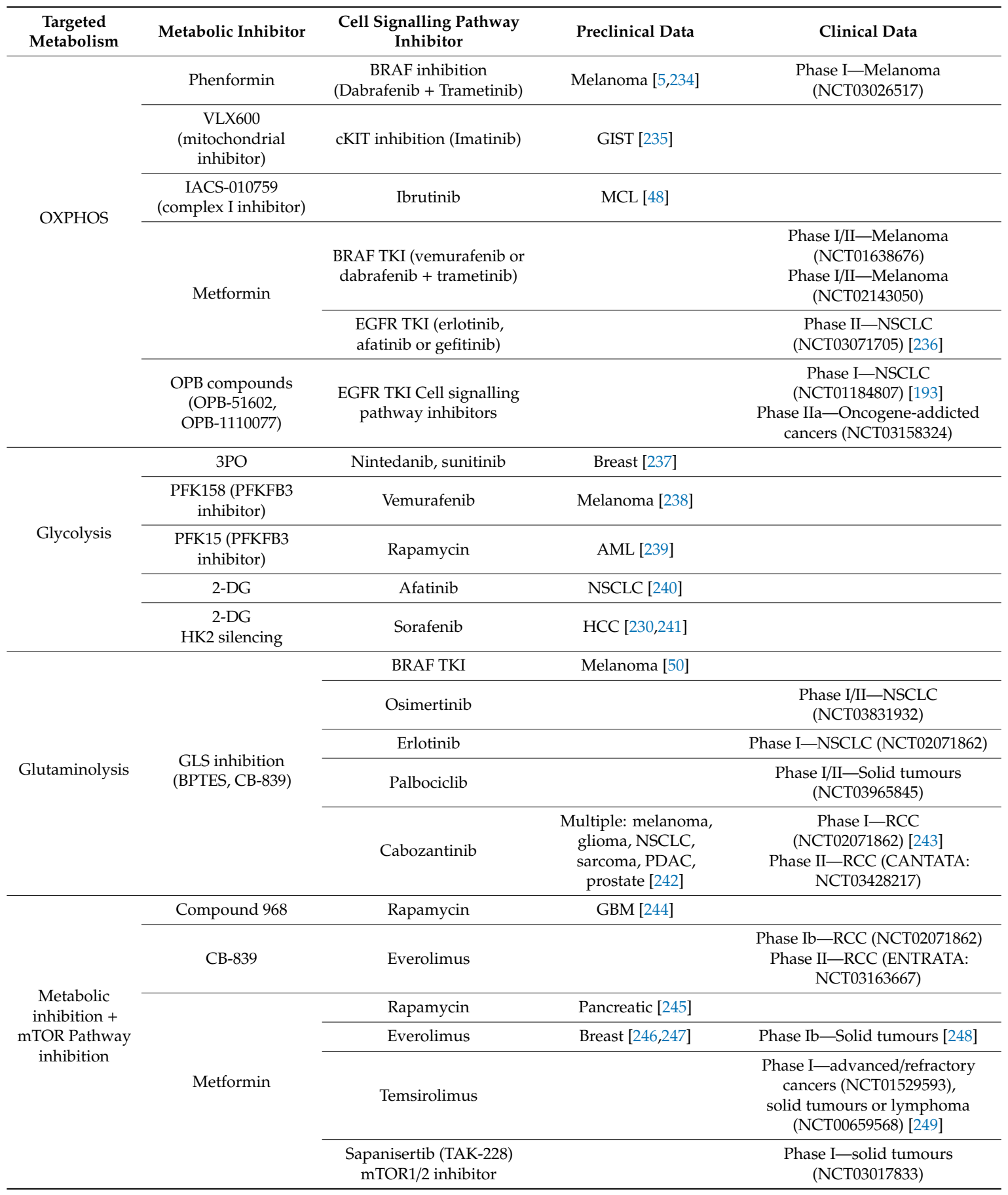

Table 3. Metabolic inhibitors in combination with chemotherapy.

\begin{tabular}{|c|c|c|c|c|}
\hline $\begin{array}{c}\text { Targeted } \\
\text { Metabolism }\end{array}$ & Metabolic Inhibitor & Chemotherapy & Preclinical Data & Clinical Data \\
\hline \multirow{3}{*}{ Glycolysis } & \multirow{3}{*}{ 3-BP (HK2 inhibitor) } & $\begin{array}{c}\text { Platinum drugs } \\
\text { (cisplatin, oxaliplatin) }\end{array}$ & CRC [250] & \\
\hline & & 5-fluorouracil & CRC [251] & \\
\hline & & Doxorubicin & Neuroblastoma [252] & \\
\hline
\end{tabular}


Table 3. Cont

\begin{tabular}{|c|c|c|c|c|}
\hline $\begin{array}{c}\text { Targeted } \\
\text { Metabolism }\end{array}$ & Metabolic Inhibitor & Chemotherapy & Preclinical Data & Clinical Data \\
\hline \multirow{3}{*}{ Glycolysis } & \multirow{2}{*}{ 2-DG } & Etoposide & Lymphoma [254] & \\
\hline & & $\begin{array}{c}\text { Doxorubicin, paclitaxel } \\
\text { Docetaxel }\end{array}$ & $\begin{array}{l}\text { Osteosarcoma, } \\
\text { NSCLC [256] }\end{array}$ & Phase I-various [257] \\
\hline & PKM2 modulation & Docetaxel & Lung [260] & \\
\hline Glutaminolysis & CB-839 & Paclitaxel & TNBC [200] & $\begin{array}{c}\text { Phase I-TNBC } \\
\text { (NCT02071862) [261] } \\
\text { Phase II-TNBC } \\
\text { (NCT03057600) [262] }\end{array}$ \\
\hline \multirow{9}{*}{$\begin{array}{l}\text { Mitochondrial } \\
\text { Metabolism }\end{array}$} & \multirow[t]{2}{*}{$\begin{array}{l}\text { CPI-613/Devimistat (PDH } \\
\text { and } \alpha-K G \text { dehydrogenase } \\
\text { complex inhibitor) }\end{array}$} & $\begin{array}{c}\text { FOLFIRINOX } \\
\text { (oxaliplain, folinic acid, } \\
\text { irinotecan, fluorouracil) }\end{array}$ & & $\begin{array}{c}\text { Phase I-PDAC } \\
\text { (NCT01835041) [263] } \\
\text { Phase III-PDAC (AVENGER } 500 \\
\text { trial, NCT03504423) }\end{array}$ \\
\hline & & $\begin{array}{l}\text { Cytarabine + } \\
\text { mitoxantrone }\end{array}$ & & $\begin{array}{c}\text { Phase III-AML (ARMADA } 2000 \\
\text { trial, NCT03504410) [264] }\end{array}$ \\
\hline & \multirow{3}{*}{ Metformin } & Doxorubicin & Prostate, lung [265] & \\
\hline & & Carboplatin & NSCLC [57] & \\
\hline & & 5-fluorouracil & & $\begin{array}{c}\text { Phase II-CRC } \\
\text { (NCT01941953) [266] }\end{array}$ \\
\hline & $\begin{array}{l}\text { IACS-010759 (complex I } \\
\text { inhibitor) }\end{array}$ & $\begin{array}{l}\text { Cytarabine + } \\
\text { doxorubicin }\end{array}$ & AML [267] & \\
\hline & OPB-111077 & $\begin{array}{l}\text { Bendamustine + } \\
\text { rituximab }\end{array}$ & & $\begin{array}{c}\text { Phase I-diffuse large B cell } \\
\text { lymphoma (DLBCL) } \\
\text { (NCT04049825) }\end{array}$ \\
\hline & \multirow{2}{*}{$\begin{array}{l}\text { Dicholoroacetate (PDK2 } \\
\text { inhibitor) }\end{array}$} & Paclitaxel & NSCLC [268] & \\
\hline & & 5-fluorouracil & CRC [269] & \\
\hline \multirow{2}{*}{$\begin{array}{l}\text { Other } \\
\text { enzymes }\end{array}$} & $\begin{array}{l}\text { CB-1158/INCB001158 } \\
\text { (Arg1 inhibitor) }\end{array}$ & Chemotherapy & & $\begin{array}{l}\text { Phase I/II-solid tumours } \\
\text { (NCT03314935) }\end{array}$ \\
\hline & $\begin{array}{l}\text { Indoximod/1-methyl-D- } \\
\text { tryptophan (IDO1 inhibitor) }\end{array}$ & $\begin{array}{l}\text { Taxane chemotherapy } \\
\text { Gemcitabine }\end{array}$ & & $\begin{array}{l}\text { Phase II-breast (NCT01792050) } \\
\text { Phase I/II-PDAC (NCT02077881) }\end{array}$ \\
\hline
\end{tabular}

Table 4. Metabolic inhibitors in combination with immunotherapy.

\begin{tabular}{|c|c|c|c|c|}
\hline $\begin{array}{c}\text { Targeted } \\
\text { Metabolism }\end{array}$ & Metabolic Inhibitor & Immunotherapy & Preclinical Data & Clinical Data \\
\hline \multirow{4}{*}{ Glutaminolysis } & \multirow{3}{*}{ CB-839 } & Anti-PD-1, anti-PD-L1 & Colon [270] & \\
\hline & & Nivolumab & & $\begin{array}{l}\text { Phase I/II-melanoma, RCC, } \\
\text { NSCLC (NCT02771626) }\end{array}$ \\
\hline & & $\begin{array}{c}\text { Pembrolizumab + } \\
\text { carboplatin + pemetrexed }\end{array}$ & & Phase II-NSCLC (NCT04265534) \\
\hline & JHU083 & Anti-PD-1 & $\begin{array}{l}\text { Lymphoma, colon, } \\
\text { melanoma [104] }\end{array}$ & \\
\hline $\begin{array}{l}\text { Amino acid } \\
\text { metabolism }\end{array}$ & $\begin{array}{l}\text { CB-1158/INCB001158 } \\
\text { (Arg1 inhibitor) }\end{array}$ & $\begin{array}{c}\text { Anti-PD-1 } \\
\text { Pembrolizumab } \\
\text { Daratumumab }\end{array}$ & Solid tumours [271] & $\begin{array}{c}\text { Phase I/II-solid tumours (NCT02903914) } \\
\text { Phase I/II-MM (NCT03837509) }\end{array}$ \\
\hline
\end{tabular}


Table 4. Cont.

\begin{tabular}{|c|c|c|c|c|}
\hline $\begin{array}{c}\text { Targeted } \\
\text { Metabolism }\end{array}$ & Metabolic Inhibitor & Immunotherapy & Preclinical Data & Clinical Data \\
\hline \multirow{3}{*}{$\begin{array}{l}\text { Amino acid } \\
\text { metabolism }\end{array}$} & \multirow[b]{2}{*}{$\begin{array}{l}\text { Epacadostat/INCB024360 } \\
\text { (IDO1 inhibitor) }\end{array}$} & $\begin{array}{l}\text { Checkpoint inhibitors } \\
\text { (various) }\end{array}$ & & $\begin{array}{l}\text { Phase I/II-solid tumours } \\
\text { (multiple clinical trials) }\end{array}$ \\
\hline & & Pembrolizumab & & $\begin{array}{c}\text { Phase III-melanoma } \\
\text { (NCT02752074) [272] } \\
\text { Phase III-melanoma, urothelial } \\
\text { carcinoma, HNSCC (Keynote-ECHO } \\
\text { trials: NCT02752074, NCT03361865, } \\
\text { NCT03374488, NCT03358472) }\end{array}$ \\
\hline & $\begin{array}{l}\text { Navoximod/GDC-0919 } \\
\text { (IDO1 inhibitor) }\end{array}$ & Atezolizumab & & $\begin{array}{c}\text { Phase Ib—solid tumours } \\
\text { (NCT02471846, NCT02048709) }\end{array}$ \\
\hline \multirow[t]{2}{*}{ Other } & \multirow[t]{2}{*}{$\begin{array}{l}\text { CPI-444/ciforadenant } \\
\text { (A2AR antagonist) }\end{array}$} & Atezolizumab & & $\begin{array}{c}\text { Phase I-RCC, prostate (NCT02655822) } \\
\text { Phase I/II-NSCLC (NCT03337698) }\end{array}$ \\
\hline & & Daratumumab & & Phase I-MM (NCT04280328) \\
\hline
\end{tabular}

\subsection{Dual Metabolic Pathway Inhibition}

Dual inhibition of OXPHOS and glycolysis is able to effectively disrupt energy metabolism and has proven to be effective against tumour growth in multiple preclinical cancer models (Table 1). For example, dual inhibition of glycolysis with 2-DG and OXPHOS with metformin-inhibited tumour growth preclinically in a broad spectrum of tumour models, including breast cancer, prostate cancer, GBM, and sarcoma [223-229]. Similarly, HK2 depletion in HCC sensitises cells to metformin [230]. Moreover, treatment of OXPHOS-competent hereditary leiomyomatosis RCC with the complex I inhibitor IACS-010759 plus simultaneous inhibition of the glycolytic enzyme phosphogluconate dehydrogenase (PGD) led to synthetic lethality [231]. Likewise in CLL cells, simultaneous inhibition of OXPHOS by IACS-010759 and glycolysis by 2-DG had a more pronounced effect than either inhibitor alone, providing a strong biological rationale for dual metabolic inhibition to deprive cancer cells of ATP [185].

Apart from OXPHOS and glycolysis inhibitor combinations, other dual metabolic inhibitor combinations have also been investigated. Many tumours rely on glutamine-mediated TCA cycle anaplerosis as an alternative source of carbon, and targeting glucose metabolism alone leads to compensatory dependency on glutaminolysis, providing the biological rationale for dual glutaminolysis plus glycolysis blockade [273]. Simultaneous glutaminolysis blockade with CB-839 and glycolysis inhibition with the HK2 inhibitor 3-BP was investigated in mice with renal tumours. The data showed promising results, as dual inhibition was able to significantly reduce overall lesions, while neither drug alone did [233]. Another combination strategy is to couple OXPHOS inhibition together with metabolite transporter blockade. Dual inhibition of the lactate transporters MCT- 1 and MCT- 4 with syrosingopine was found to be synthetic lethal with metformin due to $\mathrm{NAD}^{+}$depletion in a mouse model of liver cancer [214]. A phase I study of metformin plus GLUT4 inhibition with ritonavir for relapsed/refractory MM or CLL is due to be completed in October 2020 (NCT02948283).

\subsection{Metabolic Inhibition and Cell Signalling Pathway Inhibition}

As a common theme, oncogene-addicted tumours that become resistant to primary TKI therapy develop OXPHOS dependency [274], and OXPHOS inhibition has been shown to resensitise cells to TKI therapy $[5,232,235]$. As a result, BRAF inhibitor-resistant melanoma was susceptible to complex I inhibition with phenformin, which re-sensitised cells to BRAF inhibition [5,234]. Similarly, the cKIT inhibitor imatinib was synergistic with the mitochondrial inhibitor VLX600 to limit the growth of GIST in mouse models [235]. Promising preclinical data have led to clinical trials testing OXPHOS inhibitor and TKI inhibitor combinations.

An ongoing phase I trial is evaluating the safety and efficacy of phenformin in combination with dabrafenib and trametinib in BRAF-mutant melanoma (NCT03026517). Various trials with metformin plus $B R A F$ inhibitor combinations are also ongoing for numerous tumour types, including melanoma 
(NCT01638676, NCT02143050). A randomised phase II trial was conducted for the use of metformin in combination with front-line EGFR-TKI for EGFR-mutant NSCLC, with promising results (NCT03071705). The median progression-free survival and overall survival were significantly longer in the EGFR-TKIs plus the metformin group compared to EGFR-TKIs group [236]. Similarly, an ongoing clinical trial is evaluating the safety and efficacy of OPB compounds in combination with targeted therapies in oncogene-addicted tumours (NCT03158324).

While some tumours upregulate OXPHOS, others are reported to increase glycolysis in response to primary TKI therapy [275]. As a result, studies using glycolysis inhibition plus TKI therapies have shown promising preclinical results (Table 2). PFKFB3 inhibition with 3PO effectively suppressed tumour growth in combination with multi-kinase inhibitors nintedanib and sunitinib in a mouse model of breast cancer [237]. Similarly, promising data has been shown for derivatives of 3PO, PFK158, and PFK15 in combination with vemurafenib for BRAF-mutant melanoma cells in-vitro [238], and in combination with rapamycin for AML, respectively [239], with plans for phase I/II trials of PFK158 in combination with targeted agents underway. Preclinical success had also been seen with glycolytic inhibition using 2-DG in combination with TKI therapy. For instance, 2-DG treatment was synergistic with and able to resensitise NSCLC to the second-generation irreversible EGFR-TKI afatinib [240]. 2-DG was also synergistic with sorafenib in inducing apoptosis of sorafenib-resistant HCC cells [241]. Similarly, HK2 silencing in combination with sorafenib produced the same effect in inhibiting HCC tumour growth [230].

Glutamine metabolism also plays a key role in metabolic reprogramming in treatment resistance to targeted therapy with raised GSH levels conferring tumours with greater ability to maintain redox homeostasis $[59,275]$. Furthermore, another proposed mechanism by which oncogene-addicted cancers develop resistance to TKI therapy is via switching to glutaminolysis as a means of increasing OXPHOS [50]. This is shown by the development of OXPHOS dependency with acquired resistance to BRAF inhibitors upon treatment in BRAF-mutant melanoma [50]. Interestingly, this shift toward oxidative metabolism is associated with a switch from glucose to glutamine metabolism, suggesting a possible link between these two metabolic pathways and resistance to targeted therapies. Treatment of melanoma cells with the GLS inhibitor BPTES enhanced the anti-tumour activity of BRAF inhibition by suppressing the switch toward glutamine metabolism and OXPHOS [50] (Table 2).

Building on this idea, ongoing phase I/II studies of the GLS inhibitor CB-839 in combination with osimertinib is being tested for EGFR-mutant NSCLC (NCT03831932) and CB-839 with palbociclib for solid tumours (NCT03965845) (Table 2). In RCC, preclinical models showed CB-839 synergism with cabozantinib (Cabo), a VEGFR2/MET/AXL inhibitor, leading to inhibition of metabolic pathways and enhanced anti-tumour activity [242,243]. A completed phase I study reported encouraging clinical activity and tolerability in heavily pre-treated RCC patients, comparing favourably to historical Cabo monotherapy (NCT02071862) [243]. This has led development into a randomised phase II study of Cabo with CB-839/placebo in RCC (CANTATA, NCT0342821).

Preclinical studies showed that treatment with mTOR kinase inhibitors led to acquired resistance associated with compensatory upregulation of glutamine metabolism. Combined inhibition of mTOR kinase and GLS resulted in synergistic tumour cell death and growth inhibition in mice bearing GBM [244] (Table 2). This concept is also utilised in clinical trials for treating RCC. A prior phase Ib study of the GLS inhibitor CB-839 plus the mTOR inhibitor everolimus demonstrated impressive disease control rates, prompting a further randomised phase II study evaluating the efficacy of everolimus with CB-839/placebo in RCC (ENTRATA (CB-839 with Everolimus vs. Placebo with Everolimus in Patients With RCC), NCT03163667). Preliminary data show promising results with tolerable safety profiles in heavily-treated patients, including those refractory to multiple TKIs and immune checkpoint inhibitors.

mTOR inhibition may also be combined with biguanides such as metformin. While Akt activity is compensatorily induced by mTOR inhibition, metformin is able to counteract this upregulation of Akt by activating AMPK, providing scientific rationale for combining these two classes of agents $[249,276]$. Several preclinical studies combining mTOR inhibition with mitochondrial inhibitors, such as 
metformin, showed synergistic inhibition of tumour growth in pancreatic and breast cancer [245-247]. However, a completed phase Ib trial showed that the combination of everolimus and metformin is poorly tolerated in patients with advanced cancer [248]. On the other hand, the combination of metformin with other mTOR inhibitors have been more promising. Two completed phase I studies investigating the combination of metformin plus temsirolimus for advanced/refractory cancers (NCT01529593) and solid tumours or lymphoma (NCT00659568) showed the combination was well-tolerated with modestly promising effectiveness [249] (Table 2). Plans for phase II trials for this combination is underway. Finally, phase I trials for treating solid tumours with metformin in combination with sapanisertib, another mTOR1/2 inhibitor, is now recruiting (NCT03017833) (Table 2).

\subsection{Metabolic Inhibition Plus Chemotherapy}

Metabolic inhibitors are thought to reduce cancer cells therapy resistance by reducing the levels of key metabolites necessary for DNA damage repair, thus enhancing chemotherapy sensitivity $[7,277]$. This highlights the rationale for metabolic inhibitor plus chemotherapy combinations to increase the efficacy of chemotherapy with an array of combinations in the developmental pipeline (Table 3).

For example, HK2 inhibitor, 3-BP, induces the imbalance of intracellular redox through glycolytic inhibition, leading to large amounts of ROS production and intracellular accumulation [278]. 3-BP was found to be a chemosensitizer in combination with cisplatin and oxaliplatin in cell models of CRC [250] (Table 3). Similarly, 3-BP is able to act as a chemosensitizer in combination with the first-line chemotherapy drug for CRC, 5-fluorouracil [251]. Another proposed mechanism of 3-BP activity is via decreasing ATP production, leading to reduced activity of the ABC transporters, which are ATP-dependent efflux pumps, thereby restoring sensitivity to chemotherapy drugs such as daunorubicin, mitoxantrone, and doxorubicin in various cancer cell lines [253]. Although 3-BP usage in human studies was halted due to toxicities, this illustrates a proof-of-concept in the synergistic effect of glycolytic inhibition with chemotherapy.

Glycolysis inhibitor, 2-DG, was found to synergise with etoposide-induced cytotoxicity in the treatment of mouse models of lymphoma [254]. Similarly, combined treatment with 2-DG and doxorubicin enhanced the in-vitro efficacy of breast cancer radiotherapy [255]. Early studies also demonstrated synergism in treating mouse xenografts of human osteosarcoma and lung cancer cell lines with 2-DG + doxorubicin and 2DG + paclitaxel, respectively [256], leading to a phase I trial of 2-DG in combination with docetaxel was studied in various malignancies, which demonstrated safety and feasibility [257]. Finally, a novel candidate for glycolytic inhibition is via PKM2 modulation with early preclinical studies demonstrating synergism with cisplatin in overcoming chemoresistance in cervical [258] and bladder cancer [259] as well as in combination with docetaxel in human lung cancer xenografts in mice [260].

Targeting glutaminolysis to counter GSH production is also a promising strategy to re-sensitise tumours to chemotherapy [59]. Particular cancer types, such as TNBC, are also associated with elevated GLS expression and glutamine dependency $[279,280]$. CB-839 synergises with paclitaxel by reversing GLS-dependent mechanisms that lead to taxane resistance [200]. Leveraging on this, a phase I showed the paclitaxel + CB-839 combination was well-tolerated and demonstrated clinical activity in heavily pre-treated TNBC patients [261]. This led to a further phase II study of Paclitaxel + CB-839 in advanced TNBC (NCT03057600) with preliminary findings, demonstrating clinical activity and tolerability [262]. Other GLS inhibition plus chemotherapy combinations are also being investigated, reaching various stages of clinical trials (Table 3).

Another metabolic inhibitor plus chemotherapy combination that shows promising data is completed via TCA cycle inhibition. CPI-613 (Devimistat, Rafael Pharmaceuticals, Cranbury, NJ, USA) is a novel lipoic acid analogue that inhibits pyruvate dehydrogenase (PDH) and $\alpha-K G$ dehydrogenase enzymatic complexes. Favourable clinical trial data led to FDA granting CPI-613 orphan drug designation in pancreatic cancer, AML, myelodysplastic syndrome (MDS), peripheral T-cell lymphoma, and Burkitt's lymphoma, and CPI-613 in combination with various chemotherapy regimens have been 
tested in clinical trials for PDAC and AML. Currently, a pivotal multicentre, open-label, randomised phase III trial (AVENGER 500, NCT03504423) is ongoing to evaluate the efficacy and safety of CPI-613 in combination with a modified FOLFIRINOX regimen for the first-line treatment of patients with metastatic pancreatic cancer [263].

A separate phase III trial is also ongoing to study CPI-613 in patients with AML (ARMADA 2000, NCT03504410). The ARMADA trial follows favourable results from multiple phase I/II studies of CPI-613 and high dose cytarabine and mitoxantrone given to relapsed or refractory AML patients. Given the favourable safety profile of this combination and the promising response achieved in these trials, further clinical evaluation is warranted.

Various combinations of metformin plus chemotherapy regimens have also shown favourable effects in preclinical models with some combinations reaching clinical trials $[57,265]$. The combination of metformin plus 5-fluorouracil for treating refractory CRC had completed a phase II trial (NCT01941953) [266]. Metformin in combination with the topoisomerase I inhibitor irinotecan is also currently being evaluated in a phase II trial for refractory CRC (NCT01930864). Metformin plus neo-adjuvant systemic therapy in HER2 positive breast cancer is being studied in a randomised phase II trial (NCT03238495, HERMET trial). Another randomized, open-label phase II trial investigating the role of metformin in addition to enzalutamide for castration-resistant prostate cancer is currently recruiting (IMPROVE trial, NCT02640534). OXPHOS inhibition with OPB-111077 is currently underway in a phase I trial for diffuse large B cell lymphoma (DLBCL) in combination with bendamustine and rituximab (NCT04049825).

\subsection{Metabolic Inhibition Plus Immunotherapy}

Anti-tumour activity of immune checkpoint inhibition may be enhanced by metabolic modulation of the TME. Promising preclinical data combining CB-839 with ICB has led to an ongoing phase I/II study of CB-839 in combination with nivolumab in immunogenic tumours including melanoma, RCC, and NSCLC (NCT02771626) (Table 4) [270]. Preliminary analyses demonstrated that CB-839 was well-tolerated when combined with nivolumab. Of note, of the eight evaluable RCC patients, $75 \%$ achieved SD on combination therapy, all of whom were progressing on a checkpoint inhibitor at study entry. Another area of focus is NSCLC containing activating mutations in the NRF2/KEAP1 pathway. A key subset of these activated genes upregulate glutamine metabolism and dependency. This clear mechanistic rationale had spurred a randomised double-blind phase II study evaluating CB-839 in combination with standard of care chemo-immunotherapy in this subgroup of NSCLC patients (NCT04265534).

Amino acid metabolism can also be targeted in combination with immunotherapy. Arg1 upregulation in MDSCs depletes $\mathrm{T}$ cells of L-arginine in the tumour milieu [118], limiting $\mathrm{T}$ cell anti-tumour activity. CB-1158 is an Arg1 inhibitor that reversed myeloid-mediated $\mathrm{T}$ cell inhibition in-vitro and suppressed tumour growth in-vivo. Furthermore, CB-1158 treatment was synergistic in combination with checkpoint blockade in multiple mouse models of cancer, resulting in increased tumour-infiltrating $\mathrm{CD}^{+} \mathrm{T}$ cells and NK cells, inflammatory cytokines, and expression of IFN-inducible genes [271]. This has led on to a phase I/II trial of CB-1158 in combination with pembrolizumab in solid tumours (NCT02903914). Currently, CB-1158 has been well-tolerated and achieves on-target inhibition, resulting in increases in plasma arginine [281]. Another phase I/II trial investigating CB-1158 plus subcutaneous daratumumab, compared to daratumumab monotherapy, in relapse or refractory MM, is currently recruiting (NCT03837509) (Table 4).

Another enzyme, indoleamine 2,3-dioxygenase (IDO), catalyses the rate-limiting step in tryptophan oxidation. This generates kynurenine, which simultaneously depletes $\mathrm{T}$ cells of the amino acid while promoting exerting immunosuppression and induces T cell apoptosis [93,106]. Furthermore, kynurenine acts as a ligand for the aryl hydrocarbon receptor (AHR), leading to Treg differentiation [282] and pro-tumourigenic effects. IDO inhibitors seek to prevent tryptophan depletion to reduce the production of immunosuppressive kynurenine. Multiple phase I/II trials showed encouraging results 
with small molecule inhibitors of IDO1, such as epacadostat, with improved responses to anti-PD-1 therapy (Table 4). However, recent results from ECHO-301, the first large phase III trial to evaluate the efficacy of epacadostat in combination with pembrolizumab in advanced melanoma, showed no indication that epacadostat provided an additional benefit. Thus, the current usefulness of IDO1 inhibition to enhance anti-PD-1 therapy remains uncertain. Other IDO1 inhibitors are being developed and, in earlier phase trials, including navoximod, currently being tested in a phase $\mathrm{Ib}$ trial for solid tumours in combination with atezolizumab [272] (Table 4).

Another immunometabolism-targeting pathway is via A2AR. CPI-444 (ciforadenant) is an A2AR antagonist that can inhibit immuno-suppressive effects of adenosine on T cells, NK cells, macrophages, and DCs. CPI-444 is currently in early-phase clinical trials in combination with atezolizumab for advanced RCC, prostate cancer, and NSCLC (NCT02655822, NCT03337698) and in combination with daratumumab for relapsed or refractory MM (NCT04280328).

\section{Conclusions}

Nearly a decade ago, cancer therapy entered a new era with the discovery of two additional hallmarks of cancer, 'reprogramming energy metabolism' and 'evading immune response.' Following intensive research and several ground-breaking discoveries, checkpoint inhibitor therapy has emerged as frontline therapy in multiple tumour types [283]. Targeting altered cell metabolism is also recognized as a potential means of achieving therapeutic selectivity due to the fundamental metabolic differences between normal and cancer cells. Yet, therapeutic advances have been much more modest on the metabolic front partly due to the nuances in deciphering complex and interconnected metabolic pathways. Moreover, the dynamic metabolic crosstalk between cancer cells and the TME, including the immune system, adds further layers of complexity to metabolic inhibition.

Nevertheless, important strides have been made toward the clinical application of metabolic inhibitors, which can be credited to the tremendous ongoing effort by researchers to tease out the intricacies of tumour metabolism and identify compounds with favourable pharmacokinetic and safety profiles. For one, the field has evolved from a small selection of agents with very narrow therapeutic windows, such as arsenic trioxide and 2-DG, to a wide selection of candidates targeting various pathways in which many have demonstrated tolerability in clinical trials. Glutamine has been identified as an excellent therapeutic target due to its contributions to both OXPHOS and glycolysis, and, not unexpectedly, the potent and selective GLS inhibitor, CB-839, has demonstrated great potential in the developmental pipeline. It has now entered phase II studies, and the strategic direction, which has been selected for its future development is in combination with chemotherapy, targeted therapies, and immunotherapy [202,243,261].

However, the therapeutic success of cell metabolism inhibitors cannot be solely reliant on the discovery of compounds with favourable pharmacologic properties. Biomarkers help stratify tumours, according to their metabolic dependencies and are a crucial element of patient selection for metabolic inhibition. To date, p53 or LKB1 loss, homozygous deletion of ENO1 and SMARCA4 mutations are strong candidate biomarkers of OXPHOS inhibition [186-188]. On the other hand, despite the excellent progress in the development of glutaminolysis inhibitors, a companion biomarker has yet to be established [284].

The discovery of altered CCM as a mechanism of resistance to standard anti-cancer therapies is arguably the most significant advancement in the field, serving as a platform for the discovery of rational synthetic lethality combinations to overcome therapeutic resistance to conventional chemotherapy and targeted therapies. Apart from targeting mechanisms of secondary resistance, preclinical studies have raised the possibility of eradicating notoriously therapy-resistant CSCs [163,285]. Several of these combinations have demonstrated both safety as well as promising activity in clinical trials [267]. Due to the synergistic action of both compounds, synthetic lethality strategies may permit the use of lower drug doses compared to single agent blockade, potentially mitigating drug toxicities. 
Cancer cells have the innate ability to escape the inhibition of a particular metabolic pathway by upregulating compensatory pathways or deriving alternative routes of nutrient supply. At present, the prevailing plasticity of the metabolic circuitry is thought to be the greatest limiting factor in the success of metabolic inhibition, rendering the singular targeting of metabolic pathways ineffective. Dual metabolic inhibition is a promising strategy to overcome this, especially combinations involving the inhibition of glycolysis and OXPHOS, or glycolysis and glutaminolysis [185,223,230,231,233]. Though supported by robust preclinical data, the clinical evaluation of dual metabolic inhibitor strategies remain in their infancy stages [286].

Emerging data have led to observations that metabolic plasticity is not merely limited to cancer cells, but also involves the surrounding TME, especially the metabolically versatile immune milieu. Altered CCM creates an unfavourable microenvironment, resulting in immunosuppression and polarisation toward pro-tumourigenic cell types. Competing energetic requirements of tumour cells and the immune environment result in the limited availability of key nutrients, blocking $T$ cell activation and proliferation. Furthermore, the immune checkpoint proteins on tumour cells, PD-1 and CTLA-4, suppress $\mathrm{T}$ cell metabolism. Hence, it is now evident that specific metabolic dependencies of immune cells lead to cancer immune evasion, which is a crucial discovery that may be exploited in order to enhance anti-cancer immune responses. This validates treatment strategies that are underway to evaluate various combinations of immune checkpoint blockades and metabolic inhibitors [79,270,272].

Although the development of metabolic inhibitors has been fraught with challenges and disappointments, significant momentum has been gained in recent times, all the more so with the discovery of effective drug combinations. With the aid of further translational studies and well-designed therapeutic strategies, the routine use of metabolic inhibitors in the clinic may become a reality in the near future.

Author Contributions: All authors contributed in the conceptualization, preparation, writing, review, and editing of the manuscript. All authors have read and agreed to the published version of the manuscript.

Funding: This research received no external funding.

Acknowledgments: Boon Cher Goh is supported by the National Medical Research Council, Singapore (NMRC/CSA-SI/0006/2016 and NMRC/CG/M005/2017_NCIS). Andrea L.A. Wong is supported by the National Medical Research Council, Singapore (NMRC/TA17nov003).

Conflicts of Interest: The authors declare no conflict of interest.

\section{References}

1. Hanahan, D.; Weinberg, R.A. Hallmarks of Cancer: The Next Generation. Cell 2011, 144, 646-674. [CrossRef] [PubMed]

2. Warburg, O. On the Origin of Cancer Cells. Science 1956, 123, 309-314. [CrossRef] [PubMed]

3. Liberti, M.V.; Locasale, J.W. The Warburg Effect: How Does it Benefit Cancer Cells? Trends Biochem. Sci. 2016, 41, 211. [CrossRef] [PubMed]

4. Ashton, T.M.; McKenna, W.G.; Kunz-Schughart, L.A.; Higgins, G.S. Oxidative Phosphorylation as an Emerging Target in Cancer Therapy. Clin. Cancer Res. 2018, 24, 2482-2490. [CrossRef]

5. Haq, R.; Shoag, J.; Andreu-Perez, P.; Yokoyama, S.; Edelman, H.; Rowe, G.C.; Frederick, D.T.; Hurley, A.D.; Nellore, A.; Kung, A.L.; et al. Oncogenic BRAF Regulates Oxidative Metabolism via PGC1 $\alpha$ and MITF. Cancer Cell 2013, 23, 302-315. [CrossRef]

6. Hirpara, J.; Eu, J.Q.; Tan, J.K.M.; Wong, A.L.; Clement, M.-V.; Kong, L.R.; Ohi, N.; Tsunoda, T.; Qu, J.; Goh, B.C. Metabolic reprogramming of oncogene-addicted cancer cells to OXPHOS as a mechanism of drug resistance. Redox Biol. 2019, 25, 101076. [CrossRef]

7. DeBerardinis, R.J.; Chandel, N.S. Fundamentals of cancer metabolism. Sci. Adv. 2016, 2, e1600200. [CrossRef]

8. Schwörer, S.; Vardhana, S.A.; Thompson, C.B. Cancer Metabolism Drives a Stromal Regenerative Response. Cell Metab. 2019, 29, 576-591. [CrossRef] 
9. Hardeman, K.N.; Peng, C.; Paudel, B.B.; Meyer, C.T.; Luong, T.; Tyson, D.R.; Young, J.D.; Quaranta, V.; Fessel, J.P. Dependence On Glycolysis Sensitizes BRAF-mutated Melanomas For Increased Response To Targeted BRAF Inhibition. Sci. Rep. 2017, 7, 42604. [CrossRef]

10. Brown, R.E.; Short, S.P.; Williams, C.S. Colorectal Cancer and Metabolism. Curr. Colorectal Cancer Rep. 2018, 14, 226-241. [CrossRef]

11. Blum, R.; Kloog, Y. Metabolism addiction in pancreatic cancer. Cell Death Dis. 2014, 5, e1065. [CrossRef] [PubMed]

12. Dang, C. V Links between metabolism and cancer. Genes Dev. 2012, 26, 877-890. [CrossRef] [PubMed]

13. Weinberg, S.E.; Chandel, N.S. Targeting mitochondria metabolism for cancer therapy. Nat. Chem. Biol. 2015, 11, 9-15. [CrossRef] [PubMed]

14. Zheng, J. Energy metabolism of cancer: Glycolysis versus oxidative phosphorylation. Oncol. Lett. 2012, 4, 1151-1157. [CrossRef] [PubMed]

15. Solaini, G.; Sgarbi, G.; Baracca, A. Oxidative phosphorylation in cancer cells. Biochim. Et Biophys. Acta (Bba) Bioenerg. 2011, 1807, 534-542. [CrossRef] [PubMed]

16. McCracken, A.N.; Edinger, A.L. Nutrient transporters: The Achilles' heel of anabolism. Trends Endocrinol. Metab. Tem 2013, 24, 200-208. [CrossRef]

17. Kaira, K.; Oriuchi, N.; Imai, H.; Shimizu, K.; Yanagitani, N.; Sunaga, N.; Hisada, T.; Tanaka, S.; Ishizuka, T.; Kanai, Y.; et al. 1-type amino acid transporter 1 and CD98 expression in primary and metastatic sites of human neoplasms. Cancer Sci. 2008, 99, 2380-2386. [CrossRef]

18. Elorza, A.; Soro-Arnáiz, I.; Meléndez-Rodríguez, F.; Rodríguez-Vaello, V.; Marsboom, G.; de Cárcer, G.; Acosta-Iborra, B.; Albacete-Albacete, L.; Ordóñez, A.; Serrano-Oviedo, L.; et al. HIF2 $\alpha$ Acts as an mTORC1 Activator through the Amino Acid Carrier SLC7A5. Mol. Cell 2012, 48, 681-691. [CrossRef]

19. Gao, P.; Tchernyshyov, I.; Chang, T.-C.; Lee, Y.-S.; Kita, K.; Ochi, T.; Zeller, K.I.; De Marzo, A.M.; Van Eyk, J.E.; Mendell, J.T.; et al. c-Myc suppression of miR-23a/b enhances mitochondrial glutaminase expression and glutamine metabolism. Nature 2009, 458, 762-765. [CrossRef]

20. Wise, D.R.; DeBerardinis, R.J.; Mancuso, A.; Sayed, N.; Zhang, X.-Y.; Pfeiffer, H.K.; Nissim, I.; Daikhin, E.; Yudkoff, M.; McMahon, S.B.; et al. Myc regulates a transcriptional program that stimulates mitochondrial glutaminolysis and leads to glutamine addiction. Proc. Natl. Acad. Sci. USA 2008, 105, 18782-18787. [CrossRef]

21. Fuchs, B.C.; Finger, R.E.; Onan, M.C.; Bode, B.P. ASCT2 silencing regulates mammalian target-of-rapamycin growth and survival signaling in human hepatoma cells. Am. J. Physiol. Cell Physiol. 2007, 293, C55-C63. [CrossRef] [PubMed]

22. Ganapathy, V.; Thangaraju, M.; Prasad, P.D. Nutrient transporters in cancer: Relevance to Warburg hypothesis and beyond. Pharmacol. Ther. 2009, 121, 29-40. [CrossRef] [PubMed]

23. Bröer, S.; Palacín, M. The role of amino acid transporters in inherited and acquired diseases. Biochem. J. 2011, 436, 193-211. [CrossRef] [PubMed]

24. Laplante, M.; Sabatini, D.M. mTOR signaling in growth control and disease. Cell 2012, 149, $274-293$. [CrossRef]

25. Hensley, C.T.; Wasti, A.T.; DeBerardinis, R.J. Glutamine and cancer: Cell biology, physiology, and clinical opportunities. J. Clin. Investig. 2013, 123, 3678-3684. [CrossRef]

26. Mohamed, A.; Deng, X.; Khuri, F.R.; Owonikoko, T.K. Altered glutamine metabolism and therapeutic opportunities for lung cancer. Clin. Lung Cancer 2014, 15, 7-15. [CrossRef]

27. Márquez, J.; Alonso, F.J.; Matés, J.M.; Segura, J.A.; Martín-Rufián, M.; Campos-Sandoval, J.A. Glutamine Addiction In Gliomas. Neurochem. Res. 2017, 42, 1735-1746. [CrossRef]

28. Zacharias, N.M.; McCullough, C.; Shanmugavelandy, S.; Lee, J.; Lee, Y.; Dutta, P.; McHenry, J.; Nguyen, L.; Norton, W.; Jones, L.W.; et al. Metabolic Differences in Glutamine Utilization Lead to Metabolic Vulnerabilities in Prostate Cancer. Sci. Rep. 2017, 7, 16159. [CrossRef]

29. Demas, D.M.; Demo, S.; Fallah, Y.; Clarke, R.; Nephew, K.P.; Althouse, S.; Sandusky, G.; He, W.; Shajahan-Haq, A.N. Glutamine Metabolism Drives Growth in Advanced Hormone Receptor Positive Breast Cancer. Front. Oncol. 2019, 9, 686. [CrossRef]

30. Cantor, J.; Sabatini, D. Cancer Cell Metabolism: One Hallmark, Many Faces. Cancer Discov. 2012, 2. [CrossRef]

31. Dibble, C.C.; Manning, B.D. Signal integration by mTORC1 coordinates nutrient input with biosynthetic output. Nat. Cell Biol. 2013, 15, 555. [CrossRef] [PubMed] 
32. Yuan, T.; Cantley, L. PI3K Pathway Alterations in Cancer: Variations on a Theme. Oncogene $2008,27$. [CrossRef] [PubMed]

33. Jain, R.K.; Munn, L.L.; Fukumura, D. Dissecting tumour pathophysiology using intravital microscopy. Nat. Rev. Cancer 2002, 2, 266-276. [CrossRef] [PubMed]

34. Cantó, C.; Gerhart-Hines, Z.; Feige, J.N.; Lagouge, M.; Noriega, L.; Milne, J.C.; Elliott, P.J.; Puigserver, P.; Auwerx, J. AMPK regulates energy expenditure by modulating NAD+ metabolism and SIRT1 activity. Nature 2009, 458, 1056-1060. [CrossRef]

35. Horton, J.D.; Goldstein, J.L.; Brown, M.S. SREBPs: Activators of the complete program of cholesterol and fatty acid synthesis in the liver. J. Clin. Investig. 2002, 109, 1125-1131. [CrossRef]

36. Düvel, K.; Yecies, J.L.; Menon, S.; Raman, P.; Lipovsky, A.I.; Souza, A.L.; Triantafellow, E.; Ma, Q.; Gorski, R.; Cleaver, S.; et al. Activation of a metabolic gene regulatory network downstream of mTOR complex 1. Mol. Cell 2010, 39, 171. [CrossRef]

37. DeBerardinis, R.J.; Lum, J.J.; Hatzivassiliou, G.; Thompson, C.B. The Biology of Cancer: Metabolic Reprogramming Fuels Cell Growth and Proliferation. Cell Metab. 2008, 7, 11-20. [CrossRef]

38. Shim, H.; Dolde, C.; Lewis, B.C.; Wu, C.-S.; Dang, G.; Jungmann, R.A.; Dalla-Favera, R.; Dang, C.V. c-Myc transactivation of LDH-A: Implications for tumor metabolism and growth. Proc. Natl. Acad. Sci. USA 1997, 94, 6658-6663. [CrossRef]

39. Osthus, R.C.; Shim, H.; Kim, S.; Li, Q.; Reddy, R.; Mukherjee, M.; Xu, Y.; Wonsey, D.; Lee, L.A.; Dang, C.V. Deregulation of Glucose Transporter 1 and Glycolytic Gene Expression by c-Myc. J. Biol. Chem. 2000, 275, 21797-21800. [CrossRef]

40. Lukey, M.J.; Wilson, K.F.; Cerione, R.A. Therapeutic strategies impacting cancer cell glutamine metabolism. Future Med. Chem. 2013, 5, 1685-1700. [CrossRef]

41. Ying, H.; Kimmelman, A.C.; Lyssiotis, C.A.; Hua, S.; Chu, G.C.; Fletcher-Sananikone, E.; Locasale, J.W.; Son, J.; Zhang, H.; Coloff, J.L.; et al. Oncogenic Kras maintains pancreatic tumors through regulation of anabolic glucose metabolism. Cell 2012, 149, 656-670. [CrossRef] [PubMed]

42. Gaglio, D.; Metallo, C.M.; Gameiro, P.A.; Hiller, K.; Danna, L.S.; Balestrieri, C.; Alberghina, L.; Stephanopoulos, G.; Chiaradonna, F. Oncogenic K-Ras decouples glucose and glutamine metabolism to support cancer cell growth. Mol. Syst. Biol. 2011, 7, 523. [CrossRef] [PubMed]

43. Kerr, E.M.; Gaude, E.; Turrell, F.K.; Frezza, C.; Martins, C.P. Mutant Kras copy number defines metabolic reprogramming and therapeutic susceptibilities. Nature 2016, 531, 110-113. [CrossRef] [PubMed]

44. Liou, G.-Y.; Döppler, H.; DelGiorno, K.E.; Zhang, L.; Leitges, M.; Crawford, H.C.; Murphy, M.P.; Storz, P. Mutant KRas-Induced Mitochondrial Oxidative Stress in Acinar Cells Upregulates EGFR Signaling to Drive Formation of Pancreatic Precancerous Lesions. Cell Rep. 2016, 14, 2325-2336. [CrossRef]

45. Puzio-Kuter, A.M. The Role of p53 in Metabolic Regulation. Genes Cancer 2011, 2, 385-391. [CrossRef]

46. Kim, J. Wild-Type p53 Promotes Cancer Metabolic Switch by Inducing PUMA-Dependent Suppression of Oxidative Phosphorylation. Cancer Cell 2019, 35, 191-203. [CrossRef]

47. Zhang, C.; Liu, J.; Liang, Y.; Wu, R.; Zhao, Y.; Hong, X.; Lin, M.; Yu, H.; Liu, L.; Levine, A.J.; et al. Tumour-associated mutant p53 drives the Warburg effect. Nat. Commun. 2013, 4, 2935. [CrossRef]

48. Zhang, L.; Yao, Y.; Zhang, S.; Liu, Y.; Guo, H.; Ahmed, M.; Bell, T.; Zhang, H.; Han, G.; Lorence, E.; et al. Metabolic reprogramming toward oxidative phosphorylation identifies a therapeutic target for mantle cell lymphoma. Sci. Transl. Med. 2019, 11. [CrossRef]

49. Gopal, Y.N.V.; Rizos, H.; Chen, G.; Deng, W.; Frederick, D.T.; Cooper, Z.A.; Scolyer, R.A.; Pupo, G.; Komurov, K.; Sehgal, V.; et al. Inhibition of mTORC1/2 Overcomes Resistance to MAPK Pathway Inhibitors Mediated by PGC1 and Oxidative Phosphorylation in Melanoma. Cancer Res. 2014, 74, 7037-7047. [CrossRef]

50. Baenke, F.; Chaneton, B.; Smith, M.; Van Den Broek, N.; Hogan, K.; Tang, H.; Viros, A.; Martin, M.; Galbraith, L.; Girotti, M.R.; et al. Resistance to BRAF inhibitors induces glutamine dependency in melanoma cells. Mol. Oncol. 2016, 10, 73-84. [CrossRef]

51. Martin, M.J.; Eberlein, C.; Taylor, M.; Ashton, S.; Robinson, D.; Cross, D.; Martin, M.J.; Eberlein, C.; Taylor, M.; Ashton, S.; et al. Inhibition of oxidative phosphorylation suppresses the development of osimertinib resistance in a preclinical model of EGFR-driven lung adenocarcinoma. Oncotarget 2016, 7, 86313-86325. [CrossRef] [PubMed] 
52. Ali, A.; Levantini, E.; Teo, J.T.; Goggi, J.; Clohessy, J.G.; Wu, C.S.; Chen, L.; Yang, H.; Krishnan, I.; Kocher, O.; et al. Fatty acid synthase mediates EGFR palmitoylation in EGFR mutated non-small cell lung cancer. Embo Mol. Med. 2018, 10, e8313. [CrossRef]

53. Lee, H.-J.; Zhuang, G.; Cao, Y.; Du, P.; Kim, H.-J.; Settleman, J. Drug resistance via feedback activation of Stat3 in oncogene-addicted cancer cells. Cancer Cell 2014, 26, 207-221. [CrossRef]

54. Lee, M.; Hirpara, J.L.; Eu, J.-Q.; Sethi, G.; Wang, L.; Goh, B.-C.; Wong, A.L. Targeting STAT3 and oxidative phosphorylation in oncogene-addicted tumors. Redox Biol. 2019, 25, 101073. [CrossRef]

55. Catanzaro, D.; Gaude, E.; Orso, G.; Giordano, C.; Guzzo, G.; Rasola, A.; Ragazzi, E.; Caparrotta, L.; Frezza, C.; Montopoli, M.; et al. Inhibition of glucose-6-phosphate dehydrogenase sensitizes cisplatin-resistant cells to death. Oncotarget 2015, 6, 30102-30114. [CrossRef] [PubMed]

56. Ruprecht, B.; Zaal, E.A.; Zecha, J.; Wu, W.; Berkers, C.R.; Kuster, B.; Lemeer, S. Lapatinib Resistance in Breast Cancer Cells Is Accompanied by Phosphorylation-Mediated Reprogramming of Glycolysis. Cancer Res. 2017, 77, 1842-1853. [CrossRef] [PubMed]

57. Liu, Y.; He, C.; Huang, X.; Liu, Y.; He, C.; Huang, X. Metformin partially reverses the carboplatin-resistance in NSCLC by inhibiting glucose metabolism. Oncotarget 2017, 8, 75206-75216. [CrossRef] [PubMed]

58. Shin, Y.-K.; Yoo, B.C.; Hong, Y.S.; Chang, H.J.; Jung, K.H.; Jeong, S.-Y.; Park, J.-G. Upregulation of glycolytic enzymes in proteins secreted from human colon cancer cells with 5-fluorouracil resistance. Electrophoresis 2009, 30, 2182-2192. [CrossRef] [PubMed]

59. Marengo, B.; Nitti, M.; Furfaro, A.L.; Colla, R.; De Ciucis, C.; Marinari, U.M.; Pronzato, M.A.; Traverso, N.; Domenicotti, C. Redox Homeostasis and Cellular Antioxidant Systems: Crucial Players in Cancer Growth and Therapy. Oxidative Med. Cell. Longev. 2016, 2016, 6235641. [CrossRef]

60. Jain, A.; Jahagirdar, D.; Nilendu, P.; Sharma, N.K. Molecular approaches to potentiate cisplatin responsiveness in carcinoma therapeutics. Expert Rev. Anticancer Ther. 2017, 17, 815-825. [CrossRef]

61. Galluzzi, L.; Senovilla, L.; Vitale, I.; Michels, J.; Martins, I.; Kepp, O.; Castedo, M.; Kroemer, G. Molecular mechanisms of cisplatin resistance. Oncogene 2012, 31, 1869-1883. [CrossRef] [PubMed]

62. Wangpaichitr, M.; Wu, C.; Li, Y.Y.; Nguyen, D.J.M.; Kandemir, H.; Shah, S.; Chen, S.; Feun, L.G.; Prince, J.S.; Kuo, M.T.; et al. Exploiting ROS and metabolic differences to kill cisplatin resistant lung cancer. Oncotarget 2017, 8, 49275-49292. [CrossRef] [PubMed]

63. Lien, E.C.; Lyssiotis, C.A.; Juvekar, A.; Hu, H.; Asara, J.M.; Cantley, L.C.; Toker, A. Glutathione biosynthesis is a metabolic vulnerability in PI(3)K/Akt-driven breast cancer. Nat. Cell Biol. 2016, 18, 572-578. [CrossRef] [PubMed]

64. Liu, H.; Liu, Y.; Zhang, J.-T. A new mechanism of drug resistance in breast cancer cells: Fatty acid synthase overexpression-mediated palmitate overproduction. Mol. Cancer Ther. 2008, 7, 263-270. [CrossRef] [PubMed]

65. Menendez, J.A.; Lupu, R.; Colomer, R. Inhibition of Tumor-associated Fatty Acid Synthase Hyperactivity Induces Synergistic Chemosensitization of HER-2/neu-Overexpressing Human Breast Cancer Cells to Docetaxel (taxotere). Breast Cancer Res. Treat. 2004, 84, 183-195. [CrossRef] [PubMed]

66. Yang, Y.; Liu, H.; Li, Z.; Zhao, Z.; Yip-Schneider, M.; Fan, Q.; Schmidt, C.M.; Chiorean, E.G.; Xie, J.; Cheng, L.; et al. Role of fatty acid synthase in gemcitabine and radiation resistance of pancreatic cancers. Int. J. Biochem. Mol. Biol. 2011, 2, 89-98.

67. Papaevangelou, E.; Almeida, G.S.; Box, C.; deSouza, N.M.; Chung, Y.-L. The effect of FASN inhibition on the growth and metabolism of a cisplatin-resistant ovarian carcinoma model. Int. J. Cancer 2018, 143, 992-1002. [CrossRef] [PubMed]

68. Vitale, I.; Manic, G.; Galassi, C.; Galluzzi, L. Stress responses in stromal cells and tumor homeostasis. Pharmacol. Ther. 2019, 200, 55-68. [CrossRef] [PubMed]

69. Muz, B.; de la Puente, P.; Azab, F.; Azab, A.K. The role of hypoxia in cancer progression, angiogenesis, metastasis, and resistance to therapy. Hypoxia (Auckl) 2015, 3, 83-92. [CrossRef]

70. Reina-Campos, M.; Moscat, J.; Diaz-Meco, M. Metabolism shapes the tumor microenvironment. Curr. Opin. Cell Biol. 2017, 48, 47-53. [CrossRef]

71. Sousa, C.M.; Biancur, D.E.; Wang, X.; Halbrook, C.J.; Sherman, M.H.; Zhang, L.; Kremer, D.; Hwang, R.F.; Witkiewicz, A.K.; Ying, H.; et al. Pancreatic stellate cells support tumour metabolism through autophagic alanine secretion. Nature 2016, 536, 479-483. [CrossRef] 
72. Martinez-Outschoorn, U.E.; Whitaker-Menezes, D.; Valsecchi, M.; Martinez-Cantarin, M.P.; Dulau-Florea, A.; Gong, J.; Howell, A.; Flomenberg, N.; Pestell, R.G.; Wagner, J.; et al. Reverse Warburg effect in a patient with aggressive B-cell lymphoma: Is lactic acidosis a paraneoplastic syndrome? Semin. Oncol. 2013, 40, 403-418. [CrossRef] [PubMed]

73. Witkiewicz, A.K.; Whitaker-Menezes, D.; Dasgupta, A.; Philp, N.J.; Lin, Z.; Gandara, R.; Sneddon, S.; Martinez-Outschoorn, U.E.; Sotgia, F.; Lisanti, M.P. Using the "reverse Warburg effect" to identify high-risk breast cancer patients. Cell Cycle 2012, 11, 1108-1117. [CrossRef] [PubMed]

74. Curry, J.M.; Tuluc, M.; Whitaker-Menezes, D.; Ames, J.A.; Anantharaman, A.; Butera, A.; Leiby, B.; Cognetti, D.M.; Sotgia, F.; Lisanti, M.P.; et al. Cancer metabolism, stemness and tumor recurrence: MCT1 and MCT4 are functional biomarkers of metabolic symbiosis in head and neck cancer. Cell Cycle (Georget. Tex.) 2013, 12, 1371-1384. [CrossRef]

75. Fiaschi, T.; Marini, A.; Giannoni, E.; Taddei, M.L.; Gandellini, P.; De Donatis, A.; Lanciotti, M.; Serni, S.; Cirri, P.; Chiarugi, P. Reciprocal metabolic reprogramming through lactate shuttle coordinately influences tumor-stroma interplay. Cancer Res. 2012, 72, 5130-5140. [CrossRef]

76. Roy, A.; Bera, S. CAF cellular glycolysis: Linking cancer cells with the microenvironment. Tumour Biol. J. Int. Soc. Oncodevelopmental Biol. Med. 2016, 37, 8503-8514. [CrossRef]

77. Pavlides, S.; Whitaker-Menezes, D.; Castello-Cros, R.; Flomenberg, N.; Witkiewicz, A.K.; Frank, P.G.; Casimiro, M.C.; Wang, C.; Fortina, P.; Addya, S.; et al. The reverse Warburg effect: Aerobic glycolysis in cancer associated fibroblasts and the tumor stroma. Cell Cycle 2009, 8, 3984-4001. [CrossRef]

78. Zhang, D.; Wang, Y.; Shi, Z.; Liu, J.; Sun, P.; Hou, X.; Zhang, J.; Zhao, S.; Zhou, B.P.; Mi, J. Metabolic reprogramming of cancer-associated fibroblasts by IDH3 $\alpha$ downregulation. Cell Rep. 2015, 10, 1335-1348. [CrossRef]

79. Yang, L.; Achreja, A.; Yeung, T.-L.; Mangala, L.S.; Jiang, D.; Han, C.; Baddour, J.; Marini, J.C.; Ni, J.; Nakahara, R.; et al. Targeting Stromal Glutamine Synthetase in Tumors Disrupts Tumor Microenvironment-Regulated Cancer Cell Growth. Cell Metab. 2016, 24, 685-700. [CrossRef]

80. Zhao, H.; Yang, L.; Baddour, J.; Achreja, A.; Bernard, V.; Moss, T.; Marini, J.C.; Tudawe, T.; Seviour, E.G.; San Lucas, F.A.; et al. Tumor microenvironment derived exosomes pleiotropically modulate cancer cell metabolism. eLife 2016, 5, e10250. [CrossRef]

81. Sherman, M.H.; Yu, R.T.; Tseng, T.W.; Sousa, C.M.; Liu, S.; Truitt, M.L.; He, N.; Ding, N.; Liddle, C.; Atkins, A.R.; et al. Stromal cues regulate the pancreatic cancer epigenome and metabolome. Proc. Natl. Acad. Sci. USA 2017, 114, 1129-1134. [CrossRef] [PubMed]

82. Zecchin, A.; Kalucka, J.; Dubois, C.; Carmeliet, P. How Endothelial Cells Adapt Their Metabolism to Form Vessels in Tumors. Front. Immunol. 2017, 8, 1750. [CrossRef] [PubMed]

83. Yeh, W.-L.; Lin, C.-J.; Fu, W.-M. Enhancement of glucose transporter expression of brain endothelial cells by vascular endothelial growth factor derived from glioma exposed to hypoxia. Mol. Pharmacol. 2008, 73, 170-177. [CrossRef] [PubMed]

84. Cantelmo, A.R.; Conradi, L.-C.; Brajic, A.; Goveia, J.; Kalucka, J.; Pircher, A.; Chaturvedi, P.; Hol, J.; Thienpont, B.; Teuwen, L.-A.; et al. Inhibition of the Glycolytic Activator PFKFB3 in Endothelium Induces Tumor Vessel Normalization, Impairs Metastasis, and Improves Chemotherapy. Cancer Cell 2016, 30, 968-985. [CrossRef] [PubMed]

85. Carmona-Fontaine, C.; Deforet, M.; Akkari, L.; Thompson, C.B.; Joyce, J.A.; Xavier, J.B. Metabolic origins of spatial organization in the tumor microenvironment. Proc. Natl. Acad. Sci. USA 2017, 114, 2934-2939. [CrossRef] [PubMed]

86. Vegran, F.; Boidot, R.; Michiels, C.; Sonveaux, P.; Feron, O. Lactate Influx through the Endothelial Cell Monocarboxylate Transporter MCT1 Supports an NF- B/IL-8 Pathway that Drives Tumor Angiogenesis. Cancer Res. 2011, 71, 2550-2560. [CrossRef]

87. Huang, H.; Vandekeere, S.; Kalucka, J.; Bierhansl, L.; Zecchin, A.; Brüning, U.; Visnagri, A.; Yuldasheva, N.; Goveia, J.; Cruys, B.; et al. Role of Glutamine and Interlinked Asparagine Metabolism in Vessel Formation. Embo J. 2017, 36, 2334-2352. [CrossRef]

88. Kim, B.; Li, J.; Jang, C.; Arany, Z. Glutamine fuels proliferation but not migration of endothelial cells. Embo J. 2017, 36, 2321-2333. [CrossRef] 
89. Vandekeere, S.; Dubois, C.; Kalucka, J.; Sullivan, M.R.; García-Caballero, M.; Goveia, J.; Chen, R.; Diehl, F.F.; Bar-Lev, L.; Souffreau, J.; et al. Serine Synthesis via PHGDH Is Essential for Heme Production in Endothelial Cells. Cell Metab. 2018, 28, 573-587. [CrossRef]

90. Guo, D.; Murdoch, C.E.; Xu, H.; Shi, H.; Duan, D.D.; Ahmed, A.; Gu, Y. Vascular endothelial growth factor signaling requires glycine to promote angiogenesis. Sci. Rep. 2017, 7, 14749. [CrossRef]

91. Schoors, S.; Bruning, U.; Missiaen, R.; Queiroz, K.C.S.; Borgers, G.; Elia, I.; Zecchin, A.; Cantelmo, A.R.; Christen, S.; Goveia, J.; et al. Fatty acid carbon is essential for dNTP synthesis in endothelial cells. Nature 2015, 520, 192-197. [CrossRef] [PubMed]

92. Coleman, M.F.; Cozzo, A.J.; Pfeil, A.J.; Etigunta, S.K.; Hursting, S.D. Cell Intrinsic and Systemic Metabolism in Tumor Immunity and Immunotherapy. Cancers 2020, 12, 852. [CrossRef] [PubMed]

93. Cairns, R.A.; Mak, T.W. Fire and water: Tumor cell adaptation to metabolic conditions. Exp. Cell Res. 2017, 356, 204-208. [CrossRef]

94. Chang, C.-H.; Qiu, J.; O’Sullivan, D.; Buck, M.D.; Noguchi, T.; Curtis, J.D.; Chen, Q.; Gindin, M.; Gubin, M.M.; van der Windt, G.J.W.; et al. Metabolic Competition in the Tumor Microenvironment Is a Driver of Cancer Progression. Cell 2015, 162, 1229-1241. [CrossRef] [PubMed]

95. Jiang, Y.; Li, Y.; Zhu, B. T-cell exhaustion in the tumor microenvironment. Cell Death Dis. 2015, 6, e1792. [CrossRef]

96. Zhang, Y.; Kurupati, R.; Liu, L.; Zhou, X.Y.; Zhang, G.; Hudaihed, A.; Filisio, F.; Giles-Davis, W.; Xu, X.; Karakousis, G.C.; et al. Enhancing CD8+ T Cell Fatty Acid Catabolism within a Metabolically Challenging Tumor Microenvironment Increases the Efficacy of Melanoma Immunotherapy. Cancer Cell 2017, 32, 377-391. [CrossRef]

97. Wherry, E.J.; Kurachi, M. Molecular and cellular insights into T cell exhaustion. Nat. Rev. Immunol. 2015, 15, 486-499. [CrossRef]

98. Johnston, R.J.; Comps-Agrar, L.; Hackney, J.; Yu, X.; Huseni, M.; Yang, Y.; Park, S.; Javinal, V.; Chiu, H.; Irving, B.; et al. The immunoreceptor TIGIT regulates antitumor and antiviral CD8(+) T cell effector function. Cancer Cell 2014, 26, 923-937. [CrossRef]

99. Chauvin, J.-M.; Pagliano, O.; Fourcade, J.; Sun, Z.; Wang, H.; Sander, C.; Kirkwood, J.M.; Chen, T.T.; Maurer, M.; Korman, A.J.; et al. TIGIT and PD-1 impair tumor antigen-specific CD8 ${ }^{+} \mathrm{T}$ cells in melanoma patients. J. Clin. Investig. 2015, 125, 2046-2058. [CrossRef]

100. Fourcade, J.; Sun, Z.; Benallaoua, M.; Guillaume, P.; Luescher, I.F.; Sander, C.; Kirkwood, J.M.; Kuchroo, V.; Zarour, H.M. Upregulation of Tim-3 and PD-1 expression is associated with tumor antigen-specific CD8 ${ }^{+} \mathrm{T}$ cell dysfunction in melanoma patients. J. Exp. Med. 2010, 207, 2175-2186. [CrossRef]

101. Peng, M.; Yin, N.; Chhangawala, S.; Xu, K.; Leslie, C.S.; Li, M.O. Aerobic glycolysis promotes T helper 1 cell differentiation through an epigenetic mechanism. Science 2016, 354, 481-484. [CrossRef] [PubMed]

102. Nakaya, M.; Xiao, Y.; Zhou, X.; Chang, J.-H.; Chang, M.; Cheng, X.; Blonska, M.; Lin, X.; Sun, S.-C. Inflammatory $\mathrm{T}$ Cell Responses Rely on Amino Acid Transporter ASCT2 Facilitation of Glutamine Uptake and mTORC1 Kinase Activation. Immunity 2014, 40, 692-705. [CrossRef] [PubMed]

103. Carr, E.L.; Kelman, A.; Wu, G.S.; Gopaul, R.; Senkevitch, E.; Aghvanyan, A.; Turay, A.M.; Frauwirth, K.A. Glutamine Uptake and Metabolism Are Coordinately Regulated by ERK/MAPK during T Lymphocyte Activation. J. Immunol. 2010, 185, 1037-1044. [CrossRef]

104. Leone, R.D.; Zhao, L.; Englert, J.M.; Sun, I.-M.; Oh, M.-H.; Sun, I.-H.; Arwood, M.L.; Bettencourt, I.A.; Patel, C.H.; Wen, J.; et al. Glutamine blockade induces divergent metabolic programs to overcome tumor immune evasion. Science 2019, 366, 1013-1021. [CrossRef]

105. Geiger, R.; Rieckmann, J.C.; Wolf, T.; Basso, C.; Feng, Y.; Fuhrer, T.; Kogadeeva, M.; Picotti, P.; Meissner, F.; Mann, M.; et al. L-Arginine Modulates T Cell Metabolism and Enhances Survival and Anti-tumor Activity. Cell 2016, 167, 829-842. [CrossRef]

106. Mándi, Y.; Vécsei, L. The kynurenine system and immunoregulation. J. Neural Transm. 2012, 119, $197-209$. [CrossRef]

107. O'Sullivan, D.; van der Windt, G.J.W.; Huang, S.C.-C.; Curtis, J.D.; Chang, C.-H.; Buck, M.D.; Qiu, J.; Smith, A.M.; Lam, W.Y.; DiPlato, L.M.; et al. Memory CD8+ T Cells Use Cell-Intrinsic Lipolysis to Support the Metabolic Programming Necessary for Development. Immunity 2014, 41, 75-88. [CrossRef] 
108. Klysz, D.; Tai, X.; Robert, P.A.; Craveiro, M.; Cretenet, G.; Oburoglu, L.; Mongellaz, C.; Floess, S.; Fritz, V.; Matias, M.I.; et al. Glutamine-dependent $\alpha$-ketoglutarate production regulates the balance between $\mathrm{T}$ helper 1 cell and regulatory T cell generation. Sci. Signal. 2015, 8, ra97. [CrossRef]

109. Anderson, K.G.; Stromnes, I.M.; Greenberg, P.D. Obstacles posed by the tumor microenvironment to T cell activity: A case for synergistic therapies. Cancer Cell 2017, 31, 311-325. [CrossRef]

110. Angelin, A.; Gil-de-Gómez, L.; Dahiya, S.; Jiao, J.; Guo, L.; Levine, M.H.; Wang, Z.; Quinn, W.J.; Kopinski, P.K.; Wang, L.; et al. Foxp3 Reprograms T Cell Metabolism to Function in Low-Glucose, High-Lactate Environments. Cell Metab. 2017, 25, 1282-1293. [CrossRef]

111. Fischer, K.; Hoffmann, P.; Voelkl, S.; Meidenbauer, N.; Ammer, J.; Edinger, M.; Gottfried, E.; Schwarz, S.; Rothe, G.; Hoves, S.; et al. Inhibitory effect of tumor cell-derived lactic acid on human T cells. Blood 2007, 109, 3812-3819. [CrossRef]

112. Brand, A.; Singer, K.; Koehl, G.E.; Kolitzus, M.; Schoenhammer, G.; Thiel, A.; Matos, C.; Bruss, C.; Klobuch, S.; Peter, K.; et al. LDHA-Associated Lactic Acid Production Blunts Tumor Immunosurveillance by T and NK Cells. Cell Metab. 2016, 24, 657-671. [CrossRef] [PubMed]

113. Waickman, A.T.; Powell, J.D. mTOR, metabolism, and the regulation of T-cell differentiation and function. Immunol. Rev. 2012, 249, 43-58. [CrossRef]

114. Choi, S.Y.C.; Collins, C.C.; Gout, P.W.; Wang, Y. Cancer-generated lactic acid: A regulatory, immunosuppressive metabolite? J. Pathol. 2013, 230, 350-355. [CrossRef]

115. Ohta, A.; Gorelik, E.; Prasad, S.J.; Ronchese, F.; Lukashev, D.; Wong, M.K.K.; Huang, X.; Caldwell, S.; Liu, K.; Smith, P.; et al. A2A adenosine receptor protects tumors from antitumor T cells. Proc. Natl. Acad. Sci. USA 2006, 103, 13132-13137. [CrossRef]

116. Fallarino, F.; Grohmann, U.; Vacca, C.; Orabona, C.; Spreca, A.; Fioretti, M.C.; Puccetti, P. T Cell Apoptosis by Kynurenines. In Developments in Tryptophan and Serotonin Metabolism; Springer: Boston, MA, USA, 2003; pp. 183-190.

117. Corzo, C.A.; Condamine, T.; Lu, L.; Cotter, M.J.; Youn, J.-I.; Cheng, P.; Cho, H.-I.; Celis, E.; Quiceno, D.G.; Padhya, T.; et al. HIF-1 $\alpha$ regulates function and differentiation of myeloid-derived suppressor cells in the tumor microenvironment. J. Exp. Med. 2010, 207, 2439-2453. [CrossRef]

118. Colegio, O.R.; Chu, N.-Q.; Szabo, A.L.; Chu, T.; Rhebergen, A.M.; Jairam, V.; Cyrus, N.; Brokowski, C.E.; Eisenbarth, S.C.; Phillips, G.M.; et al. Functional polarization of tumour-associated macrophages by tumour-derived lactic acid. Nature 2014, 513, 559-563. [CrossRef]

119. Noman, M.Z.; Desantis, G.; Janji, B.; Hasmim, M.; Karray, S.; Dessen, P.; Bronte, V.; Chouaib, S. PD-L1 is a novel direct target of HIF-1 $\alpha$, and its blockade under hypoxia enhanced MDSC-mediated T cell activation. J. Exp. Med. 2014, 211, 781-790. [CrossRef]

120. Kumar, V.; Patel, S.; Tcyganov, E.; Gabrilovich, D.I. The Nature of Myeloid-Derived Suppressor Cells in the Tumor Microenvironment. Trends Immunol. 2016, 37, 208-220. [CrossRef]

121. Dietl, K.; Renner, K.; Dettmer, K.; Timischl, B.; Eberhart, K.; Dorn, C.; Hellerbrand, C.; Kastenberger, M.; Kunz-Schughart, L.A.; Oefner, P.J.; et al. Lactic Acid and Acidification Inhibit TNF Secretion and Glycolysis of Human Monocytes. J. Immunol. 2010, 184, 1200-1209. [CrossRef]

122. Zelenay, S.; van der Veen, A.G.; Böttcher, J.P.; Snelgrove, K.J.; Rogers, N.; Acton, S.E.; Chakravarty, P.; Girotti, M.R.; Marais, R.; Quezada, S.A.; et al. Cyclooxygenase-Dependent Tumor Growth through Evasion of Immunity. Cell 2015, 162, 1257-1270. [CrossRef] [PubMed]

123. Giovanelli, P.; Sandoval, T.A.; Cubillos-Ruiz, J.R. Dendritic Cell Metabolism and Function in Tumors. Trends Immunol. 2019, 40, 699-718. [CrossRef] [PubMed]

124. Krawczyk, C.M.; Holowka, T.; Sun, J.; Blagih, J.; Amiel, E.; DeBerardinis, R.J.; Cross, J.R.; Jung, E.; Thompson, C.B.; Jones, R.G.; et al. Toll-like receptor-induced changes in glycolytic metabolism regulate dendritic cell activation. Blood 2010, 115, 4742-4749. [CrossRef] [PubMed]

125. Zhao, F.; Xiao, C.; Evans, K.S.; Theivanthiran, T.; DeVito, N.; Holtzhausen, A.; Liu, J.; Liu, X.; Boczkowski, D.; Nair, S.; et al. Paracrine Wnt5a- $\beta$-Catenin Signaling Triggers a Metabolic Program that Drives Dendritic Cell Tolerization. Immunity 2018, 48, 147-160. [CrossRef]

126. Belladonna, M.L.; Orabona, C.; Grohmann, U.; Puccetti, P. TGF- $\beta$ and kynurenines as the key to infectious tolerance. Trends Mol. Med. 2009, 15, 41-49. [CrossRef] [PubMed] 
127. Eibinger, G.; Fauler, G.; Bernhart, E.; Frank, S.; Hammer, A.; Wintersperger, A.; Eder, H.; Heinemann, A.; Mischel, P.S.; Malle, E.; et al. On the role of 25-hydroxycholesterol synthesis by glioblastoma cell lines. Implications for chemotactic monocyte recruitment. Exp. Cell Res. 2013, 319, 1828-1838. [CrossRef]

128. Assmann, N.; O’Brien, K.L.; Donnelly, R.P.; Dyck, L.; Zaiatz-Bittencourt, V.; Loftus, R.M.; Heinrich, P.; Oefner, P.J.; Lynch, L.; Gardiner, C.M.; et al. Srebp-controlled glucose metabolism is essential for NK cell functional responses. Nat. Immunol. 2017, 18, 1197-1206. [CrossRef]

129. Rice, C.M.; Davies, L.C.; Subleski, J.J.; Maio, N.; Gonzalez-Cotto, M.; Andrews, C.; Patel, N.L.; Palmieri, E.M.; Weiss, J.M.; Lee, J.-M.; et al. Tumour-elicited neutrophils engage mitochondrial metabolism to circumvent nutrient limitations and maintain immune suppression. Nat. Commun. 2018, 9, 5099. [CrossRef]

130. Buchbinder, E.I.; Desai, A. CTLA-4 and PD-1 Pathways. Am. J. Clin. Oncol. 2016, 39, 98-106. [CrossRef]

131. Frebel, H.; Nindl, V.; Schuepbach, R.A.; Braunschweiler, T.; Richter, K.; Vogel, J.; Wagner, C.A.; Loffing-Cueni, D.; Kurrer, M.; Ludewig, B.; et al. Programmed death 1 protects from fatal circulatory failure during systemic virus infection of mice. J. Exp. Med. 2012, 209, 2485-2499. [CrossRef]

132. Sharpe, A.H.; Pauken, K.E. The diverse functions of the PD1 inhibitory pathway. Nat. Rev. Immunol. 2018, 18, 153-167. [CrossRef] [PubMed]

133. Hui, E.; Cheung, J.; Zhu, J.; Su, X.; Taylor, M.J.; Wallweber, H.A.; Sasmal, D.K.; Huang, J.; Kim, J.M.; Mellman, I.; et al. T Cell Costimulatory Receptor CD28 Is a Primary Target for PD-1-mediated Inhibition. Science 2017, 355, 1428-1433. [CrossRef] [PubMed]

134. Parry, R.V.; Chemnitz, J.M.; Frauwirth, K.A.; Lanfranco, A.R.; Braunstein, I.; Kobayashi, S.V.; Linsley, P.S.; Thompson, C.B.; Riley, J.L. CTLA-4 and PD-1 Receptors Inhibit T-cell Activation by Distinct Mechanisms. Mol. Cell. Biol. 2005, 25, 9543-9553. [CrossRef]

135. Yokosuka, T.; Takamatsu, M.; Kobayashi-Imanishi, W.; Hashimoto-Tane, A.; Azuma, M.; Saito, T. Programmed Cell Death 1 Forms Negative Costimulatory Microclusters That Directly Inhibit T Cell Receptor Signaling by Recruiting Phosphatase SHP2. J. Exp. Med. 2012, 209, 1201-1217. [CrossRef]

136. Chen, L.; Han, X. Anti-PD-1/PD-L1 therapy of human cancer: Past, present, and future. J. Clin. Investig. 2015, 125, 3384-3391. [CrossRef]

137. Patsoukis, N.; Bardhan, K.; Chatterjee, P.; Sari, D.; Liu, B.; Bell, L.N.; Karoly, E.D.; Freeman, G.J.; Petkova, V.; Seth, P.; et al. PD-1 alters T-cell metabolic reprogramming by inhibiting glycolysis and promoting lipolysis and fatty acid oxidation. Nat. Commun. 2015, 6, 6692. [CrossRef]

138. Chamoto, K.; Chowdhury, P.S.; Kumar, A.; Sonomura, K.; Matsuda, F.; Fagarasan, S.; Honjo, T. Mitochondrial activation chemicals synergize with surface receptor PD-1 blockade for T cell-dependent antitumor activity. Proc. Natl. Acad. Sci. USA 2017, 114, E761-E770. [CrossRef]

139. Sambi, M.; Bagheri, L.; Szewczuk, M.R. Current Challenges in Cancer Immunotherapy: Multimodal Approaches to Improve Efficacy and Patient Response Rates. J. Oncol. 2019, 2019, 4508794. [CrossRef]

140. Whiteside, T.L.; Demaria, S.; Rodriguez-Ruiz, M.E.; Zarour, H.M.; Melero, I. Emerging Opportunities and Challenges in Cancer Immunotherapy. Clin. Cancer Res. Off. J. Am. Assoc. Cancer Res. 2016, 22, 1845-1855. [CrossRef]

141. Emens, L.A.; Ascierto, P.A.; Darcy, P.K.; Demaria, S.; Eggermont, A.M.M.; Redmond, W.L.; Seliger, B.; Marincola, F.M. Cancer immunotherapy: Opportunities and challenges in the rapidly evolving clinical landscape. Eur. J. Cancer 2017, 81, 116-129. [CrossRef]

142. David, C.J.; Chen, M.; Assanah, M.; Canoll, P.; Manley, J.L. HnRNP proteins controlled by c-Myc deregulate pyruvate kinase mRNA splicing in cancer. Nature 2010, 463, 364-368. [CrossRef] [PubMed]

143. Palsson-McDermott, E.M.; Dyck, L.; Zasłona, Z.; Menon, D.; McGettrick, A.F.; Mills, K.H.G.; O’Neill, L.A. Pyruvate Kinase M2 Is Required for the Expression of the Immune Checkpoint PD-L1 in Immune Cells and Tumors. Front. Immunol. 2017, 8, 1300. [CrossRef] [PubMed]

144. Liu, W.-R.; Tian, M.-X.; Yang, L.-X.; Lin, Y.-L.; Jin, L.; Ding, Z.-B.; Shen, Y.-H.; Peng, Y.-F.; Gao, D.-M.; Zhou, J.; et al. PKM2 promotes metastasis by recruiting myeloid-derived suppressor cells and indicates poor prognosis for hepatocellular carcinoma. Oncotarget 2015, 6, 846-861. [CrossRef] [PubMed]

145. van Elsas, M.J.; van Hall, T.; van der Burg, S.H. Future Challenges in Cancer Resistance to Immunotherapy. Cancers 2020, 12, 935. [CrossRef] [PubMed]

146. Turgeon, M.-O.; Perry, N.J.S.; Poulogiannis, G. DNA Damage, Repair, and Cancer Metabolism. Front. Oncol. 2018, 8, 15. [CrossRef] 
147. Kinnaird, A.; Zhao, S.; Wellen, K.E.; Michelakis, E.D. Metabolic control of epigenetics in cancer. Nat. Rev. Cancer 2016, 16, 694-707. [CrossRef]

148. Harryvan, T.J.; Verdegaal, E.M.E.; Hardwick, J.C.H.; Hawinkels, L.J.A.C.; van der Burg, S.H. Targeting of the Cancer-Associated Fibroblast-T-Cell Axis in Solid Malignancies. J. Clin. Med. 2019, 8, 1989. [CrossRef] [PubMed]

149. Pinchuk, I.V.; Saada, J.I.; Beswick, E.J.; Boya, G.; Qiu, S.M.; Mifflin, R.C.; Raju, G.S.; Reyes, V.E.; Powell, D.W. PD-1 ligand expression by human colonic myofibroblasts/fibroblasts regulates CD4 ${ }^{+}$T-cell activity. Gastroenterology 2008, 135, 1228-1237. [CrossRef]

150. Lakins, M.A.; Ghorani, E.; Munir, H.; Martins, C.P.; Shields, J.D. Cancer-associated fibroblasts induce antigen-specific deletion of CD8 + T Cells to protect tumour cells. Nat. Commun. 2018, 9, 948. [CrossRef]

151. Mariathasan, S.; Turley, S.J.; Nickles, D.; Castiglioni, A.; Yuen, K.; Wang, Y.; Kadel III, E.E.; Koeppen, H.; Astarita, J.L.; Cubas, R.; et al. TGF $\beta$ attenuates tumour response to PD-L1 blockade by contributing to exclusion of T cells. Nature 2018, 554, 544-548. [CrossRef]

152. Tauriello, D.V.F.; Palomo-Ponce, S.; Stork, D.; Berenguer-Llergo, A.; Badia-Ramentol, J.; Iglesias, M.; Sevillano, M.; Ibiza, S.; Cañellas, A.; Hernando-Momblona, X.; et al. TGF $\beta$ drives immune evasion in genetically reconstituted colon cancer metastasis. Nature 2018, 554, 538-543. [CrossRef] [PubMed]

153. Galon, J.; Costes, A.; Sanchez-Cabo, F.; Kirilovsky, A.; Mlecnik, B.; Lagorce-Pagès, C.; Tosolini, M.; Camus, M.; Berger, A.; Wind, P.; et al. Type, density, and location of immune cells within human colorectal tumors predict clinical outcome. Science 2006, 313, 1960-1964. [CrossRef]

154. Salmon, H.; Franciszkiewicz, K.; Damotte, D.; Dieu-Nosjean, M.-C.; Validire, P.; Trautmann, A.; Mami-Chouaib, F.; Donnadieu, E. Matrix architecture defines the preferential localization and migration of T cells into the stroma of human lung tumors. J. Clin. Investig. 2012, 122, 899-910. [CrossRef] [PubMed]

155. Chakravarthy, A.; Khan, L.; Bensler, N.P.; Bose, P.; De Carvalho, D.D. TGF- $\beta$-associated extracellular matrix genes link cancer-associated fibroblasts to immune evasion and immunotherapy failure. Nat. Commun. 2018, 9, 4692. [CrossRef] [PubMed]

156. Visvader, J.E.; Lindeman, G.J. Cancer Stem Cells: Current Status and Evolving Complexities. Cell Stem Cell 2012, 10, 717-728. [CrossRef] [PubMed]

157. Prager, B.C.; Xie, Q.; Bao, S.; Rich, J.N. Cancer Stem Cells: The Architects of the Tumor Ecosystem. Cell Stem Cell 2019, 24, 41. [CrossRef]

158. Shen, Y.-A.; Wang, C.-Y.; Hsieh, Y.-T.; Chen, Y.-J.; Wei, Y.-H. Metabolic reprogramming orchestrates cancer stem cell properties in nasopharyngeal carcinoma. Cell Cycle 2015, 14, 86-98. [CrossRef]

159. Gabay, M.; Li, Y.; Felsher, D.W. MYC Activation Is a Hallmark of Cancer Initiation and Maintenance. Cold Spring Harb. Perspect. Med. 2014, 4, a014241. [CrossRef]

160. Folmes, C.D.L.; Martinez-Fernandez, A.; Faustino, R.S.; Yamada, S.; Perez-Terzic, C.; Nelson, T.J.; Terzic, A. Nuclear Reprogramming with c-Myc Potentiates Glycolytic Capacity of Derived Induced Pluripotent Stem Cells. J. Cardiovasc. Transl. Res. 2013, 6, 10-21. [CrossRef]

161. Kuntz, E.M.; Baquero, P.; Michie, A.M.; Dunn, K.; Tardito, S.; Holyoake, T.L.; Helgason, G.V.; Gottlieb, E. Targeting mitochondrial oxidative phosphorylation eradicates therapy-resistant chronic myeloid leukemia stem cells. Nat. Med. 2017, 23, 1234-1240. [CrossRef]

162. Viale, A.; Pettazzoni, P.; Lyssiotis, C.A.; Ying, H.; Sánchez, N.; Marchesini, M.; Carugo, A.; Green, T.; Seth, S.; Giuliani, V.; et al. Oncogene ablation-resistant pancreatic cancer cells depend on mitochondrial function. Nature 2014, 514, 628-632. [CrossRef] [PubMed]

163. Sancho, P.; Burgos-Ramos, E.; Tavera, A.; Bou Kheir, T.; Jagust, P.; Schoenhals, M.; Barneda, D.; Sellers, K.; Campos-Olivas, R.; Graña, O.; et al. MYC/PGC-1 $\alpha$ Balance Determines the Metabolic Phenotype and Plasticity of Pancreatic Cancer Stem Cells. Cell Metab. 2015, 22, 590-605. [CrossRef] [PubMed]

164. Patra, K.C.; Wang, Q.; Bhaskar, P.T.; Miller, L.; Wang, Z.; Wheaton, W.; Chandel, N.; Laakso, M.; Muller, W.J.; Allen, E.L.; et al. Hexokinase 2 is required for tumor initiation and maintenance and its systemic deletion is therapeutic in mouse models of cancer. Cancer Cell 2013, 24, 213-228. [CrossRef] [PubMed]

165. Kurtoglu, M.; Maher, J.C.; Lampidis, T.J. Differential Toxic Mechanisms of 2-Deoxy-D-Glucose versus 2-Fluorodeoxy-D -Glucose in Hypoxic and Normoxic Tumor Cells. Antioxid. Redox Signal. 2007, 9, 1383-1390. [CrossRef] [PubMed] 
166. Nancolas, B.; Guo, L.; Zhou, R.; Nath, K.; Nelson, D.S.; Leeper, D.B.; Blair, I.A.; Glickson, J.D.; Halestrap, A.P. The anti-tumour agent lonidamine is a potent inhibitor of the mitochondrial pyruvate carrier and plasma membrane monocarboxylate transporters. Biochem. J. 2016, 473, 929-936. [CrossRef]

167. Lu, L.; Chen, Y.; Zhu, Y. The molecular basis of targeting PFKFB3 as a therapeutic strategy against cancer. Oncotarget 2017, 8, 62793-62802. [CrossRef]

168. Clem, B.F.; O’Neal, J.; Tapolsky, G.; Clem, A.L.; Imbert-Fernandez, Y.; Kerr, D.A.; Klarer, A.C.; Redman, R.; Miller, D.M.; Trent, J.O.; et al. Targeting 6-phosphofructo-2-kinase (PFKFB3) as a therapeutic strategy against cancer. Mol. Cancer Ther. 2013, 12, 1461-1470. [CrossRef]

169. Redman, R.A.; Pohlmann, P.R.; Kurman, M.R.; Tapolsky, G.; Chesney, J.A. A phase I, dose-escalation, multi-center study of PFK-158 in patients with advanced solid malignancies explores a first-in-man inhbibitor of glycolysis. J. Clin. Oncol. 2015, 33, TPS2606. [CrossRef]

170. Wu, K.-H.; Ho, C.-T.; Chen, Z.-F.; Chen, L.-C.; Whang-Peng, J.; Lin, T.-N.; Ho, Y.-S. The apple polyphenol phloretin inhibits breast cancer cell migration and proliferation via inhibition of signals by type 2 glucose transporter. J. Food Drug Anal. 2018, 26, 221-231. [CrossRef]

171. Chan, D.A.; Sutphin, P.D.; Nguyen, P.; Turcotte, S.; Lai, E.W.; Banh, A.; Reynolds, G.E.; Chi, J.-T.; Wu, J.; Solow-Cordero, D.E.; et al. Targeting GLUT1 and the Warburg effect in renal cell carcinoma by chemical synthetic lethality. Sci. Transl. Med. 2011, 3, 94ra70. [CrossRef]

172. Liu, Y.; Cao, Y.; Zhang, W.; Bergmeier, S.; Qian, Y.; Akbar, H.; Colvin, R.; Ding, J.; Tong, L.; Wu, S.; et al. A Small-Molecule Inhibitor of Glucose Transporter 1 Downregulates Glycolysis, Induces Cell-Cycle Arrest, and Inhibits Cancer Cell Growth In Vitro and In Vivo. Mol. Cancer Ther. 2012, 11, 1672-1682. [CrossRef] [PubMed]

173. Le Calvé, B.; Rynkowski, M.; Le Mercier, M.; Bruyère, C.; Lonez, C.; Gras, T.; Haibe-Kains, B.; Bontempi, G.; Decaestecker, C.; Ruysschaert, J.-M.; et al. Long-term In Vitro Treatment of Human Glioblastoma Cells with Temozolomide Increases Resistance In Vivo through Up-regulation of GLUT Transporter and Aldo-Keto Reductase Enzyme AKR1C Expression. Neoplasia 2010, 12, 727. [CrossRef]

174. McBrayer, S.K.; Cheng, J.C.; Singhal, S.; Krett, N.L.; Rosen, S.T.; Shanmugam, M. Multiple myeloma exhibits novel dependence on GLUT4, GLUT8, and GLUT11: Implications for glucose transporter-directed therapy. Blood 2012, 119, 4686. [CrossRef] [PubMed]

175. Dalva-Aydemir, S.; Bajpai, R.; Martinez, M.; Adekola, K.U.A.; Kandela, I.; Wei, C.; Singhal, S.; Koblinski, J.E.; Raje, N.S.; Rosen, S.T.; et al. Targeting the Metabolic Plasticity of Multiple Myeloma with FDA-Approved Ritonavir and Metformin. Clin. Cancer Res. Off. J. Am. Assoc. Cancer Res. 2015, 21, 1161. [CrossRef]

176. Stipanuk, M.H.; Dominy, J.E.; Lee, J.-I.; Coloso, R.M. Mammalian cysteine metabolism: New insights into regulation of cysteine metabolism. J. Nutr. 2006, 136, 1652S-1659S. [CrossRef] [PubMed]

177. Liu, X.; Olszewski, K.; Zhang, Y.; Lim, E.W.; Shi, J.; Zhang, X.; Zhang, J.; Lee, H.; Koppula, P.; Lei, G.; et al. Cystine transporter regulation of pentose phosphate pathway dependency and disulfide stress exposes a targetable metabolic vulnerability in cancer. Nat. Cell Biol. 2020, 22, 476-486. [CrossRef]

178. Romero, I.L.; Mukherjee, A.; Kenny, H.A.; Litchfield, L.M.; Lengyel, E. Molecular pathways: Trafficking of metabolic resources in the tumor microenvironment. Clin. Cancer Res. Off. J. Am. Assoc. Cancer Res. 2015, 21, 680-686. [CrossRef]

179. Shackelford, D.B.; Abt, E.; Gerken, L.; Vasquez, D.S.; Seki, A.; Leblanc, M.; Wei, L.; Fishbein, M.C.; Czernin, J.; Mischel, P.S.; et al. LKB1 Inactivation Dictates Therapeutic Response of Non-Small Cell Lung Cancer to the Metabolism Drug Phenformin. Cancer Cell 2013, 23, 143-158. [CrossRef]

180. Cai, D.; Sun, H.; Qi, Y.; Zhao, X.; Feng, M.; Wu, X. Insulin-Like Growth Factor 1/Mammalian Target of Rapamycin and AMP-Activated Protein Kinase Signaling Involved in the Effects of Metformin in the Human Endometrial Cancer. Int. J. Gynecol. Cancer 2016, 26, 1667-1672. [CrossRef]

181. Coyle, C.; Cafferty, F.H.; Vale, C.; Langley, R.E. Metformin as an adjuvant treatment for cancer: A systematic review and meta-analysis. Ann. Oncol. 2016, 27, 2184-2195. [CrossRef]

182. Sancho, P.; Barneda, D.; Heeschen, C. Hallmarks of cancer stem cell metabolism. Br. J. Cancer 2016, 114, 1305-1312. [CrossRef] [PubMed]

183. Janzer, A.; German, N.J.; Gonzalez-Herrera, K.N.; Asara, J.M.; Haigis, M.C.; Struhl, K. Metformin and phenformin deplete tricarboxylic acid cycle and glycolytic intermediates during cell transformation and NTPs in cancer stem cells. Proc. Natl. Acad. Sci. USA 2014, 111, 10574-10579. [CrossRef] [PubMed] 
184. Zhuang, Y.; Miskimins, W.K. Metformin induces both caspase-dependent and poly(ADP-ribose) polymerase-dependent cell death in breast cancer cells. Mol. Cancer Res. 2011, 9, 603-615. [CrossRef]

185. Vangapandu, H.V.; Alston, B.; Morse, J.; Ayres, M.L.; Wierda, W.G.; Keating, M.J.; Marszalek, J.R.; Gandhi, V. Biological and metabolic effects of IACS-010759, an OxPhos inhibitor, on chronic lymphocytic leukemia cells. Oncotarget 2018, 9, 24980-24991. [CrossRef] [PubMed]

186. Molina, J.R.; Sun, Y.; Protopopova, M.; Gera, S.; Bandi, M.; Bristow, C.; McAfoos, T.; Morlacchi, P.; Ackroyd, J.; Agip, A.-N.A.; et al. An inhibitor of oxidative phosphorylation exploits cancer vulnerability. Nat. Med. 2018, 24, 1036-1046. [CrossRef]

187. Lissanu Deribe, Y.; Sun, Y.; Terranova, C.; Khan, F.; Martinez-Ledesma, J.; Gay, J.; Gao, G.; Mullinax, R.A.; Khor, T.; Feng, N.; et al. Mutations in the SWI/SNF complex induce a targetable dependence on oxidative phosphorylation in lung cancer. Nat. Med. 2018, 24, 1047-1057. [CrossRef]

188. Yap, T.A.; Rodon Ahnert, J.; Piha-Paul, S.A.; Fu, S.; Janku, F.; Karp, D.D.; Naing, A.; Ileana Dumbrava, E.E.; Pant, S.; Subbiah, V.; et al. Phase I trial of IACS-010759 (IACS), a potent, selective inhibitor of complex I of the mitochondrial electron transport chain, in patients (pts) with advanced solid tumors. J. Clin. Oncol. 2019, 37, 3014. [CrossRef]

189. Diamond, J.R.; Goff, B.; Forster, M.D.; Bendell, J.C.; Britten, C.D.; Gordon, M.S.; Gabra, H.; Waterhouse, D.M.; Poole, M.; Ross Camidge, D.; et al. Phase Ib study of the mitochondrial inhibitor ME-344 plus topotecan in patients with previously treated, locally advanced or metastatic small cell lung, ovarian and cervical cancers. Investig. New Drugs 2017, 35, 627-633. [CrossRef]

190. Johnson, E.A.; Marks, R.S.; Mandrekar, S.J.; Hillman, S.L.; Hauge, M.D.; Bauman, M.D.; Wos, E.J.; Moore, D.F.; Kugler, J.W.; Windschitl, H.E.; et al. Phase III randomized, double-blind study of maintenance CAI or placebo in patients with advanced non-small cell lung cancer (NSCLC) after completion of initial therapy (NCCTG 97-24-51). Lung Cancer 2008, 60, 200-207. [CrossRef]

191. Shi, Y.; Lim, S.K.; Liang, Q.; Iyer, S.V.; Wang, H.-Y.; Wang, Z.; Xie, X.; Sun, D.; Chen, Y.-J.; Tabar, V.; et al. Gboxin is an oxidative phosphorylation inhibitor that targets glioblastoma. Nature 2019, 567, 341-346. [CrossRef]

192. Wegrzyn, J.; Potla, R.; Chwae, Y.-J.; Sepuri, N.B.V.; Zhang, Q.; Koeck, T.; Derecka, M.; Szczepanek, K.; Szelag, M.; Gornicka, A.; et al. Function of mitochondrial Stat3 in cellular respiration. Science 2009, 323, 793-797. [CrossRef] [PubMed]

193. Wong, A.L.; Soo, R.A.; Tan, D.S.; Lee, S.C.; Lim, J.S.; Marban, P.C.; Kong, L.R.; Lee, Y.J.; Wang, L.Z.; Thuya, W.L.; et al. Phase I and biomarker study of OPB-51602, a novel signal transducer and activator of transcription (STAT) 3 inhibitor, in patients with refractory solid malignancies. Ann. Oncol. 2015, 26, 998-1005. [CrossRef]

194. Tolcher, A.; Flaherty, K.; Shapiro, G.I.; Berlin, J.; Witzig, T.; Habermann, T.; Bullock, A.; Rock, E.; Elekes, A.; Lin, C.; et al. A First-in-Human Phase I Study of OPB-111077, a Small-Molecule STAT3 and Oxidative Phosphorylation Inhibitor, in Patients with Advanced Cancers. Oncologist 2018, 23, 658. [CrossRef] [PubMed]

195. Škrtić, M.; Sriskanthadevan, S.; Jhas, B.; Gebbia, M.; Wang, X.; Wang, Z.; Hurren, R.; Jitkova, Y.; Gronda, M.; Maclean, N.; et al. Inhibition of Mitochondrial Translation as a Therapeutic Strategy for Human Acute Myeloid Leukemia. Cancer Cell 2011, 20, 674-688. [CrossRef]

196. Gupta, P.B.; Onder, T.T.; Jiang, G.; Tao, K.; Kuperwasser, C.; Weinberg, R.A.; Lander, E.S. Identification of Selective Inhibitors of Cancer Stem Cells by High-Throughput Screening. Cell 2009, 138, 645-659. [CrossRef]

197. Chae, Y.C.; Angelin, A.; Lisanti, S.; Kossenkov, A.V.; Speicher, K.D.; Wang, H.; Powers, J.F.; Tischler, A.S.; Pacak, K.; Fliedner, S.; et al. Landscape of the mitochondrial Hsp90 metabolome in tumours. Nat. Commun. 2013, 4, 2139. [CrossRef] [PubMed]

198. Xiang, Y.; Stine, Z.E.; Xia, J.; Lu, Y.; O’Connor, R.S.; Altman, B.J.; Hsieh, A.L.; Gouw, A.M.; Thomas, A.G.; Gao, P.; et al. Targeted inhibition of tumor-specific glutaminase diminishes cell-autonomous tumorigenesis. J. Clin. Investig. 2015, 125, 2293-2306. [CrossRef]

199. Chen, L.; Cui, H. Targeting Glutamine Induces Apoptosis: A Cancer Therapy Approach. Int. J. Mol. Sci. 2015, 16, 22830. [CrossRef]

200. Gross, M.I.; Demo, S.D.; Dennison, J.B.; Chen, L.; Chernov-Rogan, T.; Goyal, B.; Janes, J.R.; Laidig, G.J.; Lewis, E.R.; Li, J.; et al. Antitumor Activity of the Glutaminase Inhibitor CB-839 in Triple-Negative Breast Cancer. Mol. Cancer Ther. 2014, 13, 890-901. [CrossRef] 
201. Jacque, N.; Ronchetti, A.M.; Larrue, C.; Meunier, G.; Birsen, R.; Willems, L.; Saland, E.; Decroocq, J.; Maciel, T.T.; Lambert, M.; et al. Targeting glutaminolysis has antileukemic activity in acute myeloid leukemia and synergizes with BCL-2 inhibition. Blood 2015, 126, 1346-1356. [CrossRef]

202. Meric-Bernstam, F.; Tannir, N.M.; Mier, J.W.; DeMichele, A.; Telli, M.L.; Fan, A.C.; Munster, P.N.; Carvajal, R.D.; Orford, K.W.; Bennett, M.K.; et al. Phase 1 study of CB-839, a small molecule inhibitor of glutaminase (GLS), alone and in combination with everolimus (E) in patients (pts) with renal cell cancer (RCC). J. Clin. Oncol. 2016, 34, 4568. [CrossRef]

203. Harding, J.J.; Telli, M.L.; Munster, P.N.; Le, M.H.; Molineaux, C.; Bennett, M.K.; Mittra, E.; Burris, H.A.; Clark, A.S.; Dunphy, M.; et al. Safety and tolerability of increasing doses of CB-839, a first-in-class, orally administered small molecule inhibitor of glutaminase, in solid tumors. J. Clin. Oncol. 2015, 33, 2512. [CrossRef]

204. Elgadi, K.; Meguid, R.; Qian, M.; Souba, W.; Abcouwer, S. Cloning and Analysis of Unique Human Glutaminase Isoforms Generated by Tissue-Specific Alternative Splicing. Physiol. Genom. 1999, 1, 51-62. [CrossRef] [PubMed]

205. Avramis, V.I.; Panosyan, E.H. Pharmacokinetic/Pharmacodynamic Relationships of Asparaginase Formulations. Clin. Pharmacokinet. 2005, 44, 367-393. [CrossRef] [PubMed]

206. Grigoryan, R.S.; Panosyan, E.H.; Seibel, N.L.; Gaynon, P.S.; Avramis, I.A.; Avramis, V.I. Changes of amino acid serum levels in pediatric patients with higher-risk acute lymphoblastic leukemia (CCG-1961). In Vivo (AthensGreece) 2004, 18, 107-112.

207. Fuchs, B.C.; Bode, B.P. Amino acid transporters ASCT2 and LAT1 in cancer: Partners in crime? Semin. Cancer Biol. 2005, 15, 254-266. [CrossRef] [PubMed]

208. Wilde, L.; Roche, M.; Domingo-Vidal, M.; Tanson, K.; Philp, N.; Curry, J.; Martinez-Outschoorn, U. Metabolic Coupling and the Reverse Warburg Effect in Cancer, implications for novel biomarker and anticancer agent development. Semin. Oncol. 2017, 44, 198. [CrossRef]

209. Hassanein, M.; Qian, J.; Hoeksema, M.D.; Wang, J.; Jacobovitz, M.; Ji, X.; Harris, F.T.; Harris, B.K.; Boyd, K.L.; Chen, H.; et al. Targeting SLC1a5-mediated glutamine dependence in non-small cell lung cancer. Int. J. Cancer 2015, 137, 1587-1597. [CrossRef]

210. Hassanein, M.; Hoeksema, M.D.; Shiota, M.; Qian, J.; Harris, B.K.; Chen, H.; Clark, J.E.; Alborn, W.E.; Eisenberg, R.; Massion, P.P. SLC1A5 Mediates Glutamine Transport Required for Lung Cancer Cell Growth and Survival. Clin. Cancer Res. 2013, 19, 560-570. [CrossRef]

211. Choi, Y.-K.; Park, K.-G. Targeting Glutamine Metabolism for Cancer Treatment. Biomol. Ther. 2018, $26,19-28$. [CrossRef]

212. Liao, J.; Liu, P.-P.; Hou, G.; Shao, J.; Yang, J.; Liu, K.; Lu, W.; Wen, S.; Hu, Y.; Huang, P. Regulation of stem-like cancer cells by glutamine through $\beta$-catenin pathway mediated by redox signaling. Mol. Cancer 2017, 16, 51. [CrossRef] [PubMed]

213. Koch, K.; Hartmann, R.; Tsiampali, J.; Uhlmann, C.; Nickel, A.-C.; He, X.; Kamp, M.A.; Sabel, M.; Barker, R.A.; Steiger, H.-J.; et al. A comparative pharmaco-metabolomic study of glutaminase inhibitors in glioma stem-like cells confirms biological effectiveness but reveals differences in target-specificity. Cell Death Discov. 2020, 6, 20. [CrossRef] [PubMed]

214. Benjamin, D.; Robay, D.; Hindupur, S.K.; Pohlmann, J.; Colombi, M.; El-Shemerly, M.Y.; Maira, S.-M.; Moroni, C.; Lane, H.A.; Hall, M.N. Dual Inhibition of the Lactate Transporters MCT1 and MCT4 Is Synthetic Lethal with Metformin due to NAD+ Depletion in Cancer Cells. Cell Rep. 2018, 25, 3047-3058. [CrossRef] [PubMed]

215. Polański, R.; Hodgkinson, C.L.; Fusi, A.; Nonaka, D.; Priest, L.; Kelly, P.; Trapani, F.; Bishop, P.W.; White, A.; Critchlow, S.E.; et al. Activity of the monocarboxylate transporter 1 inhibitor AZD3965 in small cell lung cancer. Clin. Cancer Res. 2014, 20, 926-937. [CrossRef] [PubMed]

216. Singleton, D.; Dechaume, A.; Murray, P.; Katt, W.; Baguley, B.; Leung, E. Pyruvate anaplerosis is a mechanism of resistance to pharmacological glutaminase inhibition in Triple-receptor Negative Breast Cancer. BMC Cancer 2020, 20, 1-13. [CrossRef] [PubMed]

217. De Bock, K.; Georgiadou, M.; Schoors, S.; Kuchnio, A.; Wong, B.W.; Cantelmo, A.R.; Quaegebeur, A.; Ghesquière, B.; Cauwenberghs, S.; Eelen, G.; et al. Role of PFKFB3-Driven Glycolysis in Vessel Sprouting. Cell 2013, 154, 651-663. [CrossRef] 
218. Fitzgerald, G.; Soro-Arnaiz, I.; De Bock, K. The Warburg effect in endothelial cells and its potential as an anti-angiogenic target in cancer. Front. Cell Dev. Biol. 2018, 6, 100. [CrossRef]

219. Coutelle, O.; Hornig-Do, H.; Witt, A.; Andree, M.; Schiffmann, L.M.; Piekarek, M.; Brinkmann, K.; Seeger, J.M.; Liwschitz, M.; Miwa, S.; et al. Embelin inhibits endothelial mitochondrial respiration and impairs neoangiogenesis during tumor growth and wound healing. Embo Mol. Med. 2014, 6, 624-639. [CrossRef]

220. Pusapati, R.V.; Daemen, A.; Wilson, C.; Sandoval, W.; Gao, M.; Haley, B.; Baudy, A.R.; Hatzivassiliou, G.; Evangelista, M.; Settleman, J. mTORC1-Dependent Metabolic Reprogramming Underlies Escape from Glycolysis Addiction in Cancer Cells. Cancer Cell 2016, 29, 548-562. [CrossRef]

221. Wallace, D.C. Mitochondria and cancer. Nat. Rev. Cancer 2012, 12, 685-698. [CrossRef]

222. Martinez-Outschoorn, U.E.; Peiris-Pagés, M.; Pestell, R.G.; Sotgia, F.; Lisanti, M.P. Cancer metabolism: A therapeutic perspective. Nat. Rev. Clin. Oncol. 2017, 14, 11-31. [CrossRef] [PubMed]

223. Bizjak, M.; Malavašič, P.; Dolinar, K.; Pohar, J.; Pirkmajer, S.; Pavlin, M. Combined treatment with Metformin and 2-deoxy glucose induces detachment of viable MDA-MB-231 breast cancer cells in vitro. Sci. Rep. 2017, 7, 1761. [CrossRef] [PubMed]

224. Cheong, J.-H.; Park, E.S.; Liang, J.; Dennison, J.B.; Tsavachidou, D.; Nguyen-Charles, C.; Wa Cheng, K.; Hall, H.; Zhang, D.; Lu, Y.; et al. Dual Inhibition of Tumor Energy Pathway by 2-Deoxyglucose and Metformin Is Effective against a Broad Spectrum of Preclinical Cancer Models. Mol. Cancer Ther. 2011, 10, 2350-2362. [CrossRef] [PubMed]

225. Issaq, S.H.; Teicher, B.A.; Monks, A. Bioenergetic properties of human sarcoma cells help define sensitivity to metabolic inhibitors. Cell Cycle 2014, 13, 1152-1161. [CrossRef] [PubMed]

226. Cheng, G.; Zielonka, J.; McAllister, D.; Tsai, S.; Dwinell, M.B.; Kalyanaraman, B. Profiling and targeting of cellular bioenergetics: Inhibition of pancreatic cancer cell proliferation. Br. J. Cancer 2014, 111, 85-93. [CrossRef]

227. Kim, E.H.; Lee, J.-H.; Oh, Y.; Koh, I.; Shim, J.-K.; Park, J.; Choi, J.; Yun, M.; Jeon, J.Y.; Huh, Y.M.; et al. Inhibition of glioblastoma tumorspheres by combined treatment with 2-deoxyglucose and metformin. Neuro Oncol. 2017, 19, 197-207. [CrossRef] [PubMed]

228. Shafaee, A.; Pirayesh Islamian, J.; Zarei, D.; Mohammadi, M.; Nejati-Koshki, K.; Farajollahi, A.; Aghamiri, S.M.R.; Rahmati Yamchi, M.; Baradaran, B.; Asghari Jafarabadi, M. Induction of apoptosis by a combination of 2-deoxyglucose and metformin in esophageal squamous cell carcinoma by targeting cancer cell metabolism. Iran. J. Med Sci. 2019, 44, 99-107. [CrossRef]

229. Zhu, J.; Zheng, Y.; Zhang, H.; Sun, H. Targeting cancer cell metabolism: The combination of metformin and 2-Deoxyglucose regulates apoptosis in ovarian cancer cells via p38 MAPK/JNK signaling pathway. Am. J. Transl. Res. 2016, 8, 4812-4821.

230. DeWaal, D.; Nogueira, V.; Terry, A.R.; Patra, K.C.; Jeon, S.M.; Guzman, G.; Au, J.; Long, C.P.; Antoniewicz, M.R.; Hay, N. Hexokinase-2 depletion inhibits glycolysis and induces oxidative phosphorylation in hepatocellular carcinoma and sensitizes to metformin. Nat. Commun. 2018, 9, 446. [CrossRef]

231. Sun, Y.; Bandi, M.; Lofton, T.; Smith, M.; Bristow, C.A.; Carugo, A.; Rogers, N.; Leonard, P.; Chang, Q.; Mullinax, R.; et al. Functional Genomics Reveals Synthetic Lethality between Phosphogluconate Dehydrogenase and Oxidative Phosphorylation. Cell Rep. 2019, 26, 469-482. [CrossRef]

232. Sica, V.; Bravo-San Pedro, J.M.; Izzo, V.; Pol, J.; Pierredon, S.; Enot, D.; Durand, S.; Bossut, N.; Chery, A.; Souquere, S.; et al. Lethal Poisoning of Cancer Cells by Respiratory Chain Inhibition plus Dimethyl $\alpha$-Ketoglutarate. Cell Rep. 2019, 27, 820-834. [CrossRef] [PubMed]

233. Jones, A.T.; Narov, K.; Yang, J.; Sampson, J.R.; Shen, M.H. Efficacy of Dual Inhibition of Glycolysis and Glutaminolysis for Therapy of Renal Lesions in Tsc2+/- Mice. Neoplasia 2019, 21, 230-238. [CrossRef]

234. Yuan, P.; Ito, K.; Perez-Lorenzo, R.; Del Guzzo, C.; Lee, J.H.; Shen, C.-H.; Bosenberg, M.W.; McMahon, M.; Cantley, L.C.; Zheng, B. Phenformin enhances the therapeutic benefit of BRAFV600E inhibition in melanoma. Proc. Natl. Acad. Sci. USA 2013, 110, 18226-18231. [CrossRef]

235. Vitiello, G.A.; Medina, B.D.; Zeng, S.; Bowler, T.G.; Zhang, J.Q.; Loo, J.K.; Param, N.J.; Liu, M.; Moral, A.J.; Zhao, J.N.; et al. Mitochondrial Inhibition Augments the Efficacy of Imatinib by Resetting the Metabolic Phenotype of Gastrointestinal Stromal Tumor. Clin. Cancer Res. 2018, 24, 972-984. [CrossRef] [PubMed] 
236. Arrieta, O.; Barrón, F.; Padilla, M.-Á.S.; Avilés-Salas, A.; Ramírez-Tirado, L.A.; Arguelles Jiménez, M.J.; Vergara, E.; Zatarain-Barrón, Z.L.; Hernández-Pedro, N.; Cardona, A.F.; et al. Effect of Metformin Plus Tyrosine Kinase Inhibitors Compared With Tyrosine Kinase Inhibitors Alone in Patients With Epidermal Growth Factor Receptor-Mutated Lung Adenocarcinoma: A Phase 2 Randomized Clinical Trial. JAMA Oncol. 2019, 5, e192553. [CrossRef]

237. Pisarsky, L.; Bill, R.; Fagiani, E.; Dimeloe, S.; Goosen, R.W.; Hagmann, J.; Hess, C.; Christofori, G. Targeting Metabolic Symbiosis to Overcome Resistance to Anti-angiogenic Therapy. Cell Rep. 2016, 15, 1161-1174. [CrossRef]

238. Telang, S.; O’Neal, J.; Tapolsky, G.; Clem, B.; Kerr, A.; Imbert-Ferndandez, Y.; Chesney, J. Discovery of a PFKFB3 inhibitor for phase I trial testing that synergizes with the B-Raf inhibitor vemurafenib. Cancer Metab. 2014, 2, 14. [CrossRef]

239. Feng, Y.; Wu, L. mTOR up-regulation of PFKFB3 is essential for acute myeloid leukemia cell survival. Biochem. Biophys. Res. Commun. 2017, 483, 897-903. [CrossRef]

240. Kim, S.M.; Yun, M.R.; Hong, Y.K.; Solca, F.; Kim, J.-H.; Kim, H.-J.; Cho, B.C. Glycolysis inhibition sensitizes non-small cell lung cancer with T790M mutation to irreversible EGFR inhibitors via translational suppression of Mcl-1 by AMPK activation. Mol. Cancer Ther. 2013, 12, 2145-2156. [CrossRef]

241. Wang, L.; Yang, Q.; Peng, S.; Liu, X. The combination of the glycolysis inhibitor 2-DG and sorafenib can be effective against sorafenib-tolerant persister cancer cells. Oncotargets Ther. 2019, 12, 5359-5373. [CrossRef]

242. Yakes, F.M.; Chen, J.; Tan, J.; Yamaguchi, K.; Shi, Y.; Yu, P.; Qian, F.; Chu, F.; Bentzien, F.; Cancilla, B.; et al. Cabozantinib (XL184), a novel MET and VEGFR2 inhibitor, simultaneously suppresses metastasis, angiogenesis, and tumor growth. Mol. Cancer 2011, 10, 2298-2308. [CrossRef] [PubMed]

243. Meric-Bernstam, F.; Lee, R.J.; Carthon, B.C.; Iliopoulos, O.; Mier, J.W.; Patel, M.R.; Tannir, N.M.; Owonikoko, T.K.; Haas, N.B.; Voss, M.H.; et al. CB-839, a glutaminase inhibitor, in combination with cabozantinib in patients with clear cell and papillary metastatic renal cell cancer (mRCC): Results of a phase I study. J. Clin. Oncol. 2019, 37, 549. [CrossRef]

244. Tanaka, K.; Sasayama, T.; Irino, Y.; Takata, K.; Nagashima, H.; Satoh, N.; Kyotani, K.; Mizowaki, T.; Imahori, T.; Ejima, Y.; et al. Compensatory glutamine metabolism promotes glioblastoma resistance to mTOR inhibitor treatment. J. Clin. Investig. 2015, 125, 1591-1602. [CrossRef] [PubMed]

245. Zhang, J.-W.; Zhao, F.; Sun, Q. Metformin synergizes with rapamycin to inhibit the growth of pancreatic cancer in vitro and in vivo. Oncol. Lett. 2018, 15, 1811-1816. [CrossRef] [PubMed]

246. Liu, H.; Scholz, C.; Zang, C.; Schefe, J.H.; Habbel, P.; Regierer, A.-C.; Schulz, C.-O.; Possinger, K.; Eucker, J. Metformin and the mTOR inhibitor everolimus (RAD001) sensitize breast cancer cells to the cytotoxic effect of chemotherapeutic drugs in vitro. Anticancer Res. 2012, 32, 1627-1637.

247. Wang, Y.; Wei, J.; Li, L.; Fan, C.; Sun, Y. Combined Use of Metformin and Everolimus Is Synergistic in the Treatment of Breast Cancer Cells. Oncol. Res. Featur. Preclin. Clin. Cancer Ther. 2015, 22, 193-201. [CrossRef]

248. Molenaar, R.J.; van de Venne, T.; Weterman, M.J.; Mathot, R.A.; Klümpen, H.-J.; Richel, D.J.; Wilmink, J.W. A phase Ib study of everolimus combined with metformin for patients with advanced cancer. Investig. New Drugs 2018, 36, 53-61. [CrossRef]

249. Khawaja, M.R.; Nick, A.M.; Madhusudanannair, V.; Fu, S.; Hong, D.; McQuinn, L.M.; Ng, C.S.; Piha-Paul, S.A.; Janku, F.; Subbiah, V.; et al. Phase I dose escalation study of temsirolimus in combination with metformin in patients with advanced/refractory cancers. Cancer Chemother. Pharmacol. 2016, 77, 973-977. [CrossRef]

250. Ihrlund, L.S.; Hernlund, E.; Khan, O.; Shoshan, M.C. 3-Bromopyruvate as inhibitor of tumour cell energy metabolism and chemopotentiator of platinum drugs. Mol. Oncol. 2008, 2, 94-101. [CrossRef]

251. Chong, D.; Ma, L.; Liu, F.; Zhang, Z.; Zhao, S.; Huo, Q.; Zhang, P.; Zheng, H.; Liu, H. Synergistic antitumor effect of 3-bromopyruvate and 5-fluorouracil against human colorectal cancer through cell cycle arrest and induction of apoptosis. Anti Cancer Drugs 2017, 28, 831-840. [CrossRef]

252. Bean, J.F.; Qiu, Y.-Y.; Yu, S.; Clark, S.; Chu, F.; Madonna, M.B. Glycolysis inhibition and its effect in doxorubicin resistance in neuroblastoma. J. Pediatric Surg. 2014, 49, 981-984. [CrossRef] [PubMed]

253. Nakano, A.; Tsuji, D.; Miki, H.; Cui, Q.; El Sayed, S.M.; Ikegame, A.; Oda, A.; Amou, H.; Nakamura, S.; Harada, T.; et al. Glycolysis Inhibition Inactivates ABC Transporters to Restore Drug Sensitivity in Malignant Cells. PLoS ONE 2011, 6, e27222. [CrossRef]

254. Bénéteau, M.; Zunino, B.; Jacquin, M.A.; Meynet, O.; Chiche, J.; Pradelli, L.A.; Marchetti, S.; Cornille, A.; Carles, M.; Ricci, J.-E. Combination of glycolysis inhibition with chemotherapy results in an antitumor immune response. Proc. Natl. Acad. Sci. USA 2012, 109, 20071-20076. [CrossRef] [PubMed] 
255. Islamian, J.P.; Aghaee, F.; Farajollahi, A.; Baradaran, B.; Fazel, M. Combined Treatment with 2-Deoxy-D-Glucose and Doxorubicin Enhances the in Vitro Efficiency of Breast Cancer Radiotherapy. Asian Pac. J. Cancer Prev. APJCP 2015, 16, 8431-8438. [CrossRef]

256. Maschek, G.; Savaraj, N.; Priebe, W.; Braunschweiger, P.; Hamilton, K.; Tidmarsh, G.F.; De Young, L.R.; Lampidis, T.J. 2-deoxy-D-glucose increases the efficacy of adriamycin and paclitaxel in human osteosarcoma and non-small cell lung cancers in vivo. Cancer Res. 2004, 64, 31-34. [CrossRef]

257. Raez, L.E.; Rosenblatt, J.; Schlesselman, J.; Langmuir, V.; Tidmarsh, G.; Rocha-Lima, C.; Papadopoulos, K.; O'Connor, J.; Baldie, P.; Lampidis, T. Combining glycolytic inhibitors with chemotherapy: Phase I trial of 2-deoxyglucose and docetaxel in patients with solid tumors. J. Clin. Oncol. 2005, 23, 3190. [CrossRef]

258. Zhu, H.; Wu, J.; Zhang, W.; Luo, H.; Shen, Z.; Cheng, H.; Zhu, X. PKM2 enhances chemosensitivity to cisplatin through interaction with the mTOR pathway in cervical cancer. Sci. Rep. 2016, 6, 30788. [CrossRef]

259. Wang, X.; Zhang, F.; Wu, X.-R. Inhibition of Pyruvate Kinase M2 Markedly Reduces Chemoresistance of Advanced Bladder Cancer to Cisplatin. Sci. Rep. 2017, 7, 45983. [CrossRef]

260. Shi, H.; Li, D.; Zhang, J.; Wang, Y.; Yang, L.; Zhang, H.; Wang, X.; Mu, B.; Wang, W.; Ma, Y.; et al. Silencing of pkm2 increases the efficacy of docetaxel in human lung cancer xenografts in mice. Cancer Sci. 2010, 101, 1447-1453. [CrossRef]

261. Kalinsky, K.; Harding, J.; DeMichele, A.; Infante, J.; Gogineni, K.; Owonikoko, T.; Isakoff, S.; Iliopoulos, O.; Patel, M.; Munster, P.; et al. Abstract PD3-13: Phase 1 study of CB-839, a first-in-class oral inhibitor of glutaminase, in combination with paclitaxel in patients with advanced triple negative breast cancer. In Poster Discussion Abstracts, Proceedings of the 2017 San Antonio Breast Cancer Symposium, San Antonio, Texas, USA, 5-9 December 2017; American Association for Cancer Research: New Orleans, LA, USA, 2018; Vol. 78, pp. PD3-13.

262. Vidal, G.; Kalinsky, K.; Stringer-Reasor, E.; Lynce, F.; Cole, J.; Valdes-Albini, F.; Soliman, H.; Nikolinakos, P.; Silber, A.; DeMichele, A.; et al. Abstract P6-20-07: Efficacy and safety of CB-839, a small molecule inhibitor of glutaminase, in combination with paclitaxel in patients with advanced triple negative breast cancer (TNBC): Initial findings from a multicenter, open-label phase 2 study. In Poster Session Abstracts, Proceedings of the 2018 San Antonio Breast Cancer Symposium, San Antonio, Texas, USA; 4-8 December 2018; Association for Cancer Research: New Orleans, LA, USA, 2019; Vol. 79, pp. P6-20-07.

263. Alistar, A.; Morris, B.B.; Desnoyer, R.; Klepin, H.D.; Hosseinzadeh, K.; Clark, C.; Cameron, A.; Leyendecker, J.; D'Agostino, R.; Topaloglu, U.; et al. Safety and tolerability of the first-in-class agent CPI-613 in combination with modified FOLFIRINOX in patients with metastatic pancreatic cancer: A single-centre, open-label, dose-escalation, phase 1 trial. Lancet. Oncol. 2017, 18, 770-778. [CrossRef]

264. Pardee, T.S.; Luther, S.; Buyse, M.E.; Powell, B.L.; Cortes, J.E. Multicentre, Open Label, Randomized Phase III Study of Cpi-613 ${ }^{\circledR}$ (devimistat) in Combination with High Dose Cytarabine and Mitoxantrone (CHAM) Compared to High Dose Cytarabine and Mitoxantrone (HAM) in Older Patients ( $\geq 60$ years) with Relapsed/Refractory Acute Myeloid Leukemia (AML)_Armada 2000 (AML003) Trial. Blood 2019, 134, 2658. [CrossRef]

265. Iliopoulos, D.; Hirsch, H.A.; Struhl, K. Metformin Decreases the Dose of Chemotherapy for Prolonging Tumor Remission in Mouse Xenografts Involving Multiple Cancer Cell Types. Cancer Res. 2011, 71, 3196-3201. [CrossRef] [PubMed]

266. Miranda, V.C.; Faria, L.D.; Braghiroli, M.I.F.M.; Jacobs, M.; Sabbaga, J.; Hoff, P.M.; Riechelmann, R.P. A phase II trial of metformin and fluorouracil (MetFU) for patients (pts) with metastatic colorectal cancer (mCRC) refractory to standard treatment. J. Clin. Oncol. 2014, 32, 601. [CrossRef]

267. Han, L.; Cavazos, A.; Baran, N.; Zhang, Q.; Kuruvilla, V.M.; Gay, J.P.; Feng, N.; Battula, V.L.; Kantarjian, H.M.; Daver, N.G.; et al. Mitochondrial Oxphos As Survival Mechanism of Minimal Residual AML Cells after Induction Chemotherapy: Survival Benefit By Complex I Inhibition with Iacs-010759. Blood 2019, 134, 5161. [CrossRef]

268. Sun, H.; Zhu, A.; Zhou, X.; Wang, F.; Sun, H.; Zhu, A.; Zhou, X.; Wang, F. Suppression of pyruvate dehydrogenase kinase-2 re-sensitizes paclitaxel-resistant human lung cancer cells to paclitaxel. Oncotarget 2017, 8, 52642-52650. [CrossRef]

269. Liang, H.; Tong, J.; Xie, G.; He, J.; Li, J.; Pan, F. Synergistic antitumor effect of dichloroacetate in combination with 5-fluorouracil in colorectal cancer. J. Biomed. Biotechnol. 2011. [CrossRef] 
270. Gross, M.; Chen, J.; Englert, J.; Janes, J.; Leone, R.; MacKinnon, A.; Parlati, F.; Rodriquez, M.; Shwonek, P.; Powell, J. Glutaminase inhibition with CB-839 enhances anti-tumor activity of PD-1 and PD-L1 antibodies by overcoming a metabolic checkpoint blocking T cell activation. Cancer Res 2016, 14, 2329.

271. Steggerda, S.M.; Bennett, M.K.; Chen, J.; Emberley, E.; Huang, T.; Janes, J.R.; Li, W.; MacKinnon, A.L.; Makkouk, A.; Marguier, G.; et al. Inhibition of arginase by CB-1158 blocks myeloid cell-mediated immune suppression in the tumor microenvironment. J. Immunother. Cancer 2017, 5, 101. [CrossRef]

272. Long, G.V.; Dummer, R.; Hamid, O.; Gajewski, T.F.; Caglevic, C.; Dalle, S.; Arance, A.; Carlino, M.S.; Grob, J.-J.; Kim, T.M.; et al. Epacadostat plus pembrolizumab versus placebo plus pembrolizumab in patients with unresectable or metastatic melanoma (ECHO-301/KEYNOTE-252): A phase 3, randomised, double-blind study. Lancet Oncol. 2019, 20, 1083-1097. [CrossRef]

273. Song, Z.; Wei, B.; Lu, C.; Li, P.; Chen, L. Glutaminase sustains cell survival via the regulation of glycolysis and glutaminolysis in colorectal cancer. Oncol. Lett. 2017, 14, 3117-3123. [CrossRef]

274. De Rosa, V.; Iommelli, F.; Monti, M.; Fonti, R.; Votta, G.; Stoppelli, M.P.; Del Vecchio, S. Reversal of Warburg Effect and Reactivation of Oxidative Phosphorylation by Differential Inhibition of EGFR Signaling Pathways in Non-Small Cell Lung Cancer. Clin. Cancer Res. 2015, 21, 5110-5120. [CrossRef] [PubMed]

275. Poliaková, M.; Aebersold, D.M.; Zimmer, Y.; Medová, M. The relevance of tyrosine kinase inhibitors for global metabolic pathways in cancer. Mol. Cancer 2018, 17, 27. [CrossRef] [PubMed]

276. Zakikhani, M.; Blouin, M.-J.; Piura, E.; Pollak, M.N. Metformin and rapamycin have distinct effects on the AKT pathway and proliferation in breast cancer cells. Breast Cancer Res. Treat. 2010, 123, 271-279. [CrossRef] [PubMed]

277. Mansoori, B.; Mohammadi, A.; Davudian, S.; Shirjang, S.; Baradaran, B. The different mechanisms of cancer drug resistance: A brief review. Adv. Pharm. Bull. 2017, 7, 339-348. [CrossRef]

278. Fan, T.; Sun, G.; Sun, X.; Zhao, L.; Zhong, R.; Peng, Y. Tumor Energy Metabolism and Potential of 3-Bromopyruvate as an Inhibitor of Aerobic Glycolysis: Implications in Tumor Treatment. Cancers 2019, 11, 317. [CrossRef]

279. Ly, S.; Nguyen, K.; Andreeff, M.; Battula, V.L. Targeting glutamine metabolism inhibits GD2 + breast cancer stem cell function in triple negative breast cancer. In Proceedings of the 2019 San Antonio Breast Cancer Symposium, Philadelphia, PA, USA, 10-14 December 2019; American Association for Cancer Research: New Orleans, LA, USA, 2020; Vol. 80, pp. P3-02-05.

280. Hudson, C.D.; Savadelis, A.; Nagaraj, A.B.; Joseph, P.; Avril, S.; DiFeo, A.; Avril, N. Altered glutamine metabolism in platinum resistant ovarian cancer. Oncotarget 2016, 7, 41637-41649. [CrossRef]

281. Papadopoulos, K.P.; Tsai, F.Y.-C.; Bauer, T.M.; Muigai, L.; Liang, Y.; Bennett, M.K.; Orford, K.W.; Fu, S. CX-1158-101: A first-in-human phase 1 study of CB-1158, a small molecule inhibitor of arginase, as monotherapy and in combination with an anti-PD-1 checkpoint inhibitor in patients (pts) with solid tumors. J. Clin. Oncol. 2017, 35, 3005. [CrossRef]

282. Mezrich, J.D.; Fechner, J.H.; Zhang, X.; Johnson, B.P.; Burlingham, W.J.; Bradfield, C.A. An Interaction between Kynurenine and the Aryl Hydrocarbon Receptor Can Generate Regulatory T Cells. J. Immunol. 2010, 185, 3190-3198. [CrossRef]

283. Darvin, P.; Toor, S.M.; Sasidharan Nair, V.; Elkord, E. Immune checkpoint inhibitors: Recent progress and potential biomarkers. Exp. Mol. Med. 2018, 50, 165. [CrossRef]

284. Hoerner, C.R.; Chen, V.J.; Fan, A.C. The 'Achilles Heel' of Metabolism in Renal Cell Carcinoma: Glutaminase Inhibition as a Rational Treatment Strategy. Kidney Cancer 2019, 3, 15-29. [CrossRef]

285. Pastò, A.; Bellio, C.; Pilotto, G.; Ciminale, V.; Silic-Benussi, M.; Guzzo, G.; Rasola, A.; Frasson, C.; Nardo, G.; Zulato, E.; et al. Cancer stem cells from epithelial ovarian cancer patients privilege oxidative phosphorylation, and resist glucose deprivation. Oncotarget 2014, 5, 4305-4319. [CrossRef]

286. Kalyanaraman, B. Teaching the basics of cancer metabolism: Developing antitumor strategies by exploiting the differences between normal and cancer cell metabolism. Redox Biol. 2017, 12, 833-842. [CrossRef]

Publisher's Note: MDPI stays neutral with regard to jurisdictional claims in published maps and institutional affiliations. 